\title{
Electrophotocatalytic $\mathrm{C}-\mathrm{H}$ Functionalization of Ethers with High Regioselectivity.
}

He Huang, ${ }^{\dagger}$ Zack M. Strater, ${ }^{\ddagger}$ and Tristan H. Lambert ${ }^{* \dagger \ddagger}$

$\dagger$ Department of Chemistry and Chemical Biology, Cornell University, Ithaca, New York 14853

$\$$ Department of Chemistry, Columbia University, New York, NY 10027, USA

*Correspondence to: Tristan.lambert@cornell.edu 


\section{Table of Contents}

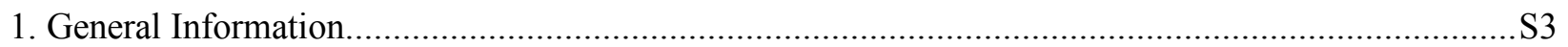

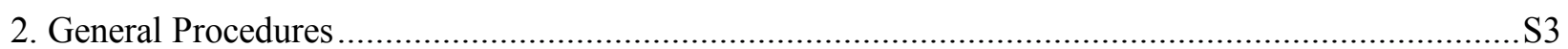

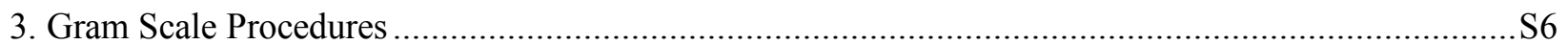

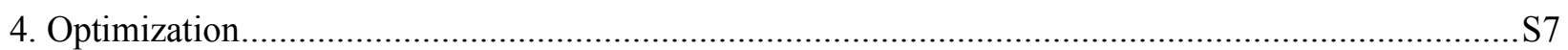

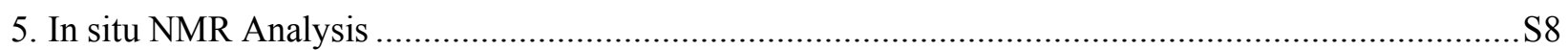

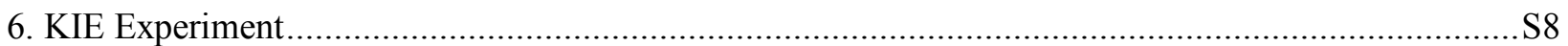

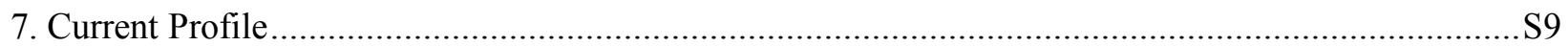

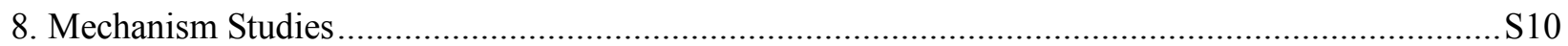

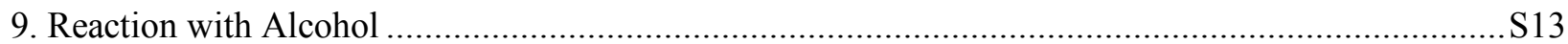

10. Comparation with Reported Electrolysis Method.........................................................................S15

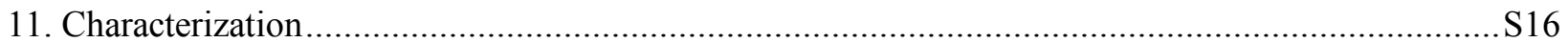

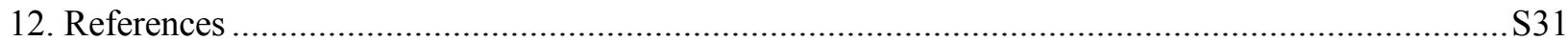

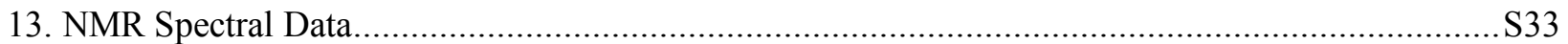




\section{General Information}

Commercially available reagents were purchased from Sigma Aldrich, Matrix Chemical, AKSci, Alfa Aesar, Oakwood chemical or TCI, and used as received unless otherwise noted. Silica gel 60 (230-400 mesh) from SiliCycle was used for chromatography, and Merck silica gel plates with a fluorescence $\mathrm{F}_{254}$ indicator were used for thin-layer chromatography (TLC) analysis. ${ }^{1} \mathrm{H}$ and ${ }^{13} \mathrm{C}$ NMR spectra were recorded on Mercury-300 (300 MHz), Inova-400 (400 MHz), and Inova-500 (500 MHz) spectrometers. Chemical shifts in ${ }^{1} \mathrm{H}$ NMR spectra are reported in parts per million (ppm) relative to residual chloroform (7.26 ppm) or dimethyl sulfoxide $(2.50 \mathrm{ppm})$ as internal standards. ${ }^{1} \mathrm{H}$ NMR data are reported as follows: chemical shift, multiplicity ( $\mathrm{s}=$ singlet, $\mathrm{d}=$ doublet, $\mathrm{t}=$ triplet, $\mathrm{q}=$ quartet, $\mathrm{dd}=$ doublet of doublets, $\mathrm{m}=$ multiplet), coupling constant in Hertz $(\mathrm{Hz})$ and number of hydrogen atoms based on integration intensities. ${ }^{13} \mathrm{C}$ NMR chemical shifts are reported in ppm relative to the central peak of $\mathrm{CDCl}_{3}(77.16 \mathrm{ppm}) \mathrm{CD}_{3} \mathrm{OD}(49.00 \mathrm{ppm})$ or $\left(\mathrm{CD}_{3}\right)_{2} \mathrm{SO}(39.52 \mathrm{ppm})$ as internal standards. ${ }^{19} \mathrm{~F}$ NMR chemical shifts are reported in ppm relative to the central peak of $\mathrm{C}_{6} \mathrm{H}_{5} \mathrm{CF}_{3}(-63.72 \mathrm{ppm})$ as an internal standard. The mass spectral (MS) data were obtained on a Thermo Fisher Scientific Exactive series DART Mass Spectrometer. Anhydrous acetonitrile, THF, 2methyltetrahydrofuran and cyclopentyl methyl ether were purchased as Sure/Seal ${ }^{\mathrm{TM}}$ bottles from SigmaAldrich.

\section{General Procedures}

Electrode preparation can be found in our pervious report ${ }^{[1]}$.

Materials used for set-up:

Platinum wire (13039-BU from Alfa Aesar, $25 \mathrm{~cm}$ ). Blue LED strips (Solid Apollo). Holmes Lil' Blizzard 8-inch oscillating table fan (Amazon). June gold $2.0 \mathrm{~mm}$ 2B pencil lead refills (Amazon). DC Power supply (Amazon, Dr.Meter 30V/5A). Carbon felt (cut around $7 \mathrm{~mm}$ x $7 \mathrm{~mm}$ x $7 \mathrm{~mm}$ ) from C200 Soft Carbon Battery Felt (fuelcellstore, Product Code: 1595010).

The set up was in Fig. S1.

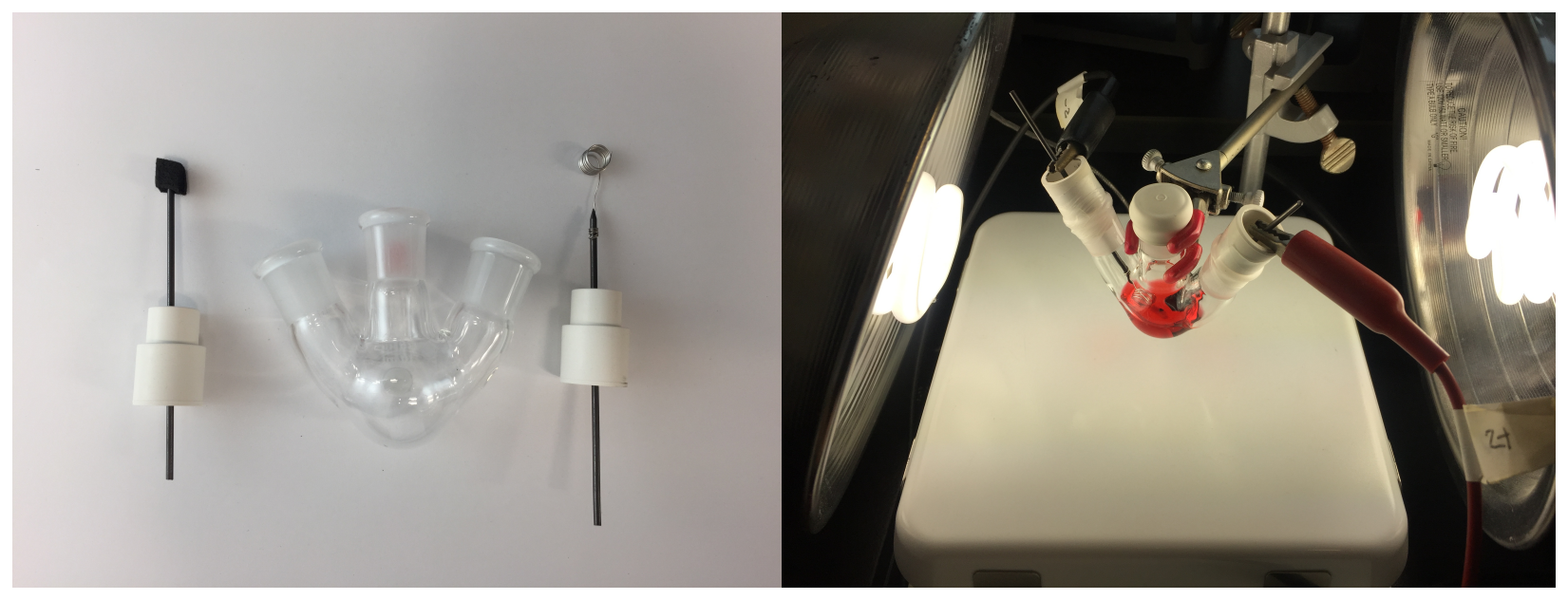

Fig. S1. Experiment set up 


\section{Procedure A for compounds 6, 8-30}

To an oven-dried 10-mL three-neck flask equipped with a stir bar, a carbon felt anode, and a platinum wire cathode was added TAC 1 (15.2 $\mathrm{mg}, 0.032 \mathrm{mmol})$, the heteroarene if solid $(0.4 \mathrm{mmol})$, and $\mathrm{LiClO}_{4}(255.3$ $\mathrm{mg}, 2.4 \mathrm{mmol}$ ). The cell was sealed using a rubber septum and parafilm then flushed with nitrogen gas for $5 \mathrm{~min}$, followed by the sequential addition via syringe of $\mathrm{CH}_{3} \mathrm{CN}$ ( $2 \mathrm{~mL}$ for $\mathbf{6}, \mathbf{8 - 1 2}, 4 \mathrm{~mL}$ for 13-28), the ether $(2.0 \mathrm{~mL})$, the heteroarene if liquid $(0.4 \mathrm{mmol})$, trifluoroacetic acid $(61 \mu \mathrm{L}, 0.8 \mathrm{mmol})$ and acetic acid $(72 \mu \mathrm{L}, 1.2 \mathrm{mmol})$. The reaction mixture was then purged with nitrogen gas for an additional $5 \mathrm{~min}$. The solution was then stirred at room temperature under irradiation from two $23 \mathrm{~W}$ CFL bulbs and electrolysis was initiated at a constant voltage of $1.5 \mathrm{~V}$ for $36 \mathrm{~h}$. The reaction mixture was subsequently poured into a saturated sodium bicarbonate solution (ca. $20 \mathrm{~mL})$. The carbon felt anode was washed with EtOAc $(3 \times 5$ $\mathrm{mL})$ in an ultrasonic bath. The aqueous layer was separated and extracted with EtOAc $(3 \times 10 \mathrm{~mL})$, and the combined organic layers and anode extraction were washed with brine and dried over anhydrous $\mathrm{Na}_{2} \mathrm{SO}_{4}$. Following concentration in vacuo, the crude residue was subjected to flash column chromatography on silica gel to yield the desired product.

\section{Procedure B for compounds 31-36}

To an oven-dried 10-mL three-neck flask equipped with a stir bar, a carbon felt anode and, a platinum wire cathode was added TAC 1 (15.2 $\mathrm{mg}, 0.032 \mathrm{mmol})$, the alkene if solid $(0.4 \mathrm{mmol})$, and $\mathrm{LiClO}_{4}(255.3 \mathrm{mg}$, $2.4 \mathrm{mmol})$. The cell was sealed using a rubber septum and parafilm then flushed with nitrogen gas for 5 min, followed by the sequential addition via syringe of $\mathrm{CH}_{3} \mathrm{CN}(2 \mathrm{~mL})$, the ether $(2.0 \mathrm{~mL})$, the alkene or alkyne if liquid $(0.4 \mathrm{mmol})$, and acetic acid $(229 \mu \mathrm{L}, 4.0 \mathrm{mmol})$. The reaction mixture was then purged with nitrogen gas for an additional $5 \mathrm{~min}$. The solution was stirred at room temperature under irradiation from two $23 \mathrm{~W}$ CFL bulbs, and electrolysis was initiated at a constant voltage of $1.5 \mathrm{~V}$ for $36 \mathrm{~h}$. The reaction mixture was subsequently poured into a saturated sodium bicarbonate solution (ca. $20 \mathrm{~mL}$ ). The carbon felt anode was washed with EtOAc $(3 \times 5 \mathrm{~mL})$ in an ultrasonic bath. The aqueous layer was separated and extracted with EtOAc $(3 \times 10 \mathrm{~mL})$, and the combined organic layers and anode extract were washed with brine and dried over anhydrous $\mathrm{Na}_{2} \mathrm{SO}_{4}$. Following concentration in vacuo, the crude residue was subjected to flash column chromatography on silica gel to yield the desired product.

\section{Procedure C for compounds 37-45}

To an oven-dried 10-mL three-neck flask equipped with a stir bar, a carbon felt anode, and a platinum wire cathode was added TAC 1 (15.2 $\mathrm{mg}, 0.032 \mathrm{mmol})$, the azole (0.4 mmol), and $\mathrm{LiClO}_{4}(255.3 \mathrm{mg}, 2.4 \mathrm{mmol})$. The cell was sealed using a rubber septum and parafilm, then flushed with nitrogen gas for 5 min, followed by the sequential addition via syringe of $\mathrm{CH}_{3} \mathrm{CN}(2 \mathrm{~mL})$, the ether $(2.0 \mathrm{~mL})$, and acetic acid $(229 \mu \mathrm{L}, 4.0$ $\mathrm{mmol})$. The reaction mixture was then purged with nitrogen gas for an additional $5 \mathrm{~min}$. The solution was stirred at room temperature under irradiation from two $23 \mathrm{~W}$ CFL bulbs, and electrolysis was initiated at a constant voltage of $2.0 \mathrm{~V}$ for $36 \mathrm{~h}$. The reaction mixture was subsequently poured into a saturated sodium bicarbonate solution (ca. $20 \mathrm{~mL})$. The carbon felt anode was washed with EtOAc $(3 \times 5 \mathrm{~mL})$ in an ultrasonic bath. The aqueous layer was separated and extracted with EtOAc $(3 \times 10 \mathrm{~mL})$, and the combined organic layers and anode extract were washed with brine and dried over anhydrous $\mathrm{Na}_{2} \mathrm{SO}_{4}$. Following concentration in vacuo, the crude residue was subjected to flash column chromatography on silica gel to yield the desired product. 


\section{Notes:}

1. Even though this reaction has not been found to be sensitive to water, anhydrous lithium perchlorate and anhydrous acetonitrile were used.

2. Ethers were freshly distilled to remove inhibitor and peroxide impurities. Ethers should be pure because peroxide contaminants can react via direct electrolysis.

3. Both acetonitrile and ethers were degassed by the freeze-pump-thaw method.

4. Because the carbon felt can absorb a significant amount of reaction solution, it should be rinsed in an ultrasonic bath for 5 min or more to obtain optimal product yields.

5. In the undivided cell, it is best to keep the anode and cathode relatively close $(\sim 0.5 \mathrm{~cm})$ to one another; however, they should not touch.

6. For the cathode, the platinum wire should be immersed in the solution, but not the pencil lead to which it is attached.

7. The carbon felt should be replaced for each reaction.

8. The system was cooled using a fan.

9. High stirring speed is required.

10. After the reaction, care should be taken when removing the septum in case of pressure build up from hydrogen gas generation. 


\section{Gram Scale Procedures}

Electrode preparation can be found in our previous report. ${ }^{[2]}$

Materials used for set-up:

Platinum foil (42456-FF, $0.05 \mathrm{~mm}$ thick from Alfa Aesar, $25 * 25 \mathrm{~mm}$ ). DC Power supply (Amazon, Dr.Meter 30V/5A). Carbon felt (cut around $20 \mathrm{~mm}$ x $10 \mathrm{~mm}$ x $7 \mathrm{~mm}$ ) from C200 Soft Carbon Battery Felt (fuelcellstore, Product Code: 1595010).

The set-up is shown in Fig. S2.

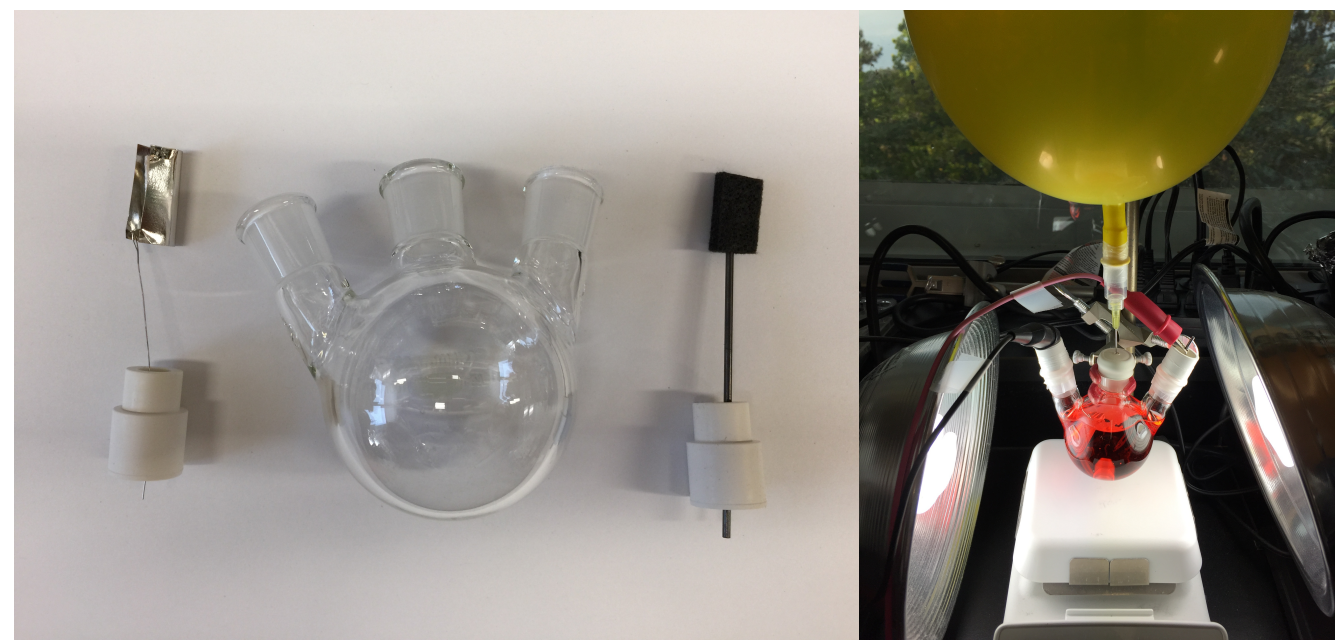

Fig. S2. Large scale experiment set up

\section{Procedure for gram scale reaction}

To an oven-dried 100-mL three-neck flask equipped with a stir bar, a carbon felt anode, and a platinum wire cathode was added TAC 1 (303.4 mg, $0.64 \mathrm{mmol}$ ), 4-bromoisoquinoline (1.66 g, $8 \mathrm{mmol}$ ), and $\mathrm{LiClO}_{4}$ $(5.11 \mathrm{~g}, 48 \mathrm{mmol})$. The cell was sealed using a rubber septum and parafilm, then flushed with nitrogen gas for $15 \mathrm{~min}$, followed by the sequential addition via syringe of $\mathrm{CH}_{3} \mathrm{CN}(30 \mathrm{~mL})$, THF $(40 \mathrm{~mL})$, trifluoroacetic acid $(1.2 \mathrm{~mL}, 16 \mathrm{mmol})$ and acetic acid $(1.4 \mathrm{~mL}, 24 \mathrm{mmol})$. The reaction mixture was then purged with nitrogen gas for an additional $15 \mathrm{~min}$. A nitrogen gas balloon was connected to the flask by a needle. The solution was stirred at room temperature under irradiation from two $23 \mathrm{~W}$ CFL bulbs, and electrolysis was initiated at a constant voltage of $1.5 \mathrm{~V}$ for $72 \mathrm{~h}$. The reaction mixture was subsequently poured into a saturated sodium bicarbonate solution (ca. $400 \mathrm{~mL})$. The carbon felt anode was washed with EtOAc $(3 \times 100$ $\mathrm{mL})$ in an ultrasonic bath. The aqueous layer was separated and extracted with EtOAc $(3 \times 200 \mathrm{~mL})$, and the combined organic layers and anode extract were washed with brine and dried over anhydrous $\mathrm{Na}_{2} \mathrm{SO}_{4}$. Following concentration in vacuo, the crude residue was subjected to flash column chromatography on silica gel to yield $1.6 \mathrm{~g}$ of the desired product. 


\section{Optimization}

Table S1. Optimization studies
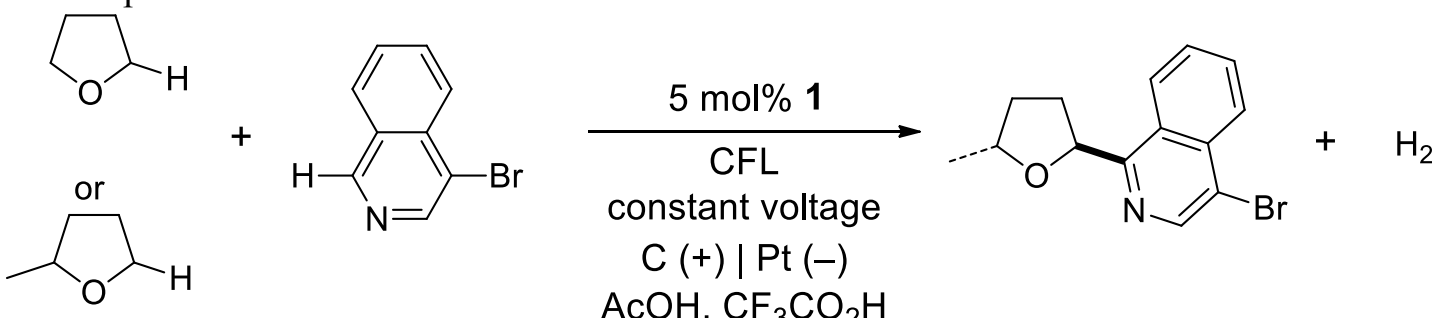

$\mathrm{C}(+) \mid \mathrm{Pt}(-)$

$\mathrm{AcOH}, \mathrm{CF}_{3} \mathrm{CO}_{2} \mathrm{H}$

$\mathrm{CH}_{3} \mathrm{CN}$, electrolyte

\begin{tabular}{rcccc}
\hline entry & $E_{\text {cell }}(\mathrm{V})$ & electrolyte (equiv) & other & yield $(\%)^{a, b}$ \\
\hline 1 & 1.5 & $\mathrm{LiClO}_{4}(6)$ & - & 42 \\
2 & 1.5 & $\mathrm{LiClO}_{4}(6)$ & no light & $<5$ \\
3 & - & $\mathrm{LiClO}_{4}(6)$ & no current & $<5$ \\
4 & 1.5 & $\mathrm{LiClO}_{4}(6)$ & no catalyst & $<5$ \\
5 & 1.5 & $\mathrm{LiClO}_{4}(6)$ & no TFA & 8 \\
6 & 1.5 & $\mathrm{LiClO}_{4}(6)$ & DMF solvent & 20 \\
7 & 1.5 & $\mathrm{LiPF}_{6}(6)$ & - & 15 \\
8 & 1.5 & $\mathrm{TBAPF}_{6}(1.5)$ & - & 10 \\
9 & 1.5 & $\mathrm{TBABF}_{4}(1.5)$ & - & 7 \\
10 & 1.5 & $\mathrm{LiClO}_{4}(6)$ & - & $82(80)^{c, d}$ \\
11 & 3.0 & $\mathrm{LiClO}_{4}(6)$ & direct electrolysis & messy \\
12 & 1.0 & $\mathrm{LiClO}_{4}(6)$ & - & $<5^{c}$ \\
13 & 1.5 & $\mathrm{LiClO}_{4}(6)$ & $1.6 \mathrm{~g}$ scale & $72^{c, d}$ \\
\hline $14^{e}$ & 1.5 & $\mathrm{LiClO}_{4}(6)$ & - & $56(55)^{c, d}$ \\
$15^{e}$ & 1.5 & $\mathrm{LiClO}_{4}(6)$ & DCM solvent & $<5^{c}$ \\
$16^{e}$ & 1.5 & $\mathrm{LiClO}_{4}(6)$ & DMF solvent & $8^{c}$ \\
$17^{e}$ & 1.5 & $\mathrm{LiPF}_{6}(6)$ & - & $30^{c}$ \\
$18^{e}$ & 1.5 & $\mathrm{TBABF}_{4}(1.5)$ & - & $6{ }^{c}$ \\
$19^{e}$ & 1.5 & $\mathrm{TBAClO}_{4}(1.5)$ & - & $10^{c}$ \\
\hline & & & &
\end{tabular}

${ }^{a}$ See procedure parts. Initial reaction conditions: 4-bromoisoquinoline (0.4 mmol, 1.0 equiv), THF (2.0 $\mathrm{mL}$ ), TAC (0.02 mmol, 0.05 equiv), $\mathrm{CH}_{3} \mathrm{CN}$ ( $\left.4.0 \mathrm{~mL}\right), \mathrm{LiClO}_{4}\left(2.4 \mathrm{mmol}, 6.0\right.$ equiv), $\mathrm{N}_{2}$, carbon felt anode, Pt cathode. Reactions performed under constant voltage (CV) conditions with light irradiation for $18 \mathrm{~h}$ at rt. ${ }^{b}$ Yields were determined by ${ }^{1} \mathrm{H}$ NMR spectroscopy. ${ }^{c}$ TAC $(0.032 \mathrm{mmol}, 0.08$ equiv $)$ ether $(2.0 \mathrm{~mL})$ and $\mathrm{CH}_{3} \mathrm{CN}(2.0 \mathrm{~mL})$ were used in the reaction for $36 \mathrm{~h}$. Others see procedure. ${ }^{d}$ Yield of isolated product. ${ }^{e} 2-$ MeTHF was used. 


\section{In situ NMR Analysis}

\begin{tabular}{|c|c|}
\hline NMR trace & Difference from standard reaction conditions \\
\hline 1 & No light \\
\hline 2 & No current \\
\hline 3 & No catalyst \\
\hline 4 & Standard reaction conditions \\
\hline 5 & $\mathrm{E}_{\text {cell }}=3.0$ V without catalyst \\
\hline
\end{tabular}

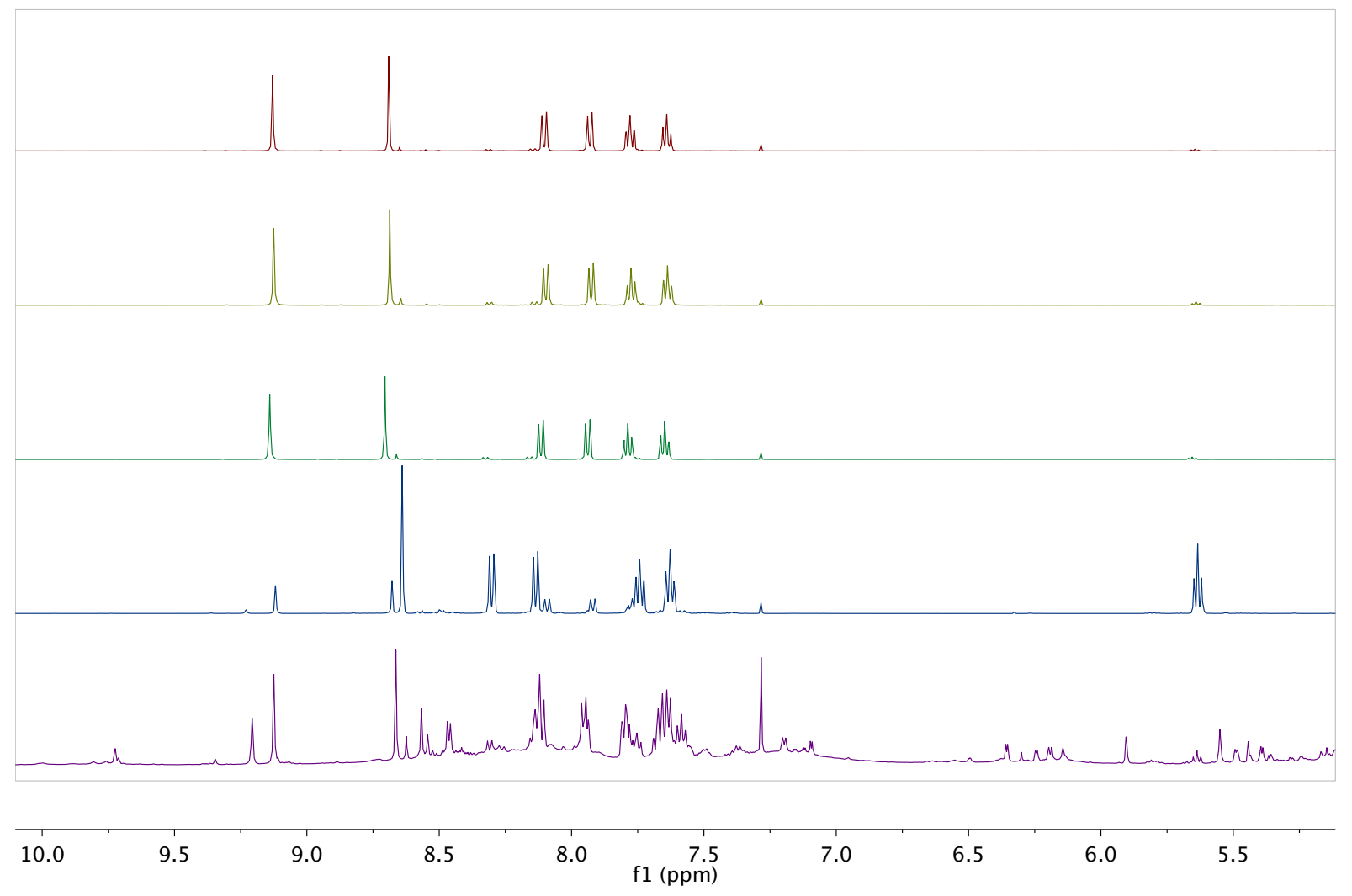

Fig. S3. In situ NMR Analysis

\section{KIE Experiment}
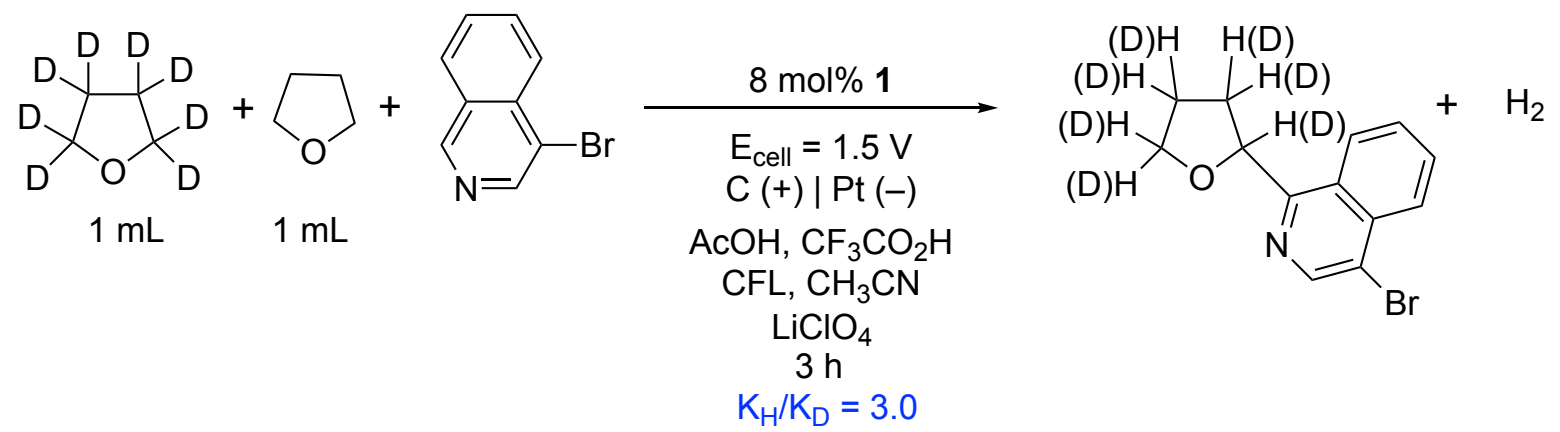

Fig S4. Kinetic isotope effect experiments 


\section{Current Profile}
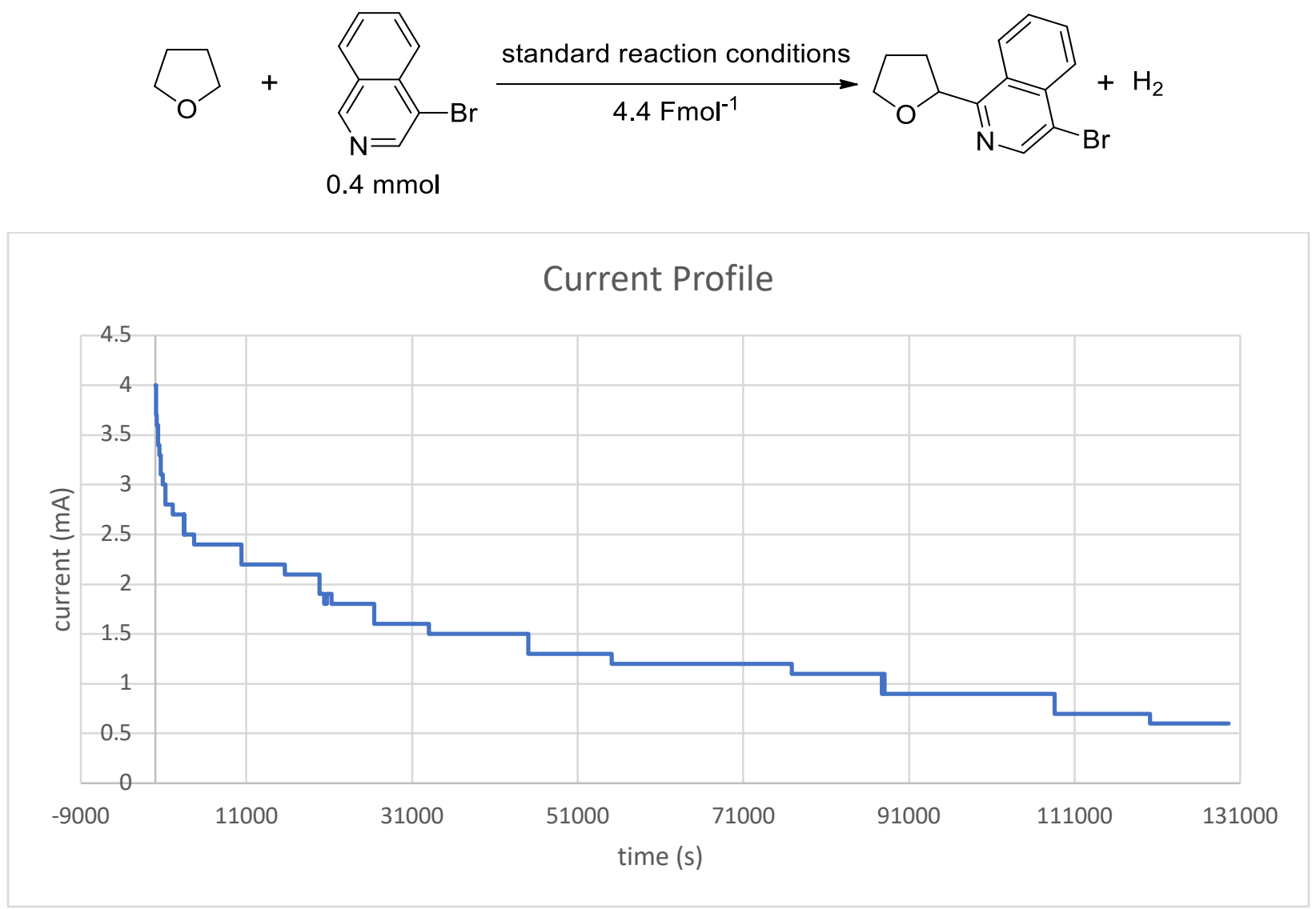

Fig S5. Current Profile 


\section{Mechanism Studies}

Reactions were performed as procedure B with deuterated acetonitrile, deuterated acetic acid or deuterated THF:

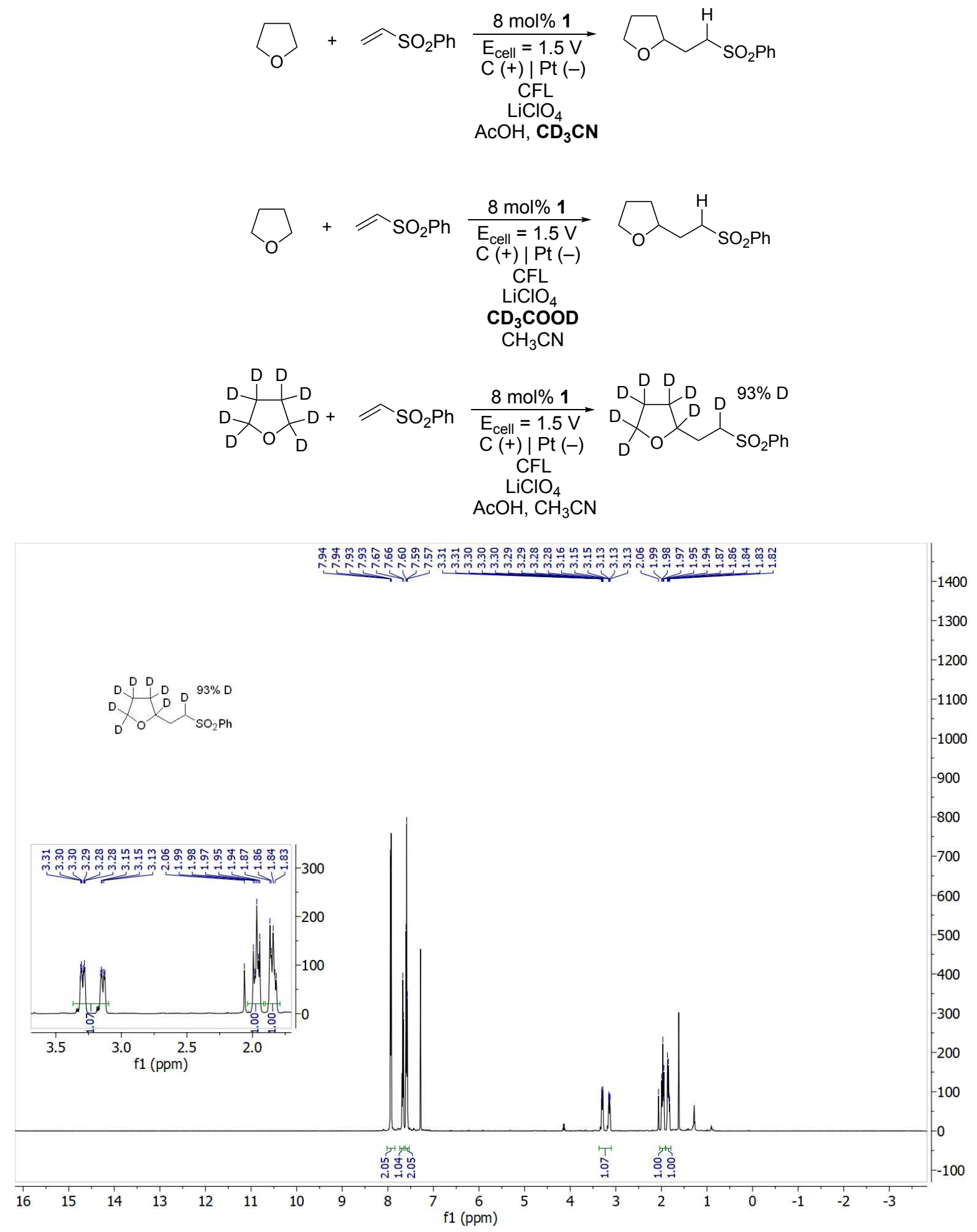

Fig S6. Isotope labeling experiments 
On-off experiment procedure: To an oven-dried 10-mL three-neck flask equipped with a stir bar, a carbon felt anode and, a platinum wire cathode was added TAC 1 (15.2 $\mathrm{mg}, 0.032 \mathrm{mmol})$, phenyl vinyl sulfone $(0.4 \mathrm{mmol}, 67.3 \mathrm{mg})$ and $\mathrm{LiClO}_{4}(255.3 \mathrm{mg}, 2.4 \mathrm{mmol})$. The cell was sealed using a rubber septum and parafilm then flushed with nitrogen gas for $5 \mathrm{~min}$, followed by the sequential addition via syringe of $\mathrm{CD}_{3} \mathrm{CN}$ $(2 \mathrm{~mL})$, the THF $(2.0 \mathrm{~mL})$, and $\mathrm{CD}_{3} \mathrm{COOD}(229 \mu \mathrm{L}, 4.0 \mathrm{mmol})$. The reaction mixture was then purged with nitrogen gas for an additional 1 min cooled by an ice bath. The mixture was stirred for 5 min and $100 \mu \mathrm{L}$ reaction aliquot was taken, diluted with $\mathrm{CDCl}_{3}$ followed by adding $1 \mu \mathrm{L}$ dibromomethane as an internal standard and analyzed by ${ }^{1} \mathrm{H}$ NMR spectroscopy. The solution was stirred at room temperature under irradiation from two 23W CFL bulbs, and electrolysis was initiated at a constant voltage of $1.5 \mathrm{~V}$ for $2 \mathrm{~h}$. Another $100 \mathrm{uL}$ reaction aliquot was taken, diluted with $\mathrm{CDCl}_{3}$ followed by adding $1 \mu \mathrm{L}$ dibromomethane as an internal standard and analyzed by ${ }^{1} \mathrm{H}$ NMR spectroscopy. Then light and electricity was switched off and the mixture was stirred in the dark for $2 \mathrm{~h}$. After that, another $100 \mathrm{uL}$ reaction aliquot was taken, diluted with $\mathrm{CDCl}_{3}$ followed by adding $1 \mu \mathrm{L}$ dibromomethane as an internal standard and analyzed by ${ }^{1} \mathrm{H} \mathrm{NMR}$ spectroscopy. The light and electricity were switched on and the mixture was stirred under light irradiation and electrolysis for $2 \mathrm{~h}$. Then another $100 \mu \mathrm{L}$ reaction aliquot was taken, diluted with $\mathrm{CDCl}_{3}$ followed by adding $1 \mu \mathrm{L}$ dibromomethane as an internal standard and analyzed by ${ }^{1} \mathrm{H}$ NMR spectroscopy. Light and electricity was switched off again and the mixture was stirred in the dark for $2 \mathrm{~h}$. After that, another $100 \mu \mathrm{L}$ reaction aliquot was taken, diluted with $\mathrm{CDCl}_{3}$ followed by adding $1 \mu \mathrm{L}$ dibromomethane as an internal standard and analyzed by ${ }^{1} \mathrm{H}$ NMR spectroscopy.
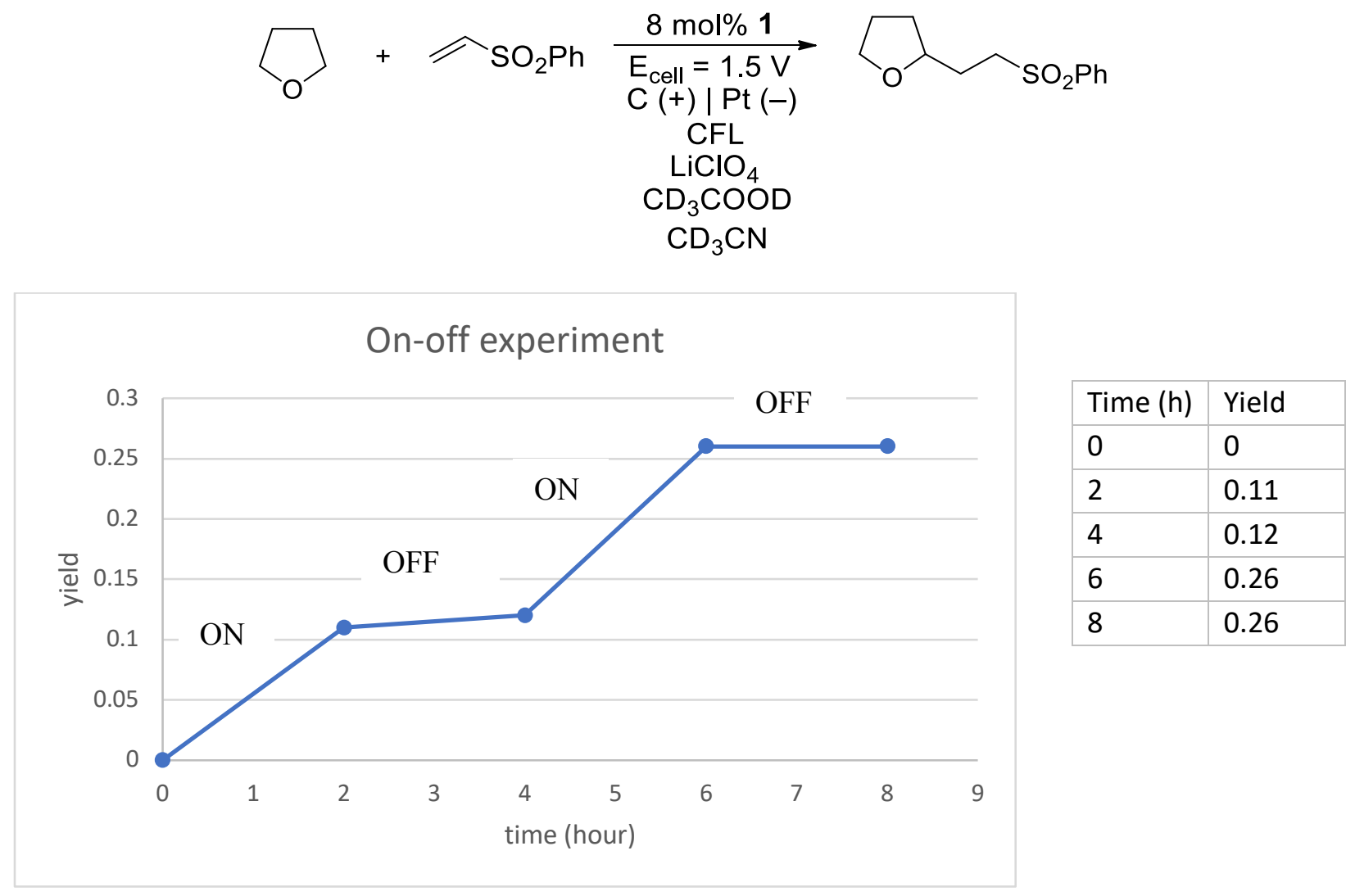

Fig S7. On-off experiments 
In order to further explore whether the alkene reaction is electrochemical initiated, control reactions were preformed and crude NMR were compared below. No reaction happened in dirctly electrolysis at $1.5 \mathrm{~V}$ method.
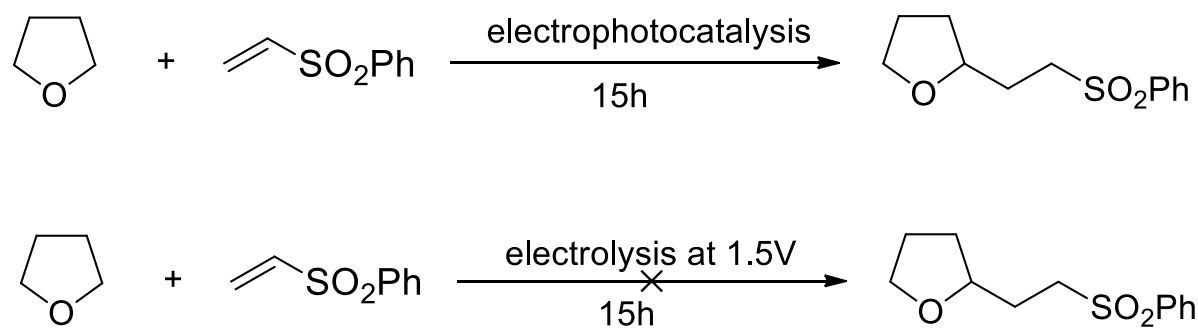

No Reaction

Electrolysis at $1.5 \mathrm{~V}$ crude NMR

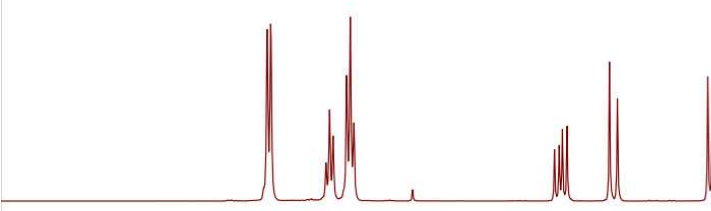

Electrophotocatalysis crude NMR

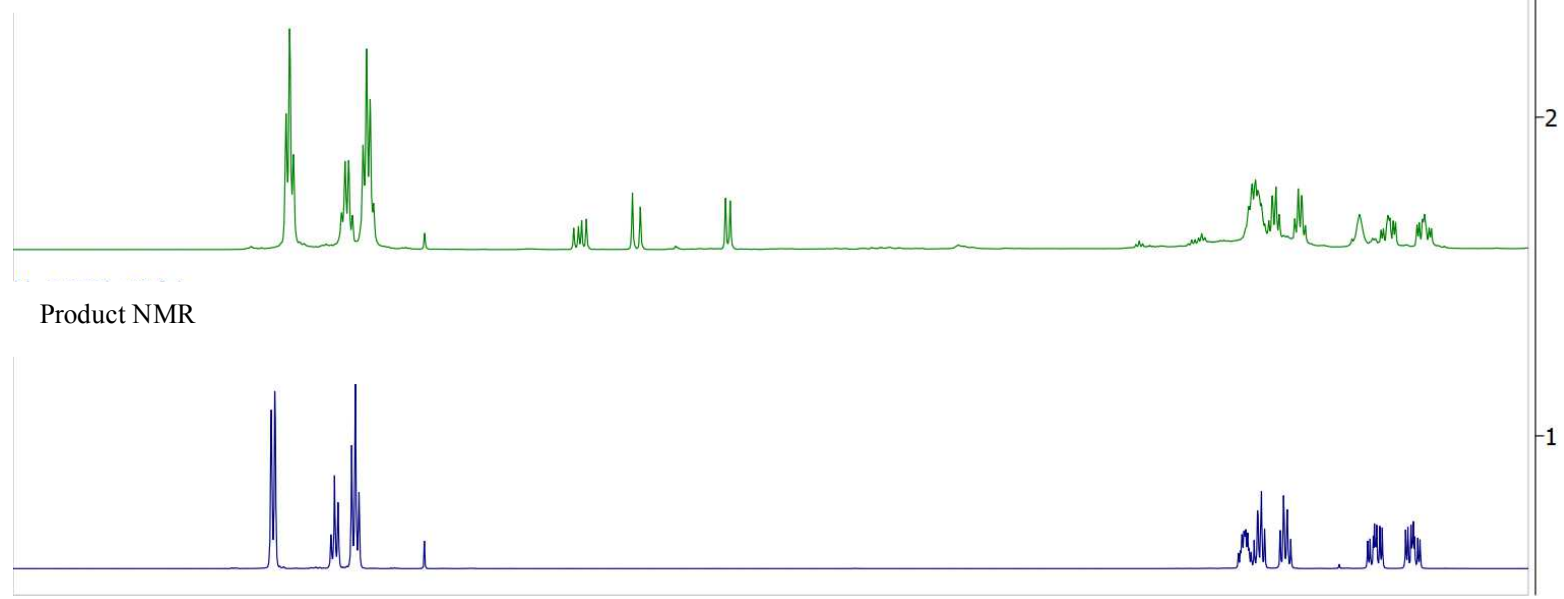

$\begin{array}{llllllllllllllllllllllllllllllll}.0 & 8.8 & 8.6 & 8.4 & 8.2 & 8.0 & 7.8 & 7.6 & 7.4 & 7.2 & 7.0 & 6.8 & 6.6 & 6.4 & 6.2 & 6.0 & 5.8 & 5.6 & 5.4 & 5.2 & 5.0 & 4.8 & 4.6 & 4.4 & 4.2 & 4.0 & 3.8 & 3.6 & 3.4 & 3.2 & 3.0 & 2.8\end{array}$ f1 (ppm)

Fig S8. THF and Alkene Reaction at Electrolysis and Electrophotocatalysis 


\section{Reaction with Alcohol to generate acetal 54.}

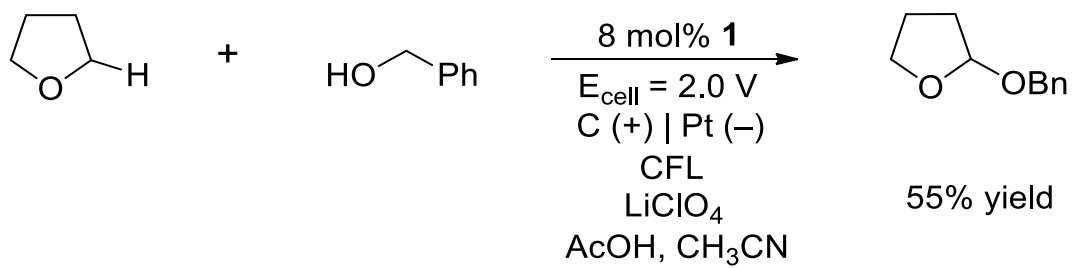

To an oven-dried 10-mL three-neck flask equipped with a stir bar, a carbon felt anode, and a platinum wire cathode was added TAC 1 (15.2 mg, $0.032 \mathrm{mmol})$, and $\mathrm{LiClO}_{4}(255.3 \mathrm{mg}, 2.4 \mathrm{mmol})$. The cell was sealed using a rubber septum and parafilm, then flushed with nitrogen gas for $5 \mathrm{~min}$, followed by the sequential addition via syringe of $\mathrm{CH}_{3} \mathrm{CN}(2 \mathrm{~mL})$, the THF $(2.0 \mathrm{~mL})$, benzyl alcohol $(0.4 \mathrm{mmol}, 41.6 \mu \mathrm{L})$ and acetic acid $(229 \mu \mathrm{L}, 4.0 \mathrm{mmol})$. The reaction mixture was then purged with nitrogen gas for an additional $5 \mathrm{~min}$. The solution was stirred at room temperature under irradiation from two $23 \mathrm{~W}$ CFL bulbs, and electrolysis was initiated at a constant voltage of $2.0 \mathrm{~V}$ for $24 \mathrm{~h}$. The reaction mixture was subsequently poured into a saturated sodium bicarbonate solution (ca. $20 \mathrm{~mL})$. The carbon felt anode was washed with EtOAc $(3 \times 5$ $\mathrm{mL})$ in an ultrasonic bath. The aqueous layer was separated and extracted with EtOAc $(3 \times 10 \mathrm{~mL})$, and the combined organic layers and anode extract were washed with brine and dried over anhydrous $\mathrm{Na}_{2} \mathrm{SO}_{4}$. Following concentration in vacuo, the crude residue was subjected to flash column chromatography on silica gel to yield the acetal product $\mathbf{5 4}$ as a colorless oil in 55\% yield (39.2 $\mathrm{mg})$.

${ }^{1} \mathrm{H}$ NMR (500 MHz, Chloroform- $d$ ) $\delta 7.40-7.30(\mathrm{~m}, 5 \mathrm{H}), 5.25(\mathrm{dd}, J=4.4,2.0 \mathrm{~Hz}, 1 \mathrm{H}), 4.75(\mathrm{~d}, J=11.9$ $\mathrm{Hz}, 1 \mathrm{H}), 4.51(\mathrm{~d}, J=11.9 \mathrm{~Hz}, 1 \mathrm{H}), 4.01-3.90(\mathrm{~m}, 2 \mathrm{H}), 2.12-1.86(\mathrm{~m}, 4 \mathrm{H}) .{ }^{13} \mathrm{C}$ NMR $(126 \mathrm{MHz}$, Chloroform- $d$ ) $\delta 138.4,128.4,127.9,127.5,103.1,68.8,67.0,32.4,23.5$. MS (DART) exact mass: calculated for $(\mathrm{M}+\mathrm{H})^{+}: 179.1067$; found: 179.1072 . 

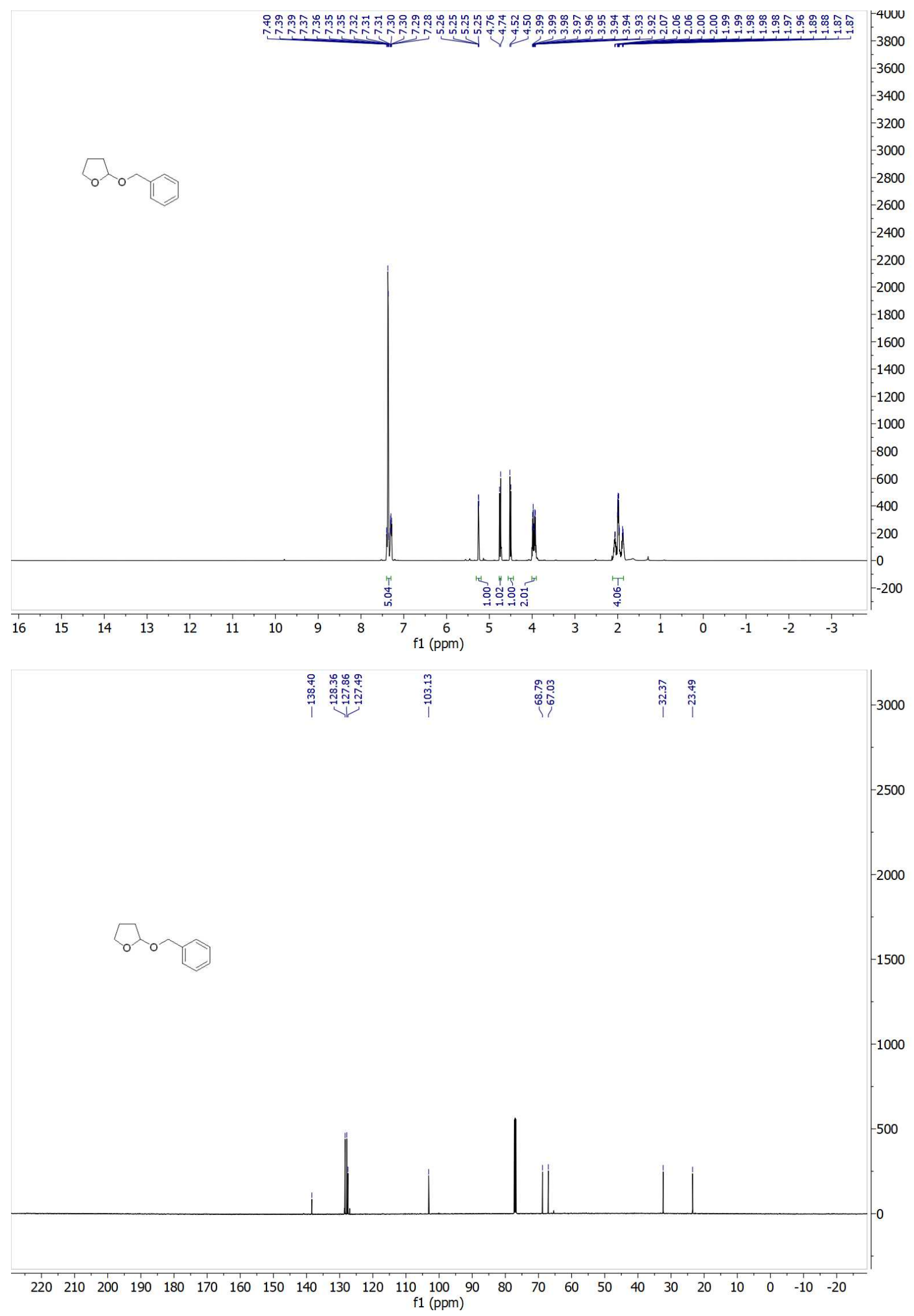


\section{Comparation with Reported Electrolysis Method}

THF and 1H-pyrazole-4-carbaldehyde were chose as model reaction substrates to compare the reported electrolysis ${ }^{[3]}$ and the electrophotocatalysis methods. After reaction, crude NMR was obtained and showed below.
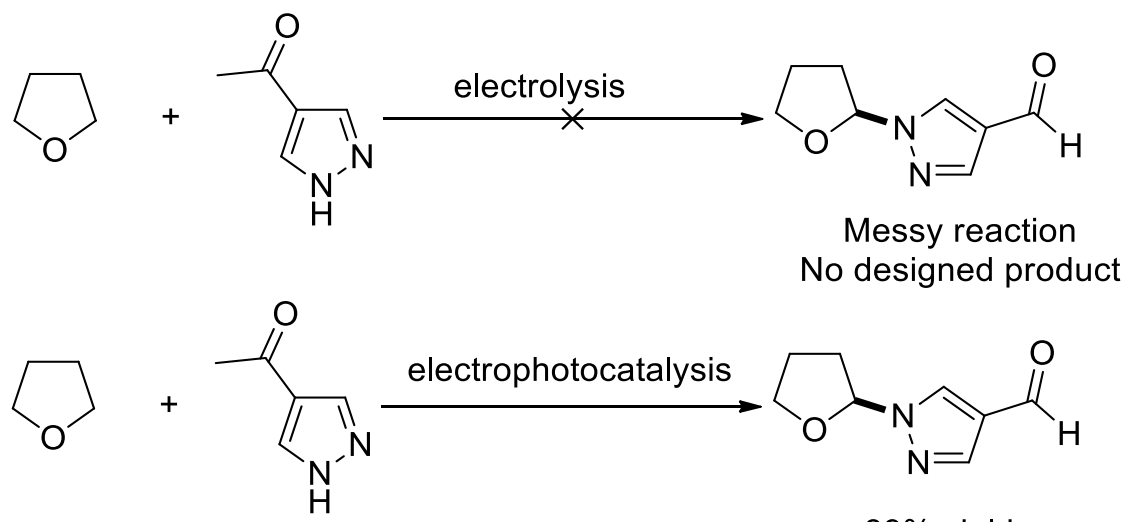

$89 \%$ yield

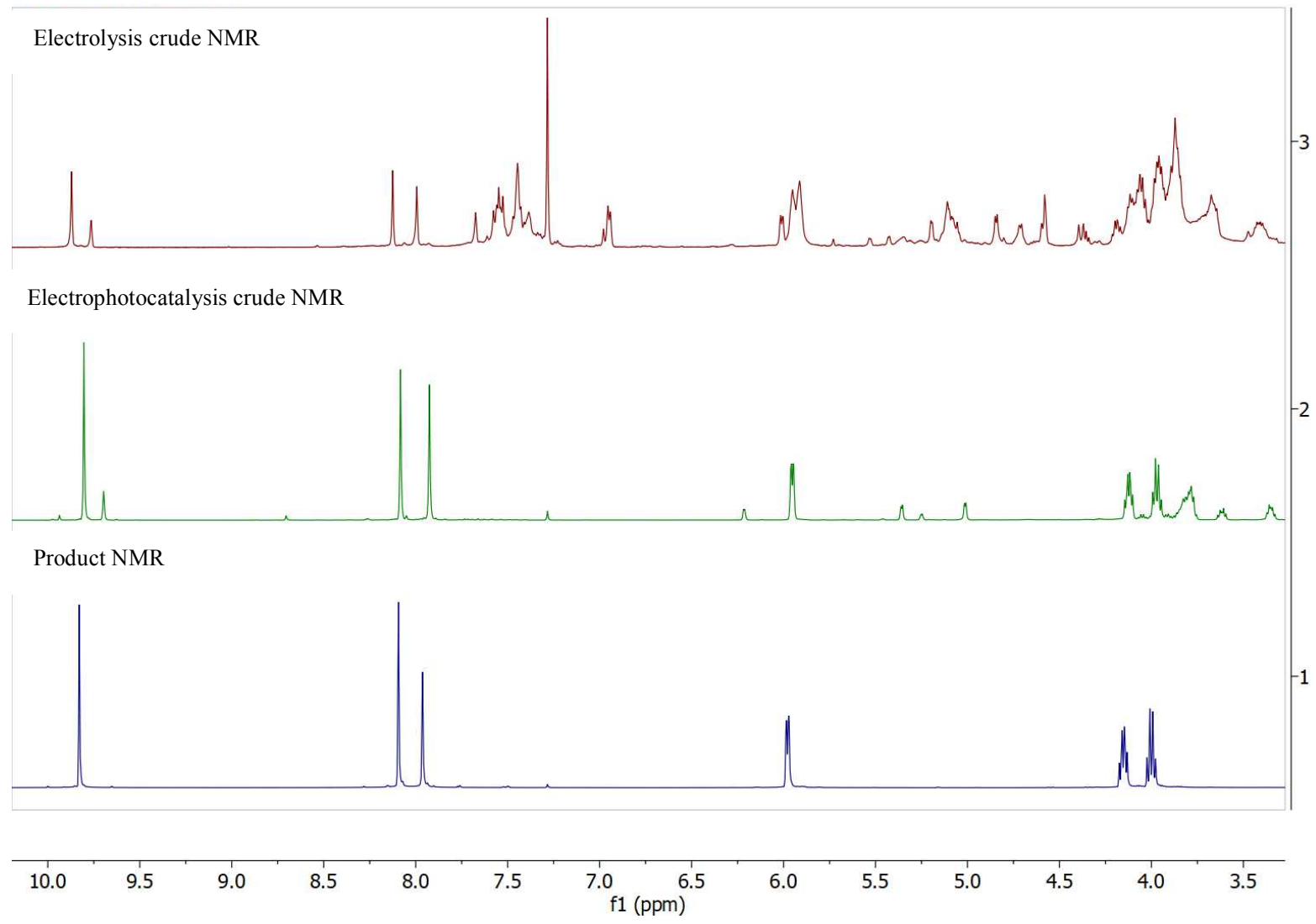

Fig S9. Comparation with Reported Electrolysis Method 


\section{Characterization}<smiles>Brc1cnc(C2CCCO2)c2ccccc12</smiles>

4-Bromo-1-(tetrahydrofuran-2-yl)isoquinoline (6): The title compound was prepared from tetrahydrofuran $(2.0 \mathrm{~mL})$ and 4-bromoisoquinoline $(0.4 \mathrm{mmol}, 83.2 \mathrm{mg})$ according to general procedure A with a reaction time of 36 hours. The crude residue was purified by column chromatography on silica gel with an eluent of hexanes to $30 \%$ EtOAc/hexanes to yield a light yellow oil in $80 \%$ yield $(89.0 \mathrm{mg})$.

6: ${ }^{1} \mathrm{H}$ NMR (500 MHz, Chloroform- $d$ ) $\delta 8.66(\mathrm{~s}, 1 \mathrm{H}), 8.33(\mathrm{~d}, J=8.5 \mathrm{~Hz}, 1 \mathrm{H}), 8.17(\mathrm{~d}, J=8.4 \mathrm{~Hz}, 1 \mathrm{H})$, $7.78-7.74(\mathrm{~m}, 1 \mathrm{H}), 7.66-7.63(\mathrm{~m}, 1 \mathrm{H}), 5.66(\mathrm{t}, J=7.0 \mathrm{~Hz}, 1 \mathrm{H}), 4.15-4.11(\mathrm{~m}, 1 \mathrm{H}), 4.03-3.98(\mathrm{~m}, 1 \mathrm{H})$, $2.53-2.49(\mathrm{~m}, 1 \mathrm{H}), 2.38-2.36(\mathrm{~m}, 1 \mathrm{H}), 2.18-2.03(\mathrm{~m}, 2 \mathrm{H}) .{ }^{13} \mathrm{C}$ NMR $(126 \mathrm{MHz}$, Chloroform- $d) \delta 159.2$, 143.2, 135.1, 131.1, 128.0, 127.9, 126.6, 125.7, 119.3, 78.8, 69.1, 30.6, 26.1. MS (DART) exact mass: calculated for $(\mathrm{M}+\mathrm{H})^{+}: 278.0175$; found: 278.0187 .<smiles>Clc1ccc2c(C3CCCO3)nccc2c1</smiles>

6-Chloro-1-(tetrahydrofuran-2-yl)isoquinoline (8): The title compound was prepared from tetrahydrofuran $(2.0 \mathrm{~mL})$ and 6-chloroisoquinoline $(0.4 \mathrm{mmol}, 65.4 \mathrm{mg})$ according to general procedure A with a reaction time of 36 hours. The crude residue was purified by column chromatography on silica gel with an eluent of hexanes to $20 \%$ EtOAc/hexanes to yield a colorless oil in $81 \%$ yield $(75.7 \mathrm{mg})$.

8: ${ }^{1} \mathrm{H}$ NMR $(500 \mathrm{MHz}$, Chloroform- $d) \delta 8.51(\mathrm{~d}, J=5.7 \mathrm{~Hz}, 1 \mathrm{H}), 8.34(\mathrm{~d}, J=9.0 \mathrm{~Hz}, 1 \mathrm{H}), 7.82(\mathrm{~d}, J=2.1$ $\mathrm{Hz}, 1 \mathrm{H}), 7.54(\mathrm{dd}, J=9.0,2.1 \mathrm{~Hz}, 1 \mathrm{H}), 7.50(\mathrm{~d}, J=5.7 \mathrm{~Hz}, 1 \mathrm{H}), 5.66(\mathrm{t}, J=7.1 \mathrm{~Hz}, 1 \mathrm{H}), 4.19-4.14(\mathrm{~m}$, $1 \mathrm{H}), 4.06-4.02(\mathrm{~m}, 1 \mathrm{H}), 2.60-2.50(\mathrm{~m}, 1 \mathrm{H}), 2.44-2.36(\mathrm{~m}, 1 \mathrm{H}), 2.22-2.09(\mathrm{~m}, 2 \mathrm{H}) .{ }^{13} \mathrm{C} \mathrm{NMR}(126$ MHz, Chloroform- $d$ ) $\delta 159.8,142.6,137.4,136.1,128.1,127.4,126.0,124.9,119.6,79.3,69.0,30.5,26.1$. MS (DART) exact mass: calculated for $(\mathrm{M}+\mathrm{H})^{+}: 234.0680$; found: 234.0688 .<smiles>COC(=O)c1cc2ccccc2c(C2CCCO2)n1</smiles>

Methyl 1-(tetrahydrofuran-2-yl)isoquinoline-3-carboxylate (9): The title compound was prepared from tetrahydrofuran $(2.0 \mathrm{~mL})$ and methyl isoquinoline-3-carboxylate $(0.4 \mathrm{mmol}, 74.9 \mathrm{mg})$ according to general procedure A with a reaction time of 36 hours. The crude residue was purified by column chromatography 
on silica gel with an eluent of hexanes to $30 \%$ EtOAc/hexanes to yield a white solid in $72 \%$ yield (74.1 $\mathrm{mg})$.

9: ${ }^{1} \mathrm{H}$ NMR (500 MHz, Chloroform- $d$ ) $\delta 8.51-8.51(\mathrm{~m}, 2 \mathrm{H}), 7.98-7.96(\mathrm{~m}, 1 \mathrm{H}), 7.76-7.73(\mathrm{~m}, 2 \mathrm{H})$, $5.68(\mathrm{t}, J=7.2 \mathrm{~Hz}, 1 \mathrm{H}), 4.22-4.14(\mathrm{~m}, 1 \mathrm{H}), 4.07-4.04(\mathrm{~m}, 4 \mathrm{H}), 2.76-2.67(\mathrm{~m}, 1 \mathrm{H}), 2.47-2.39(\mathrm{~m}, 1 \mathrm{H})$, $2.27-2.11(\mathrm{~m}, 2 \mathrm{H}) .{ }^{13} \mathrm{C}$ NMR $(126 \mathrm{MHz}$, Chloroform- $d) \delta 166.5,160.0,140.0,136.4,130.5,129.3,128.8$, 128.2, 126.0, 124.2, 80.5, 69.0, 52.7, 30.2, 26.1. MS (DART) exact mass: calculated for $(\mathrm{M}+\mathrm{H})^{+}: 258.1125$; found: 258.1135 .<smiles>Brc1cccc2c(C3CCCO3)nccc12</smiles>

5-Bromo-1-(tetrahydrofuran-2-yl)isoquinoline (10): The title compound was prepared from tetrahydrofuran $(2.0 \mathrm{~mL})$ and 5-bromoisoquinoline $(0.4 \mathrm{mmol}, 83.2 \mathrm{mg})$ according to general procedure A with a reaction time of 36 hours. The crude residue was purified by column chromatography on silica gel with an eluent of hexanes to $20 \%$ EtOAc/hexanes to yield a colorless oil in $78 \%$ yield $(86.8 \mathrm{mg})$.

10: ${ }^{1} \mathrm{H}$ NMR (500 MHz, Chloroform- $d$ ) $\delta{ }^{1} \mathrm{H}$ NMR $(500 \mathrm{MHz}$, Chloroform- $d$ ) $\delta 8.60(\mathrm{~d}, J=5.9 \mathrm{~Hz}, 1 \mathrm{H})$, $8.35(\mathrm{~d}, J=8.5 \mathrm{~Hz}, 1 \mathrm{H}), 8.03-7.88(\mathrm{~m}, 2 \mathrm{H}), 7.47-7.43(\mathrm{~m}, 1 \mathrm{H}), 5.71(\mathrm{t}, J=7.0 \mathrm{~Hz}, 1 \mathrm{H}), 4.18-4.14(\mathrm{~m}$, $1 \mathrm{H}), 4.06-4.01(\mathrm{~m}, 1 \mathrm{H}), 2.59-2.54(\mathrm{~m}, 1 \mathrm{H}), 2.42-2.38(\mathrm{~m}, 1 \mathrm{H}), 2.19-2.10(\mathrm{~m}, 2 \mathrm{H}) .{ }^{13} \mathrm{C} \mathrm{NMR}(126 \mathrm{MHz}$, Chloroform- $d$ ) $\delta 160.0,142.9,135.6,133.6,127.8,127.4,125.1,122.3,119.4,79.0,69.1,30.6,26.1$. MS (DART) exact mass: calculated for $(\mathrm{M}+\mathrm{H})^{+}: 278.0175$; found: 278.0186 .<smiles>Brc1cnc(C2CCCCO2)c2ccccc12</smiles>

4-Bromo-1-(tetrahydro-2H-pyran-2-yl)isoquinoline (11): The title compound was prepared from tetrahydropyran $(2.0 \mathrm{~mL})$ and 4-bromoisoquinoline $(0.4 \mathrm{mmol}, 83.2 \mathrm{mg})$ according to general procedure A with a reaction time of 36 hours. The crude residue was purified by column chromatography on silica gel with an eluent of hexanes to $15 \%$ EtOAc/hexanes to yield a white solid in $62 \%$ yield $(72.5 \mathrm{mg})$.

11: ${ }^{1} \mathrm{H}$ NMR (500 MHz, Chloroform- $d$ ) $\delta 8.73(\mathrm{~s}, 1 \mathrm{H}), 8.40(\mathrm{~d}, J=8.5 \mathrm{~Hz}, 1 \mathrm{H}), 8.22(\mathrm{~d}, J=8.5 \mathrm{~Hz}, 1 \mathrm{H})$, $7.81(\mathrm{ddd}, J=8.4,6.9,1.2 \mathrm{~Hz}, 1 \mathrm{H}), 7.68$ (ddd, $J=8.3,6.8,1.3 \mathrm{~Hz}, 1 \mathrm{H}), 5.16(\mathrm{dd}, J=10.9,2.3 \mathrm{~Hz}, 1 \mathrm{H})$, $4.34-4.21(\mathrm{~m}, 1 \mathrm{H}), 3.83-3.77(\mathrm{~m}, 1 \mathrm{H}), 2.17-1.64(\mathrm{~m}, 6 \mathrm{H}) .{ }^{13} \mathrm{C}$ NMR $(126 \mathrm{MHz}$, Chloroform- $d) \delta 159.3$, 143.5, 135.2, 131.1, 127.9, 127.4, 126.7, 125.7, 119.3, 79.0, 69.5, 31.0, 25.9, 23.8. MS (DART) exact mass: calculated for $(\mathrm{M}+\mathrm{H})^{+}: 292.0332$; found: 292.0343 . 


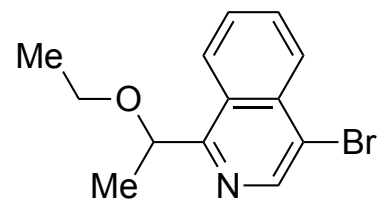

4-Bromo-1-(1-ethoxyethyl)isoquinoline (12): The title compound was prepared from diethyl ether $(2.0 \mathrm{~mL})$ and 4-bromoisoquinoline $(0.4 \mathrm{mmol}, 83.2 \mathrm{mg})$ according to general procedure A with a reaction time of 36 hours. The crude residue was purified by column chromatography on silica gel with an eluent of hexanes to $15 \%$ EtOAc/hexanes to yield a colorless oil in $52 \%$ yield $(58.3 \mathrm{mg})$.

12: ${ }^{1} \mathrm{H}$ NMR (500 MHz, Chloroform- $d$ ) $\delta 8.74(\mathrm{~d}, J=8.6 \mathrm{~Hz}, 1 \mathrm{H}), 8.68(\mathrm{~s}, 1 \mathrm{H}), 8.27-8.22(\mathrm{~m}, 1 \mathrm{H}), 7.84$ $-7.81(\mathrm{~m}, 1 \mathrm{H}), 7.69-7.66(\mathrm{~m}, 1 \mathrm{H}), 5.16(\mathrm{q}, J=6.8 \mathrm{~Hz}, 1 \mathrm{H}), 3.57-3.50(\mathrm{~m}, 1 \mathrm{H}), 3.45-3.38(\mathrm{~m}, 1 \mathrm{H})$, $1.71(\mathrm{~d}, J=6.7 \mathrm{~Hz}, 3 \mathrm{H}), 1.21(\mathrm{t}, J=7.0 \mathrm{~Hz}, 3 \mathrm{H}) .{ }^{13} \mathrm{C}$ NMR $(126 \mathrm{MHz}$, Chloroform- $d) \delta 161.5,143.3,135.3$, 131.2, 127.8, 127.4, 126.8, 125.9, 119.3, 79.7, 64.6, 21.6, 15.5. MS (DART) exact mass: calculated for (M - EtO) ${ }^{+}: 233.9918$; found: 233.9922.<smiles>CC1CCC(c2ncc(Br)c3ccccc23)O1</smiles>

4-Bromo-1-(5-methyltetrahydrofuran-2-yl)isoquinoline (13): The title compound was prepared from 2methyltetrahydrofuran $(2.0 \mathrm{~mL})$ and 4-bromoisoquinoline $(0.4 \mathrm{mmol}, 83.2 \mathrm{mg})$ according to general procedure A with a reaction time of 36 hours. The crude residue was purified by column chromatography on silica gel with an eluent of hexanes to $20 \%$ EtOAc/hexanes to yield a white solid in $55 \%$ yield (64.3 $\mathrm{mg}$, diastereoisomers, d.r. $=1: 1.1$ ).

13: ${ }^{1} \mathrm{H}$ NMR $\left(500 \mathrm{MHz}, \mathrm{CDCl}_{3}\right) \delta 8.69(\mathrm{~s}, 1 \mathrm{H}), 8.41(\mathrm{dd}, J=38.2,8.5 \mathrm{~Hz}, 1 \mathrm{H}), 8.20(\mathrm{ddd}, J=8.5,2.4,1.2$ $\mathrm{Hz}, 1 \mathrm{H}), 7.83-7.76(\mathrm{~m}, 1 \mathrm{H}), 7.71-7.64(\mathrm{~m}, 1 \mathrm{H}), 5.84(\mathrm{t}, J=7.1 \mathrm{~Hz}, 0.5 \mathrm{H}), 5.61(\mathrm{t}, J=7.2 \mathrm{~Hz}, 0.5 \mathrm{H})$, $4.42(\mathrm{dt}, J=8.0,6.1 \mathrm{~Hz}, 0.5 \mathrm{H}), 4.29(\mathrm{dt}, J=8.0,6.2 \mathrm{~Hz}, 0.5 \mathrm{H}), 2.74-2.53(\mathrm{~m}, 1 \mathrm{H}), 2.50-2.18(\mathrm{~m}, 2 \mathrm{H})$, $1.82-1.69(\mathrm{~m}, 1 \mathrm{H}), 1.37(\mathrm{t}, J=6.0 \mathrm{~Hz}, 3 \mathrm{H}) .{ }^{13} \mathrm{C} \mathrm{NMR}\left(126 \mathrm{MHz}, \mathrm{CDCl}_{3}\right) \delta 159.7,158.8,143.2,143.2$, 135.1, 135.1, 131.1, 131.1, 128.2, 128.0, 128.0, 127.9, 126.6, 126.5, 126.1, 125.7, 119.4, 119.2, 79.4, 78.1, 77.0, 76.1, 34.0, 33.2, 31.2, 30.2, 21.4, 21.2. MS (DART) exact mass: calculated for $(\mathrm{M}+\mathrm{H})^{+}:$292.0332; found: 292.0348 . 
<smiles>COC(=O)c1cc2ccccc2c(C2CCC(C)O2)n1</smiles>

Methyl 1-(5-methyltetrahydrofuran-2-yl)isoquinoline-3-carboxylate (14): The title compound was prepared from 2-methyltetrahydrofuran $(2.0 \mathrm{~mL})$ and methyl isoquinoline-3-carboxylate $(0.4 \mathrm{mmol}, 74.9$ $\mathrm{mg}$ ) according to general procedure A with a reaction time of 36 hours. The crude residue was purified by column chromatography on silica gel with an eluent of hexanes to $30 \%$ EtOAc/hexanes to yield a white solid in $41 \%$ yield $(44.5 \mathrm{mg}$, diastereoisomers, d.r. $=1: 1.6)$.

14: ${ }^{1} \mathrm{H}$ NMR (599 MHz, Chloroform- $d$ ) $\delta 8.58-8.47(\mathrm{~m}, 2 \mathrm{H}), 7.97-7.89(\mathrm{~m}, 1 \mathrm{H}), 7.78-7.63(\mathrm{~m}, 2 \mathrm{H})$, $5.80(\mathrm{t}, J=7.2 \mathrm{~Hz}, 0.37 \mathrm{H}), 5.61(\mathrm{t}, J=7.4 \mathrm{~Hz}, 0.63 \mathrm{H}), 4.50-4.39(\mathrm{~m}, 0.41 \mathrm{H}), 4.26(\mathrm{dt}, J=8.2,6.2 \mathrm{~Hz}$, $0.61 \mathrm{H}), 4.01(\mathrm{~s}, 3 \mathrm{H}), 2.78-2.62(\mathrm{~m}, 1 \mathrm{H}), 2.46-2.38(\mathrm{~m}, 1 \mathrm{H}), 2.34-2.18(\mathrm{~m}, 1 \mathrm{H}), 1.83-1.75(\mathrm{~m}, 1 \mathrm{H})$, $1.40-1.34(\mathrm{~m}, 3 \mathrm{H}) .{ }^{13} \mathrm{C} \mathrm{NMR}\left(126 \mathrm{MHz}, \mathrm{CDCl}_{3}\right) \delta 166.6,160.5,159.9,140.0,136.5,130.5,129.3,129.2$, 128.8, 128.8, 128.2, 126.2, 126.0, 124.2, 124.1, 81.2, 79.7, 77.1, 76.1, 52.7, 34.0, 33.0, 31.0, 30.5, 21.5, 21.1. MS (DART) exact mass: calculated for $(\mathrm{M}+\mathrm{H})^{+}: 272.1281$; found: 272.1297 .<smiles>CC1CCC(c2nccc3c(Br)cccc23)O1</smiles>

5-Bromo-1-(5-methyltetrahydrofuran-2-yl)isoquinoline (15): The title compound was prepared from 2methyltetrahydrofuran $(2.0 \mathrm{~mL})$ and 5-bromoisoquinoline $(0.4 \mathrm{mmol}, 83.2 \mathrm{mg})$ according to general procedure A with a reaction time of 36 hours. The crude residue was purified by column chromatography on silica gel with an eluent of hexanes to $20 \%$ EtOAc/hexanes to yield a white solid in $57 \%$ yield (66.6 mg, diastereoisomers, d.r. $=1: 1.2$ ).

15: ${ }^{1} \mathrm{H}$ NMR $\left(500 \mathrm{MHz}, \mathrm{CDCl}_{3}\right) \delta 8.62(\mathrm{dd}, J=5.9,4.0 \mathrm{~Hz}, 1 \mathrm{H}), 8.39(\mathrm{dd}, J=40.0,8.5 \mathrm{~Hz}, 1 \mathrm{H}), 8.05-$ $7.90(\mathrm{~m}, 2 \mathrm{H}), 7.47(\mathrm{~m}, 1 \mathrm{H}), 5.90(\mathrm{t}, J=7.1 \mathrm{~Hz}, 0.5 \mathrm{H}), 5.67(\mathrm{t}, J=7.3 \mathrm{~Hz}, 0.5 \mathrm{H}), 4.45(\mathrm{dt}, J=8.1,6.1 \mathrm{~Hz}$, $0.5 \mathrm{H}), 4.30(\mathrm{dt}, J=8.0,6.2 \mathrm{~Hz}, 0.5 \mathrm{H}), 2.76-2.17(\mathrm{~m}, 3 \mathrm{H}), 1.86-1.69(\mathrm{~m}, 1 \mathrm{H}), 1.37(\mathrm{~d}, J=7.7 \mathrm{~Hz}, 3 \mathrm{H})$. ${ }^{13} \mathrm{C}$ NMR $\left(126 \mathrm{MHz}, \mathrm{CDCl}_{3}\right) \delta 160.6,159.7,142.8,142.8,135.7,135.7,133.7,133.7,128.0,127.6,127.5$, 127.4, 125.4, 125.0, 122.3, 122.2, 119.5, 119.4, 79.7, 78.4, 77.0, 76.2, 34.0, 33.2, 31.7, 30.6, 21.4, 21.1. MS (DART) exact mass: calculated for $(\mathrm{M}+\mathrm{H})^{+}: 292.0332$; found: 292.0350 . 
<smiles>CC1CCC(c2nccc3c(C=O)cccc23)O1</smiles>

1-(5-Methyltetrahydrofuran-2-yl)isoquinoline-5-carbaldehyde (16): The title compound was prepared from 2-methyltetrahydrofuran $(2.0 \mathrm{~mL})$ and isoquinoline-5-carbaldehyde $(0.4 \mathrm{mmol}, 62.9 \mathrm{mg})$ according to general procedure A with a reaction time of 36 hours. The crude residue was purified by column chromatography on silica gel with an eluent of hexanes to $25 \%$ EtOAc/hexanes to yield a white solid in $40 \%$ yield $(38.6 \mathrm{mg}$, diastereoisomers, d.r. $=1: 1)$.

16: ${ }^{1} \mathrm{H}$ NMR $\left(500 \mathrm{MHz}, \mathrm{CDCl}_{3}\right) \delta 10.42(\mathrm{~s}, 1 \mathrm{H}), 9.10-8.92(\mathrm{~m}, 1 \mathrm{H}), 8.88-8.72(\mathrm{~m}, 1 \mathrm{H}), 8.72-8.64(\mathrm{~m}$, $1 \mathrm{H}), 8.26-8.14(\mathrm{~m}, 1 \mathrm{H}), 7.85-7.74(\mathrm{~m}, 1 \mathrm{H}), 5.88(\mathrm{t}, J=7.1 \mathrm{~Hz}, 0.5 \mathrm{H}), 5.65(\mathrm{t}, J=7.3 \mathrm{~Hz}, 0.5 \mathrm{H}), 4.36-$ $4.30(\mathrm{~m}, 1 \mathrm{H}), 2.82-2.63(\mathrm{~m}, 1 \mathrm{H}), 2.51-2.24(\mathrm{~m}, 2 \mathrm{H}), 1.83-1.74(\mathrm{~m}, 1 \mathrm{H}), 1.38(\mathrm{~d}, J=6.1 \mathrm{~Hz}, 3 \mathrm{H}) .{ }^{13} \mathrm{C}$ NMR $\left(126 \mathrm{MHz}, \mathrm{CDCl}_{3}\right) \delta 192.6,192.6,192.6,160.4,159.5,144.6,144.5,139.2,139.2,134.3,134.3$, 133.0, 132.6, 130.9, 130.8, 127.1, 126.8, 126.2, 126.1, 117.3, 117.1, 80.1, 78.7, 76.2, 34.0, 33.1, 31.0, 30.0, 21.4, 21.2. MS (DART) exact mass: calculated for $(\mathrm{M}+\mathrm{H})^{+}: 242.1176$; found: 242.1192 .<smiles>CC1CCC(c2ncc(F)c3ccccc23)O1</smiles>

4-Fluoro-1-(5-methyltetrahydrofuran-2-yl)isoquinoline (17): The title compound was prepared from 2methyltetrahydrofuran $(2.0 \mathrm{~mL})$ and 4-fluoroisoquinoline $(0.4 \mathrm{mmol}, 58.9 \mathrm{mg})$ according to general procedure A with a reaction time of 36 hours. The crude residue was purified by column chromatography on silica gel with an eluent of hexanes to $20 \%$ EtOAc/hexanes to yield a white solid in $61 \%$ yield $(56.4 \mathrm{mg}$, diastereoisomers, d.r. $=1: 1)$.

17: ${ }^{1} \mathrm{H}$ NMR $\left(500 \mathrm{MHz}, \mathrm{CDCl}_{3}\right) \delta 8.53-8.37(\mathrm{~m}, 1 \mathrm{H}), 8.35(\mathrm{~d}, J=1.8 \mathrm{~Hz}, 1 \mathrm{H}), 8.17-8.03(\mathrm{~m}, 1 \mathrm{H}), 7.84$ $-7.60(\mathrm{~m}, 2 \mathrm{H}), 5.82(\mathrm{t}, J=7.1 \mathrm{~Hz}, 0.5 \mathrm{H}), 5.59(\mathrm{t}, J=7.3 \mathrm{~Hz}, 0.5 \mathrm{H}), 4.50-4.19(\mathrm{~m}, 1 \mathrm{H}), 2.77-2.53(\mathrm{~m}$, $1 \mathrm{H}), 2.49-2.15(\mathrm{~m}, 2 \mathrm{H}), 1.84-1.67(\mathrm{~m}, 1 \mathrm{H}), 1.38(\mathrm{~d}, J=3.4 \mathrm{~Hz}, 3 \mathrm{H}) .{ }^{13} \mathrm{C} \mathrm{NMR}\left(126 \mathrm{MHz}, \mathrm{CDCl}_{3}\right) \delta$ 156.0, 156.0, $154.2(J=260.8 \mathrm{~Hz}) ., 155.2,155.1,130.1,130.1,130.1,130.1,128.1,128.1,128.0,127.9$, 127.8, 127.8, $127.1(J=10.7 \mathrm{~Hz}), 126.4(J=17.2 \mathrm{~Hz}), 125.5(J=39.1 \mathrm{~Hz}), 120.1(J=5.6 \mathrm{~Hz}), 79.6,78.2$, 76.9, 76.0, 34.0, 33.1, 31.0, 30.1, 21.4, 21.2. ${ }^{19} \mathrm{~F} \mathrm{NMR}\left(470 \mathrm{MHz}, \mathrm{CDCl}_{3}\right) \delta$-140.8. MS (DART) exact mass: calculated for $(\mathrm{M}+\mathrm{H})^{+}: 232.1132$; found: 232.1145 . 
<smiles>CC1CCC(c2nccc3cc(Cl)ccc23)O1</smiles>

6-Chloro-1-(5-methyltetrahydrofuran-2-yl)isoquinoline (18): The title compound was prepared from 2methyltetrahydrofuran $(2.0 \mathrm{~mL})$ and 6-chloroisoquinoline $(0.4 \mathrm{mmol}, 65.4 \mathrm{mg})$ according to general procedure A with a reaction time of 36 hours. The crude residue was purified by column chromatography on silica gel with an eluent of hexanes to $20 \%$ EtOAc/hexanes to yield a white solid in $62 \%$ yield $(61.4 \mathrm{mg}$, diastereoisomers, d.r. $=1: 1.1)$.

18: ${ }^{1} \mathrm{H}$ NMR (500 MHz, $\left.\mathrm{CDCl}_{3}\right) \delta 8.53(\mathrm{~m}, 1 \mathrm{H}), 8.40(\mathrm{~m}, 1 \mathrm{H}), 7.83(\mathrm{~d}, J=2.7 \mathrm{~Hz}, 1 \mathrm{H}), 7.60-7.46(\mathrm{~m}$, 2H), $5.82(\mathrm{t}, J=7.2 \mathrm{~Hz}, 0.5 \mathrm{H}), 5.59(\mathrm{t}, J=7.4 \mathrm{~Hz}, 0.5 \mathrm{H}), 4.44(\mathrm{q}, J=6.5 \mathrm{~Hz}, 0.5 \mathrm{H}), 4.29$ (q, $J=6.6 \mathrm{~Hz}$, $0.5 \mathrm{H}), 2.74-2.53(\mathrm{~m}, 1 \mathrm{H}), 2.51-2.19(\mathrm{~m}, 2 \mathrm{H}), 1.81-1.70(\mathrm{~m}, 1 \mathrm{H}), 1.39(\mathrm{~d}, J=3.1 \mathrm{~Hz}, 3 \mathrm{H}) .{ }^{13} \mathrm{C} \mathrm{NMR}$ $\left(126 \mathrm{MHz}, \mathrm{CDCl}_{3}\right) \delta 160.3,159.4,142.5,142.5,137.5,137.5,136.2,136.1,131.7,131.6,128.1,128.1$, 127.8, 127.4, 126.0, 125.9, 125.2, 124.9, 119.8, 119.6, 80.1, 78.6, 77.0, 76.2, 34.1, 33.1, 31.3, 30.3, 21.4, 21.2. MS (DART) exact mass: calculated for $(\mathrm{M}+\mathrm{H})^{+}: 248.0837$; found: 248.0855 .<smiles>CC1CCC(c2nccc3ccccc23)O1</smiles>

1-(5-Methyltetrahydrofuran-2-yl)isoquinoline (19): The title compound was prepared from 2methyltetrahydrofuran $(2.0 \mathrm{~mL})$ and isoquinoline $(0.4 \mathrm{mmol}, 47.0 \mu \mathrm{L})$ according to general procedure A with a reaction time of 36 hours. The crude residue was purified by column chromatography on silica gel with an eluent of hexanes to $20 \%$ EtOAc/hexanes to yield a light yellow oil in $41 \%$ yield $(35.0 \mathrm{mg}$, diastereoisomers, d.r. $=1: 1.0)$. Characterization data is consistent with reported literature values. ${ }^{[4]}$

19: ${ }^{1} \mathrm{H}$ NMR (500 MHz, Chloroform- $d$ ) $\delta 8.52(\mathrm{dd}, J=5.7,1.6 \mathrm{~Hz}, 1 \mathrm{H}), 8.42(\mathrm{dd}, J=40.0,8.5 \mathrm{~Hz}, 1 \mathrm{H})$, $7.84(\mathrm{dt}, J=8.2,1.8 \mathrm{~Hz}, 1 \mathrm{H}), 7.74-7.54(\mathrm{~m}, 3 \mathrm{H}), 5.90$ (t, $J=7.2 \mathrm{~Hz}, 0.5 \mathrm{H}), 5.65$ (t, $J=7.4 \mathrm{~Hz}, 1 \mathrm{H}), 4.58$ $-4.24(\mathrm{~m}, 1 \mathrm{H}), 2.75-2.55(\mathrm{~m}, 1 \mathrm{H}), 2.51-2.21(\mathrm{~m}, 2 \mathrm{H}), 1.84-1.71(\mathrm{~m}, 1 \mathrm{H}), 1.40(\mathrm{dd}, J=6.1,3.1 \mathrm{~Hz}$, $3 \mathrm{H}) .{ }^{13} \mathrm{C}$ NMR (126 MHz, Chloroform- $d$ ) $\delta 160.1,159.2$, 141.5, 141.5, 136.6, 136.6, 129.8, 129.8, 127.3, 127.2, 127.1, 127.0, 126.9, 125.7, 125.3, 120.6, 120.4, 80.0, 78.4, 76.8, 76.1, 34.1, 33.2, 31.4, 30.4, 21.4, 21.2. MS (DART) exact mass: calculated for $(\mathrm{M}+\mathrm{H})^{+}: 214.1226$; found: 214.1228 . 
<smiles>CCC(C)OCc1ncc(Br)c2ccccc12</smiles>

4-Bromo-1-(sec-butoxymethyl)isoquinoline (20): The title compound was prepared from sec-butyl methyl ether $(2.0 \mathrm{~mL})$ and 4-bromoisoquinoline $(0.4 \mathrm{mmol}, 83.2 \mathrm{mg})$ according to general procedure A with a reaction time of 36 hours. The crude residue was purified by column chromatography on silica gel with an eluent of hexanes to $20 \%$ EtOAc/hexanes to yield a light yellow oil in 39\% yield (45.9 mg).

20: ${ }^{1} \mathrm{H}$ NMR (500 MHz, $\left.\mathrm{CDCl}_{3}\right) \delta 8.65(\mathrm{~s}, 1 \mathrm{H}), 8.41(\mathrm{~d}, J=8.4 \mathrm{~Hz}, 1 \mathrm{H}), 8.19(\mathrm{~d}, J=8.5 \mathrm{~Hz}, 1 \mathrm{H}), 7.81$ (ddd, $J=8.4,6.9,1.2 \mathrm{~Hz}, 1 \mathrm{H}), 7.69$ (ddd, $J=8.3,6.9,1.3 \mathrm{~Hz}, 1 \mathrm{H}), 5.18-4.91(\mathrm{~m}, 2 \mathrm{H}), 3.54(\mathrm{q}, J=6.1$ $\mathrm{Hz}, 1 \mathrm{H}), 1.61-1.58(\mathrm{~m}, 1 \mathrm{H}), 1.53-1.44(\mathrm{~m}, 1 \mathrm{H}), 1.21(\mathrm{~d}, J=6.1 \mathrm{~Hz}, 3 \mathrm{H}), 0.85(\mathrm{t}, J=7.4 \mathrm{~Hz}, 3 \mathrm{H}) .{ }^{13} \mathrm{C}$ NMR $\left(126 \mathrm{MHz}, \mathrm{CDCl}_{3}\right) \delta 157.4,143.2,135.2,131.4,128.7,128.2,126.7,126.4,119.9,77.0,70.9,29.2$, 19.1, 9.8. MS (DART) exact mass: calculated for $(\mathrm{M}+\mathrm{H})^{+}: 294.0488$; found: 294.0507.<smiles>Brc1cnc(COC2CCCC2)c2ccccc12</smiles>

4-Bromo-1-((cyclopentyloxy)methyl)isoquinoline (21): The title compound was prepared from cyclopentyl methyl ether $(2.0 \mathrm{~mL})$ and 4-bromoisoquinoline $(0.4 \mathrm{mmol}, 83.2 \mathrm{mg})$ according to general procedure A with a reaction time of 36 hours. The crude residue was purified by column chromatography on silica gel with an eluent of hexanes to $20 \%$ EtOAc/hexanes to yield a white solid in $40 \%$ yield (49.0 $\mathrm{mg})$.

21: ${ }^{1} \mathrm{H}$ NMR $\left(500 \mathrm{MHz}, \mathrm{CDCl}_{3}\right) \delta 8.68(\mathrm{~s}, 1 \mathrm{H}), 8.40(\mathrm{~d}, J=8.4 \mathrm{~Hz}, 1 \mathrm{H}), 8.22(\mathrm{~d}, J=8.4 \mathrm{~Hz}, 1 \mathrm{H}), 7.83$ (ddd, $J=8.3,6.9,1.2 \mathrm{~Hz}, 1 \mathrm{H}), 7.71(\mathrm{ddd}, J=8.3,6.9,1.3 \mathrm{~Hz}, 1 \mathrm{H}), 5.04(\mathrm{~s}, 2 \mathrm{H}), 4.12(\mathrm{tt}, J=5.6,2.7 \mathrm{~Hz}$, $1 \mathrm{H}), 1.83-1.56(\mathrm{~m}, 8 \mathrm{H}) .{ }^{13} \mathrm{C}$ NMR $\left(126 \mathrm{MHz}, \mathrm{CDCl}_{3}\right) \delta 157.3,143.2,135.2,131.4,128.7,128.2,126.6$, 126.5, 119.9, 81.9, 71.5, 32.3, 23.5. MS (DART) exact mass: calculated for $(\mathrm{M}+\mathrm{H})^{+}: 306.0488$; found: 306.0509 .<smiles>Brc1cnc(COC2CCCCC2)c2ccccc12</smiles>

4-Bromo-1-((cyclohexyloxy)methyl)isoquinoline (22): The title compound was prepared from methoxycyclohexane $(2.0 \mathrm{~mL})$ and 4-bromoisoquinoline $(0.4 \mathrm{mmol}, 83.2 \mathrm{mg})$ according to general procedure A with a reaction time of 36 hours. The crude residue was purified by column chromatography 
on silica gel with an eluent of hexanes to $30 \%$ EtOAc/hexanes to yield a white solid in 51\% yield (65.3 $\mathrm{mg})$.

22: ${ }^{1} \mathrm{H}$ NMR $\left(500 \mathrm{MHz}, \mathrm{CDCl}_{3}\right) \delta 8.67(\mathrm{~s}, 1 \mathrm{H}), 8.45(\mathrm{~d}, J=8.4 \mathrm{~Hz}, 1 \mathrm{H}), 8.21(\mathrm{~d}, J=8.4 \mathrm{~Hz}, 1 \mathrm{H}), 7.86-$ $7.80(\mathrm{~m}, 1 \mathrm{H}), 7.74-7.67(\mathrm{~m}, 1 \mathrm{H}), 5.10(\mathrm{~s}, 2 \mathrm{H}), 3.50-3.41(\mathrm{~m}, 1 \mathrm{H}), 2.01-1.93(\mathrm{~m}, 2 \mathrm{H}), 1.79-1.71(\mathrm{~m}$, $2 \mathrm{H}), 1.55(\mathrm{dd}, J=9.6,4.5 \mathrm{~Hz}, 1 \mathrm{H}), 1.38-1.27(\mathrm{~m}, 6 \mathrm{H}) .{ }^{13} \mathrm{C} \mathrm{NMR}\left(126 \mathrm{MHz}, \mathrm{CDCl}_{3}\right) \delta 157.6,143.2,135.2$, 131.4, 128.7, 128.2, 126.6, 126.4, 119.9, 77.8, 70.6, 32.2, 25.7, 24.2. MS (DART) exact mass: calculated for $(\mathrm{M}+\mathrm{H})^{+}: 320.0645$; found: 320.0665 .<smiles>CCCOCc1ncc(Br)c2ccccc12</smiles>

4-Bromo-1-(1-methoxypropyl)isoquinoline (23A) and 4-bromo-1-(propoxymethyl)isoquinoline (23B): The title compound was prepared from 1-methoxypropane $(2.0 \mathrm{~mL})$ and 4-bromoisoquinoline $(0.4 \mathrm{mmol}$, $83.2 \mathrm{mg}$ ) according to general procedure A with a reaction time of 36 hours. The crude residue was purified by column chromatography on silica gel with an eluent of hexanes to $30 \%$ EtOAc/hexanes to yield a white solid in $45 \%$ yield $(50.4 \mathrm{mg})$ as a mixture of regioisomers.

23: ${ }^{1} \mathrm{H}$ NMR $\left(500 \mathrm{MHz}, \mathrm{CDCl}_{3}\right.$, mixture of 23A and 23B) $\delta 8.78-8.62(\mathrm{~m}, 3 \mathrm{H}), 8.47-8.17(\mathrm{~m}, 2 \mathrm{H}), 7.90$ $-7.61(\mathrm{~m}, 4 \mathrm{H}), 5.08(\mathrm{~s}, 1 \mathrm{H}), 4.82(\mathrm{dd}, J=7.7,6.2 \mathrm{~Hz}, 1 \mathrm{H}), 3.54(\mathrm{t}, J=6.7 \mathrm{~Hz}, 1 \mathrm{H}), 3.32(\mathrm{~s}, 3 \mathrm{H}), 2.24-$ $1.89(\mathrm{~m}, 2 \mathrm{H}), 1.65(\mathrm{~d}, J=7.1 \mathrm{~Hz}, 3 \mathrm{H}), 0.98(\mathrm{t}, J=7.4 \mathrm{~Hz}, 3 \mathrm{H}), 0.91(\mathrm{t}, J=7.5 \mathrm{~Hz}, 2 \mathrm{H}) .{ }^{13} \mathrm{C}$ NMR $(126$ $\mathrm{MHz}, \mathrm{CDCl}_{3}$, mixture of 23A and 23B ) $\delta 160.3,157.1,143.3,143.2,135.3,135.2,131.4,131.3,128.5$, $128.3,127.9,127.7,126.8,126.5,126.4,125.8,120.0,119.4,87.0,73.3,72.7,57.2,29.1,22.9,10.7,10.6$. MS (DART) exact mass: calculated for $(\mathrm{M}+\mathrm{H})^{+}: 280.0332$; found: 280.0351 .<smiles>CCC(C)OC(C)c1ncc(Br)c2ccccc12</smiles>

4-Bromo-1-(1-(sec-butoxy)ethyl)isoquinoline (24): The title compound was prepared from sec-butyl ethyl ether $(2.0 \mathrm{~mL})$ and 4-bromoisoquinoline $(0.4 \mathrm{mmol}, 83.2 \mathrm{mg})$ according to general procedure A with a reaction time of 36 hours. The crude residue was purified by column chromatography on silica gel with an eluent of hexanes to $30 \%$ EtOAc/hexanes to yield a colorless oil in $43 \%$ yield $(53.0 \mathrm{mg})$. 
24: ${ }^{1} \mathrm{H}$ NMR $\left(500 \mathrm{MHz}, \mathrm{CDCl}_{3}\right) \delta 8.83(\mathrm{dd}, J=8.6,2.0 \mathrm{~Hz}, 1 \mathrm{H}), 8.65(\mathrm{~s}, 1 \mathrm{H}), 8.30-8.14(\mathrm{~m}, 1 \mathrm{H}), 7.89-$ $7.74(\mathrm{~m}, 1 \mathrm{H}), 7.73-7.59(\mathrm{~m}, 1 \mathrm{H}), 5.25-5.17(\mathrm{~m}, 1 \mathrm{H}), 3.46-3.30(\mathrm{~m}, 1 \mathrm{H}), 1.70(\mathrm{dd}, J=6.8,5.4 \mathrm{~Hz}, 3 \mathrm{H})$, $1.66-1.36(\mathrm{~m}, 2 \mathrm{H}), 1.22-0.92(\mathrm{~m}, 3 \mathrm{H}), 0.97-0.70(\mathrm{~m}, 3 \mathrm{H}) .{ }^{13} \mathrm{C}$ NMR $\left(126 \mathrm{MHz}, \mathrm{CDCl}_{3}\right) \delta 162.4,162.1$, 143.1, 135.5, 135.4, 131.2, 131.2, 127.5, 127.5, 127.4, 126.8, 126.7, 126.7, 126.7, 119.3, 119.2, 78.5, 77.8, $75.6,75.1,30.0,28.4,22.5,22.2,20.1,18.7,10.0,9.4$. MS (DART) exact mass: calculated for $(\mathrm{M}+\mathrm{H})^{+}$: 308.0645; found: 308.0662 .<smiles>CC(C)OC(C)c1ncc(Br)c2ccccc12</smiles>

4-Bromo-1-(1-isopropoxyethyl)isoquinoline (25): The title compound was prepared from 2ethoxypropane $(2.0 \mathrm{~mL})$ and 4-bromoisoquinoline $(0.4 \mathrm{mmol}, 83.2 \mathrm{mg})$ according to general procedure A with a reaction time of 36 hours. The crude residue was purified by column chromatography on silica gel with an eluent of hexanes to $25 \%$ EtOAc/hexanes to yield a colorless oil in $51 \%$ yield $(60.0 \mathrm{mg})$.

25: ${ }^{1} \mathrm{H}$ NMR $\left(500 \mathrm{MHz}, \mathrm{CDCl}_{3}\right) \delta 8.83(\mathrm{~d}, J=8.6 \mathrm{~Hz}, 1 \mathrm{H}), 8.66(\mathrm{~s}, 1 \mathrm{H}), 8.24(\mathrm{dd}, J=8.5,1.2 \mathrm{~Hz}, 1 \mathrm{H})$, 7.82 (ddd, $J=8.4,6.9,1.2 \mathrm{~Hz}, 1 \mathrm{H}), 7.67$ (ddd, $J=8.4,6.9,1.3 \mathrm{~Hz}, 1 \mathrm{H}), 5.26-5.22(\mathrm{~m}, 1 \mathrm{H}), 3.60-3.55$ $(\mathrm{m}, 1 \mathrm{H}), 1.69(\mathrm{~d}, J=6.7 \mathrm{~Hz}, 3 \mathrm{H}), 1.23(\mathrm{~d}, J=6.0 \mathrm{~Hz}, 3 \mathrm{H}), 1.06(\mathrm{~d}, J=6.1 \mathrm{~Hz}, 3 \mathrm{H}) .{ }^{13} \mathrm{C} \mathrm{NMR}(126 \mathrm{MHz}$, $\left.\mathrm{CDCl}_{3}\right) \delta 162.2,143.1,135.4,131.2,127.6,127.4,126.7,126.5,119.3,77.7,69.9,23.1,22.4,21.5$. MS (DART) exact mass: calculated for $(\mathrm{M}+\mathrm{H})^{+}: 294.0488$; found: 294.0504 .<smiles>CCCCOC(C)c1ncc(Br)c2ccccc12</smiles><smiles>CCCC(OCC)c1ncc(Br)c2ccccc12</smiles>

4-Bromo-1-(1-butoxyethyl)isoquinoline and 4-bromo-1-(1-ethoxybutyl)isoquinoline (26A and 26B): The title compound was prepared from 1-ethoxybutane $(2.0 \mathrm{~mL})$ and 4-bromoisoquinoline $(0.4 \mathrm{mmol}, 83.2 \mathrm{mg})$ according to general procedure A with a reaction time of 36 hours. The crude residue was purified by column chromatography on silica gel with an eluent of hexanes to $20 \%$ EtOAc/hexanes to yield a light yellow oil in $56 \%$ yield $(69.0 \mathrm{mg})$ as a mixture of regioisomers.

26: ${ }^{1} \mathrm{H}$ NMR (400 MHz, Chloroform- $d$, mixture of 26A and 26B) $\delta 8.83-8.54(\mathrm{~m}, 2 \mathrm{H}), 8.20(\mathrm{~d}, J=8.5$ $\mathrm{Hz}, 1 \mathrm{H}), 7.78(\mathrm{t}, J=7.7 \mathrm{~Hz}, 1 \mathrm{H}), 7.67-7.59(\mathrm{~m}, 1 \mathrm{H}), 5.09(\mathrm{q}, J=6.8 \mathrm{~Hz}, 0.56 \mathrm{H}), 4.96-4.86(\mathrm{~m}, 0.44 \mathrm{H})$, $3.45-3.27(\mathrm{~m}, 2 \mathrm{H}), 2.15-1.80(\mathrm{~m}, 1 \mathrm{H}), 1.67(\mathrm{dd}, J=6.8,1.1 \mathrm{~Hz}, 1 \mathrm{H}), 1.59-1.48(\mathrm{~m}, 1 \mathrm{H}), 1.36-1.22$ $(\mathrm{m}, 2 \mathrm{H}), 1.15(\mathrm{t}, J=7.0 \mathrm{~Hz}, 1 \mathrm{H}), 0.94-0.78(\mathrm{~m}, 3 \mathrm{H}) .{ }^{13} \mathrm{C} \mathrm{NMR}\left(126 \mathrm{MHz}, \mathrm{CDCl}_{3}\right.$, mixture of $26 \mathrm{~A}$ and 
26B ) $\delta 161.5,161.3,143.2,135.3,135.3,131.2,131.2,127.8,127.7,127.7,127.4,126.7,126.7,126.1$, 126.1, 119.3, 119.3, 84.3, 80.1, 69.1, 64.8, 38.4, 32.0, 21.6, 19.6, 19.3, 15.4, 13.9, 13.9. MS (DART) exact mass: calculated for $(\mathrm{M}+\mathrm{H})^{+}: 308.0645$; found: 308.0663 .<smiles>CC1COC(c2ncc(Br)c3ccccc23)C1</smiles><smiles>CC1CCOC1c1ncc(Br)c2ccccc12</smiles>

4-Bromo-1-(4-methyltetrahydrofuran-2-yl)isoquinoline and 4-bromo-1-(3-methyltetrahydrofuran-2yl)isoquinoline (27A and 27B): The title compound was prepared from 3-methyltetrahydrofuran $(2.0 \mathrm{~mL})$ and 4-bromoisoquinoline $(0.4 \mathrm{mmol}, 83.2 \mathrm{mg}$ ) according to general procedure A with a reaction time of 36 hours. The crude residue was purified by column chromatography on silica gel with an eluent of hexanes to $20 \%$ EtOAc/hexanes to yield a light yellow oil in $58 \%$ yield $(67.8 \mathrm{mg})$ as a mixture of regioisomers.

27: ${ }^{1} \mathrm{H}$ NMR $\left(500 \mathrm{MHz}, \mathrm{CDCl}_{3}\right.$, mixture of 27A and 27B) $\delta 8.71(\mathrm{~d}, J=11.2 \mathrm{~Hz}, 1 \mathrm{H}), 8.42-8.35(\mathrm{~m}, 1 \mathrm{H})$, $8.22(\mathrm{dd}, J=8.5,2.9 \mathrm{~Hz}, 1 \mathrm{H}), 7.87-7.76(\mathrm{~m}, 1 \mathrm{H}), 7.74-7.61(\mathrm{~m}, 1 \mathrm{H}), 5.82(\mathrm{dd}, J=7.8,5.6 \mathrm{~Hz}, 0.5 \mathrm{H})$, $5.73(\mathrm{dd}, J=9.3,6.3 \mathrm{~Hz}, 0.06 \mathrm{H}), 5.15(\mathrm{~d}, J=7.6 \mathrm{~Hz}, 0.42 \mathrm{H}), 4.28(\mathrm{dd}, J=8.2,6.8 \mathrm{~Hz}, 0.52 \mathrm{H}), 4.24-4.10$ $(\mathrm{m}, 0.91 \mathrm{H}), 3.67(\mathrm{t}, J=8.3 \mathrm{~Hz}, 0.06 \mathrm{H}), 3.63-3.51(\mathrm{~m}, 0.51 \mathrm{H}), 3.16-2.86(\mathrm{~m}, 0.42 \mathrm{H}), 2.80-2.68(\mathrm{~m}$, $0.52 \mathrm{H}), 2.68-2.51(\mathrm{~m}, 0.66 \mathrm{H}), 2.43-2.25(\mathrm{~m}, 0.44 \mathrm{H}), 2.21(\mathrm{~d}, J=12.1 \mathrm{~Hz}, 0.08 \mathrm{H}), 2.09-1.98(\mathrm{~m}$, $0.56 \mathrm{H}), 1.91-1.80(\mathrm{~m}, 1 \mathrm{H}), 1.24-1.12(\mathrm{~m}, 3 \mathrm{H}) .{ }^{13} \mathrm{C} \mathrm{NMR}\left(126 \mathrm{MHz}, \mathrm{CDCl}_{3}\right.$, mixture of 27A and 27B) $\delta 159.4,158.5,143.4,143.2,135.2,135.1,131.1,128.5,128.0,128.0,127.8,126.7,126.6,125.8,125.7$, $119.5,119.3,85.7,78.4,76.0,75.5,68.3,39.4,38.7,38.6,34.8,34.7,33.6,17.9,17.4,17.0$. MS (DART) exact mass: calculated for $(\mathrm{M}+\mathrm{H})^{+}: 292.0332$; found: 292.0348 .<smiles>Brc1ccc2c(C3CCCO3)ccnc2c1</smiles><smiles>Brc1ccc2ccc(C3CCCO3)nc2c1</smiles>

7-bromo-4-(tetrahydrofuran-2-yl)quinoline (29A) and 7-bromo-2-(tetrahydrofuran-2-yl)quinoline (29B): The title compound was prepared from tetrahydrofuran $(2.0 \mathrm{~mL})$ and 7-bromoquinoline $(0.4 \mathrm{mmol}$, $83.2 \mathrm{mg}$ ) according to general procedure A with a reaction time of 36 hours. The crude residue was purified by column chromatography on silica gel with an eluent of hexanes to $20 \%$ EtOAc/hexanes to yield a light yellow oil in $60 \%$ yield $(66.7 \mathrm{mg})$ as a mixture of regioisomers.

29A: ${ }^{1} \mathrm{H}$ NMR $(500 \mathrm{MHz}$, Chloroform- $d$ ) $\delta 8.88(\mathrm{~d}, J=4.5 \mathrm{~Hz}, 1 \mathrm{H}), 8.32(\mathrm{~d}, J=2.1 \mathrm{~Hz}, 1 \mathrm{H}), 7.80(\mathrm{~d}, J=$ $8.9 \mathrm{~Hz}, 1 \mathrm{H}), 7.64(\mathrm{dd}, J=8.9,2.1 \mathrm{~Hz}, 1 \mathrm{H}), 7.57(\mathrm{~d}, J=4.5 \mathrm{~Hz}, 1 \mathrm{H}), 5.56(\mathrm{t}, J=7.2 \mathrm{~Hz}, 1 \mathrm{H}), 4.22$ (td, $J=$ 7.7, $5.8 \mathrm{~Hz}, 1 \mathrm{H}), 4.05$ (q, $J=7.4 \mathrm{~Hz}, 1 \mathrm{H}), 2.72-2.52(\mathrm{~m}, 1 \mathrm{H}), 2.16-1.95(\mathrm{~m}, 2 \mathrm{H}), 1.91-1.76(\mathrm{~m}, 1 \mathrm{H})$. 
${ }^{13} \mathrm{C}$ NMR (126 MHz, Chloroform- $d$ ) $\delta 151.5,149.8,148.8,132.5,129.9,124.7,124.3,123.1,116.9,76.6$, 69.1, 34.0, 26.0. MS (DART) exact mass: calculated for $(\mathrm{M}+\mathrm{H})^{+}: 278.0175$; found: 278.0180 .

29B: ${ }^{1} \mathrm{H}$ NMR (500 MHz, Chloroform- $d$ ) $\delta 8.27(\mathrm{~d}, J=1.9 \mathrm{~Hz}, 1 \mathrm{H}), 8.14(\mathrm{~d}, J=8.5 \mathrm{~Hz}, 1 \mathrm{H}), 7.71-7.60$ $(\mathrm{m}, 3 \mathrm{H}), 5.18(\mathrm{dd}, J=7.4,6.4 \mathrm{~Hz}, 1 \mathrm{H}), 4.21-4.04(\mathrm{~m}, 2 \mathrm{H}), 2.60-2.45(\mathrm{~m}, 1 \mathrm{H}), 2.15-2.01(\mathrm{~m}, 3 \mathrm{H}) .{ }^{13} \mathrm{C}$ NMR (126 MHz, Chloroform-d) $\delta 164.8,148.2,136.5,131.5,129.6,128.8,126.0,123.5,118.5,81.9,69.3$, 33.2, 25.9. MS (DART) exact mass: calculated for $(\mathrm{M}+\mathrm{H})^{+}: 278.0175$; found: 278.0181 .<smiles>N#Cc1ccnc(C2CCCO2)c1</smiles>

2-(Tetrahydrofuran-2-yl)isonicotinonitrile (30): The title compound was prepared from tetrahydrofuran $(2.0 \mathrm{~mL})$ and 4-pyridinecarbonitrile $(0.4 \mathrm{mmol}, 41.6 \mathrm{mg})$ according to general procedure A with an irradiation/electrolysis time of 65 hours. The crude residue was purified by column chromatography on silica gel with an eluent of hexanes to $30 \%$ EtOAc/hexanes to yield a yellow oil in $28 \%$ yield $(19.5 \mathrm{mg})$.

30: ${ }^{1} \mathrm{H}$ NMR $(500 \mathrm{MHz}$, Chloroform- $d$ ) $\delta 8.74(\mathrm{~d}, J=4.9 \mathrm{~Hz}, 1 \mathrm{H}), 7.74(\mathrm{~s}, 1 \mathrm{H}), 7.41(\mathrm{~d}, J=4.9 \mathrm{~Hz}, 1 \mathrm{H})$, $5.08(\mathrm{t}, J=6.7 \mathrm{~Hz}, 1 \mathrm{H}), 4.19-4.09(\mathrm{~m}, 1 \mathrm{H}), 4.05-4.00(\mathrm{~m}, 1 \mathrm{H}), 2.54-2.46(\mathrm{~m}, 1 \mathrm{H}), 2.06-1.95(\mathrm{~m}, 3 \mathrm{H})$. ${ }^{13} \mathrm{C}$ NMR (126 MHz, Chloroform- $d$ ) $\delta 165.3,149.9,123.4,121.6,120.9,116.8,80.7,69.3,33.1$, 25.7. MS (DART) exact mass: calculated for $(\mathrm{M}+\mathrm{H})^{+}:$175.0866; found: 175.0873 .<smiles>O=S(=O)(CCC1CCCO1)c1ccccc1</smiles>

2-(2-(Phenylsulfonyl)ethyl)tetrahydrofuran (31): The title compound was prepared from tetrahydrofuran $(2.0 \mathrm{~mL})$ and phenyl vinyl sulfone $(0.4 \mathrm{mmol}, 67.3 \mathrm{mg})$ according to general procedure B with a reaction time of 36 hours. The crude residue was purified by column chromatography on silica gel with an eluent of hexanes to $50 \%$ EtOAc/hexanes to yield a white solid in $72 \%$ yield $(69.2 \mathrm{mg})$.

31: ${ }^{1} \mathrm{H}$ NMR $\left(500 \mathrm{MHz}, \mathrm{CDCl}_{3}\right) \delta 7.98-7.82(\mathrm{~m}, 2 \mathrm{H}), 7.72-7.62(\mathrm{~m}, 1 \mathrm{H}), 7.62-7.50(\mathrm{~m}, 2 \mathrm{H}), 3.91-$ $3.82(\mathrm{~m}, 1 \mathrm{H}), 3.82-3.74(\mathrm{~m}, 1 \mathrm{H}), 3.72-3.61(\mathrm{~m}, 1 \mathrm{H}), 3.30$ (ddd, $J=14.0,11.5,4.8 \mathrm{~Hz}, 1 \mathrm{H}), 3.14$ (ddd, $J=14.1,11.4,4.8 \mathrm{~Hz}, 1 \mathrm{H}), 2.07-1.92(\mathrm{~m}, 2 \mathrm{H}), 1.91-1.79(\mathrm{~m}, 3 \mathrm{H}), 1.53-1.39(\mathrm{~m}, 1 \mathrm{H}) .{ }^{13} \mathrm{C}$ NMR $(126$ $\left.\mathrm{MHz}, \mathrm{CDCl}_{3}\right) \delta 139.2,133.7,129.3,128.0,77.0,67.9,53.6,31.2,28.5,25.6$. MS (DART) exact mass: calculated for $(\mathrm{M}+\mathrm{H})^{+}: 241.0893$; found: 241.0909 .<smiles>CC1CCC(CCS(=O)(=O)c2ccccc2)O1</smiles>

2-Methyl-5-(2-(phenylsulfonyl)ethyl)tetrahydrofuran (32): The title compound was prepared from 2methyltetrahydrofuran $(2.0 \mathrm{~mL})$ and phenyl vinyl sulfone $(0.4 \mathrm{mmol}, 67.3 \mathrm{mg})$ according to general procedure $\mathrm{B}$ with a reaction time of 36 hours. The crude residue was purified by column chromatography on silica gel with an eluent of hexanes to $50 \%$ EtOAc/hexanes to yield a light yellow oil in $60 \%$ yield (61.0 $\mathrm{mg})$. 
32: ${ }^{1} \mathrm{H}$ NMR $\left(500 \mathrm{MHz}, \mathrm{CDCl}_{3}\right) \delta 7.93(\mathrm{dt}, J=7.2,1.4 \mathrm{~Hz}, 2 \mathrm{H}), 7.72-7.64(\mathrm{~m}, 1 \mathrm{H}), 7.62-7.54(\mathrm{~m}, 2 \mathrm{H})$, $4.10-3.65(\mathrm{~m}, 2 \mathrm{H}), 3.35-3.10(\mathrm{~m}, 2 \mathrm{H}), 2.08-1.81(\mathrm{~m}, 4 \mathrm{H}), 1.76-1.52(\mathrm{~m}, 2 \mathrm{H}), 1.24-1.08(\mathrm{~m}, 3 \mathrm{H})$. ${ }^{13} \mathrm{C} \mathrm{NMR}\left(126 \mathrm{MHz}, \mathrm{CDCl}_{3}\right) \delta 139.2,133.7,129.3,129.3,128.1,128.0,128.0,80.8,75.8,67.4,53.5,52.4$, 37.2, 32.9, 32.7, 32.1, 31.1, 29.1, 25.9, 25.7, 21.3, 21.1. MS (DART) exact mass: calculated for $(\mathrm{M}+\mathrm{H})^{+}$: 255.1049; found: 255.1062 .<smiles>O=S(=O)(OC(CC1CCC(CC(S(=O)(=O)O)S(=O)(=O)c2ccccc2)O1)S(=O)(=O)c1ccccc1)c1ccccc1</smiles>

1-(5-Methyltetrahydrofuran-2-yl)isoquinoline (33): The title compound was prepared from tetrahydrofuran $(2.0 \mathrm{~mL})$ and 1,1-bis(phenylsulfonyl)ethylene $(0.4 \mathrm{mmol}, 123.4 \mathrm{mg})$ according to general procedure B with a reaction time of 36 hours. The crude residue was purified by column chromatography on silica gel with an eluent of hexanes to $60 \%$ EtOAc/hexanes to yield a white solid in $65 \%$ yield $(89.5$ $\mathrm{mg})$. Characterization data is consistent with reported literature values. ${ }^{[5]}$

33: ${ }^{1} \mathrm{H}$ NMR (500 MHz, Chloroform- $d$ ) $\delta 7.99(\mathrm{dd}, J=15.6,7.8 \mathrm{~Hz}, 4 \mathrm{H}), 7.92(\mathrm{t}, J=8.1 \mathrm{~Hz}, 4 \mathrm{H}), 7.86-$ $7.62(\mathrm{~m}, 4 \mathrm{H}), 7.62-7.41(\mathrm{~m}, 8 \mathrm{H}), 4.95(\mathrm{dd}, J=8.2,3.0 \mathrm{~Hz}, 0.83 \mathrm{H}), 4.79(\mathrm{t}, J=5.3 \mathrm{~Hz}, 1.17 \mathrm{H}), 4.34-$ $4.19(\mathrm{~m}, 0.83 \mathrm{H}), 4.11(\mathrm{p}, J=6.1 \mathrm{~Hz}, 1.19 \mathrm{H}), 2.41-2.22(\mathrm{~m}, 4 \mathrm{H}), 2.13-1.97(\mathrm{~m}, 2 \mathrm{H}), 1.64-1.43(\mathrm{~m}, 2 \mathrm{H})$. ${ }^{13} \mathrm{C}$ NMR (126 MHz, Chloroform-d) $\delta 138.2$, 137.6, 134.6, 134.6, 134.6, 134.4, 130.0, 129.6, 129.5, 129.3, 129.2, 129.1, 129.1, 129.0, 80.5, 80.4, 76.3, 75.3, 32.2, 31.3, 31.2, 31.0. MS (DART) exact mass: calculated for $(\mathrm{M}+\mathrm{H})^{+}: 689.1002$; found:689.1011.<smiles>O=C(CCC1CCCO1)Oc1ccccc1</smiles>

Phenyl 3-(tetrahydrofuran-2-yl)propanoate (34): The title compound was prepared from tetrahydrofuran $(2.0 \mathrm{~mL})$ and phenyl acrylate $(0.4 \mathrm{mmol}, 59.3 \mathrm{mg})$ according to general procedure B with a reaction time of 36 hours. The crude residue was purified by column chromatography on silica gel with an eluent of hexanes to $20 \%$ EtOAc/hexanes to yield a colorless oil. Yield were determined by ${ }^{1} \mathrm{H}$ NMR spectroscopy with dibromomethane as an internal standard. Characterization data is consistent with reported literature values. $^{[6]}$

34: ${ }^{1} \mathrm{H}$ NMR (500 MHz, Chloroform- $d$ ) $\delta 7.41-7.38(\mathrm{~m}, 2 \mathrm{H}), 7.25-7.23(\mathrm{~m}, 1 \mathrm{H}), 7.10(\mathrm{~d}, J=8.0 \mathrm{~Hz}, 2 \mathrm{H})$, $3.98-3.87(\mathrm{~m}, 2 \mathrm{H}), 3.80-3.77(\mathrm{~m}, 1 \mathrm{H}), 2.74-2.67(\mathrm{~m}, 2 \mathrm{H}), 2.07-1.92(\mathrm{~m}, 5 \mathrm{H}), 1.58-1.54(\mathrm{~m}, 1 \mathrm{H})$. ${ }^{13} \mathrm{C}$ NMR (126 MHz, Chloroform- $d$ ) $\delta$ 172.2, 150.8, 129.4, 125.7, 121.6, 78.1, 67.8, 31.3, 31.3, 30.7, 25.8. MS (DART) exact mass: calculated for $(\mathrm{M}-\mathrm{PhO})^{+}: 127.0759$; found: 127.0761 .<smiles>COC(C)CCC1CCCO1</smiles>

Methyl 3-(tetrahydrofuran-2-yl)propanoate (35): The title compound was prepared from tetrahydrofuran $(2.0 \mathrm{~mL})$ and methyl acrylate $(0.4 \mathrm{mmol}, 36.0 \mu \mathrm{L})$ according to general procedure B with a reaction time of 36 hours. The crude residue was purified by column chromatography on silica gel with an eluent of hexanes to $30 \%$ EtOAc/hexanes to yield a colorless oil. Yield were determined by ${ }^{1} \mathrm{H}$ NMR spectroscopy 
with dibromomethane as an internal standard. Characterization data is consistent with reported literature values. $^{[7]}$<smiles>COC(=O)/C=C/C1CCCO1</smiles>

Methyl 3-(tetrahydrofuran-2-yl)acrylate (36): The title compound was prepared from tetrahydrofuran (2.0 $\mathrm{mL})$ and methyl propiolate $(0.4 \mathrm{mmol}, 35.6 \mu \mathrm{L})$ according to general procedure $\mathrm{B}$ with a reaction time of 36 hours. The crude residue was purified by column chromatography on silica gel with an eluent of hexanes to $20 \%$ EtOAc/hexanes to yield a colorless oil. Yield were determined by ${ }^{1} \mathrm{H}$ NMR spectroscopy with terephthalonitrile as an internal standard. Characterization data is consistent with reported literature values. $^{[8]}$

36: ${ }^{1} \mathrm{H}$ NMR (500 MHz, Chloroform- $d$, mixture of $\boldsymbol{Z}-36$ and $\boldsymbol{E}$-36) $\delta 6.94(\mathrm{dd}, J=15.6,4.8 \mathrm{~Hz}, 1 \mathrm{H}), 6.34$ (dd, $J=11.7,7.4 \mathrm{~Hz}, 1 \mathrm{H}), 6.04(\mathrm{dd}, J=15.6,1.7 \mathrm{~Hz}, 1 \mathrm{H}), 5.80(\mathrm{dd}, J=11.7,1.6 \mathrm{~Hz}, 1 \mathrm{H}), 5.30(\mathrm{~m}, 1 \mathrm{H})$, $4.61-4.47(\mathrm{~m}, 1 \mathrm{H}), 3.97-3.92(\mathrm{~m}, 2 \mathrm{H}), 3.89-3.82(\mathrm{~m}, 2 \mathrm{H}), 3.74(\mathrm{~d}, J=11.6 \mathrm{~Hz}, 6 \mathrm{H}), 2.37$ (dd, $J=12.6$, $6.5 \mathrm{~Hz}, 1 \mathrm{H}), 2.20-2.10(\mathrm{~m}, 1 \mathrm{H}), 1.97-1.90(\mathrm{~m}, 4 \mathrm{H}), 1.76-1.67(\mathrm{~m}, 1 \mathrm{H}), 1.58(\mathrm{dd}, J=12.4,8.2 \mathrm{~Hz}, 1 \mathrm{H})$.<smiles>O=Cc1cnn(C2CCCO2)c1</smiles>

1-(Tetrahydrofuran-2-yl)-1H-pyrazole-4-carbaldehyde (37): The title compound was prepared from tetrahydrofuran $(2.0 \mathrm{ml})$ and $1 \mathrm{H}$-pyrazole-4-carbaldehyde $(0.4 \mathrm{mmol}, 38.4 \mathrm{mg})$ according to general procedure $\mathrm{C}$ with a reaction time of 36 hours. The crude residue was purified by column chromatography on silica gel with an eluent of hexanes to $50 \%$ EtOAc/hexanes to yield a white solid in $89 \%$ yield $(59.2$ $\mathrm{mg})$.

37: ${ }^{1} \mathrm{H}$ NMR (500 MHz, Chloroform- $d$ ) $\delta 9.83(\mathrm{~s}, 1 \mathrm{H}), 8.09(\mathrm{~s}, 1 \mathrm{H}), 7.96(\mathrm{~s}, 1 \mathrm{H}), 5.98(\mathrm{dd}, J=6.5,2.1 \mathrm{~Hz}$, $1 \mathrm{H}), 4.17-4.13(\mathrm{~m}, 1 \mathrm{H}), 4.02-3.98(\mathrm{~m}, 1 \mathrm{H}), 2.57-2.49(\mathrm{~m}, 1 \mathrm{H}), 2.38-2.30(\mathrm{~m}, 1 \mathrm{H}), 2.08-2.00(\mathrm{~m}$, 2H). ${ }^{13} \mathrm{C}$ NMR (126 MHz, Chloroform- $d$ ) $\delta 184.2,140.9,131.5,124.0,90.8,69.8,32.2,23.8$. MS (DART) exact mass: calculated for $(\mathrm{M}+\mathrm{H})^{+}: 167.0815$; found: 167.0825 .

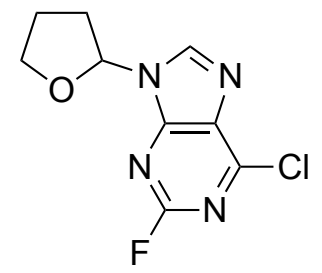

6-Chloro-2-fluoro-9-(tetrahydrofuran-2-yl)-9H-purine (38): The title compound was prepared from tetrahydrofuran $(2.0 \mathrm{ml})$ and 6-chloro-2-fluoro-9H-purine $(0.4 \mathrm{mmol}, 69.0 \mathrm{mg})$ according to general procedure $\mathrm{C}$ with a reaction time of 36 hours. The crude residue was purified by column chromatography on silica gel with an eluent of hexanes to $50 \%$ EtOAc/hexanes to yield a white solid in $78 \%$ yield $(75.7$ $\mathrm{mg})$. 
38: ${ }^{1} \mathrm{H}$ NMR $\left(500 \mathrm{MHz}, \mathrm{CDCl}_{3}\right) \delta 8.22(\mathrm{~s}, 1 \mathrm{H}), 6.28(\mathrm{dd}, J=5.9,3.6 \mathrm{~Hz}, 1 \mathrm{H}), 4.31(\mathrm{ddd}, J=8.6,7.1,5.8 \mathrm{~Hz}$, $1 \mathrm{H}), 4.10(\mathrm{q}, J=7.5 \mathrm{~Hz}, 1 \mathrm{H}), 2.63-2.49(\mathrm{~m}, 2 \mathrm{H}), 2.26-2.12(\mathrm{~m}, 2 \mathrm{H}) .{ }^{13} \mathrm{C}$ NMR $\left(126 \mathrm{MHz}, \mathrm{CDCl}_{3}\right) \delta$ $157.01(J=219.8 \mathrm{~Hz}), 152.69,152.55,144.09(J=3.3 \mathrm{~Hz}), 131.06(J=5.2 \mathrm{~Hz}), 86.78,70.12,32.50,24.18$. ${ }^{19} \mathrm{~F}$ NMR $\left(470 \mathrm{MHz}, \mathrm{CDCl}_{3}\right) \delta$-49.4. MS (DART) exact mass: calculated for $(\mathrm{M}+\mathrm{H})^{+}: 243.0443$; found: 243.0460 .<smiles>Clc1cnn(C2CCCCO2)c1</smiles>

4-Chloro-1-(tetrahydro-2H-pyran-2-yl)-1H-pyrazole (39): The title compound was prepared from tetrahydro-2H-pyran $(2.0 \mathrm{ml})$ and 4-chloro-1H-pyrazole $(0.4 \mathrm{mmol}, 41.0 \mathrm{mg})$ according to general procedure $\mathrm{C}$ with a reaction time of 48 hours. The crude residue was purified by column chromatography on silica gel with an eluent of hexanes to $30 \%$ EtOAc/hexanes to yield a light yellow oil in $73 \%$ yield (54.5 $\mathrm{mg})$.

39: ${ }^{1} \mathrm{H}$ NMR $(500 \mathrm{MHz}$, Chloroform- $d) \delta 7.59(\mathrm{~s}, 1 \mathrm{H}), 7.46(\mathrm{~s}, 1 \mathrm{H}), 5.31(\mathrm{dd}, J=7.5,4.5 \mathrm{~Hz}, 1 \mathrm{H}), 4.06-$ $3.99(\mathrm{~m}, 1 \mathrm{H}), 3.72-3.64(\mathrm{~m}, 1 \mathrm{H}), 2.08-1.98(\mathrm{~m}, 3 \mathrm{H}), 1.73-1.58(\mathrm{~m}, 3 \mathrm{H}) .{ }^{13} \mathrm{C}$ NMR $(126 \mathrm{MHz}$, Chloroform- $d$ ) $\delta 137.9,125.7,110.7,88.0,67.7,30.3,24.9,22.1$. MS (DART) exact mass: calculated for $(\mathrm{M}+\mathrm{H})^{+}: 187.0633$; found: 187.0642 .
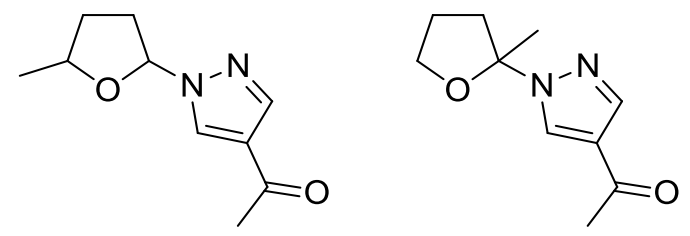

1-(1-(5-methyltetrahydrofuran-2-yl)-1H-pyrazol-4-yl)ethanone

(40A) and 1-(1-(1methyltetrahydrofuran-2-yl)-1H-pyrazol-4-yl)ethanone (40B): The title compound was prepared from 2methyltetrahydrofuran $(2.0 \mathrm{ml})$ and 1-(1H-pyrazol-4-yl)ethanone $(0.4 \mathrm{mmol}, 44.0 \mathrm{mg})$ according to general procedure $\mathrm{C}$ with a reaction time of 36 hours. The crude residue was purified by column chromatography on silica gel with an eluent of hexanes to $50 \%$ EtOAc/hexanes to yield a light yellow oil in $80 \%$ yield (62.1 $\mathrm{mg}$, as a mixture of regioisomers and diastereoisomers (d.r. $=1: 1.5)$.

40: ${ }^{1} \mathrm{H}$ NMR (500 MHz, Chloroform- $d$, mixture of 40A and 40B) $\delta 8.19-7.99(\mathrm{~m}, 1.3 \mathrm{H}), 7.917 .90(\mathrm{~m}$, $1.3 \mathrm{H}), 5.99(\mathrm{dd}, J=6.6,3.4 \mathrm{~Hz}, 0.61 \mathrm{H}), 5.92-5.88(\mathrm{~m}, 1 \mathrm{H}), 4.50-4.22(\mathrm{~m}, 1 \mathrm{H}), 4.14-3.98(\mathrm{~m}, 0.56 \mathrm{H})$, $2.93-2.81(\mathrm{~m}, 0.27 \mathrm{H}), 2.60-2.32(\mathrm{~m}, 5.85 \mathrm{H}), 2.27-1.96(\mathrm{~m}, 1.6 \mathrm{H}), 1.84-1.52(\mathrm{~m}, 2.2 \mathrm{H}), 1.33(\mathrm{~m}, 3 \mathrm{H})$. ${ }^{13} \mathrm{C}$ NMR (126 MHz, Chloroform- $d$ ) $\delta$ 192.1, 140.7, 140.4, 130.4, 130.2, 129.2, 124.0, 90.7, 90.7, 78.8, 77.2, 69.5, 37.7, 33.3, 31.8, 31.5, 31.3, 27.9, 27.8, 27.0, 24.3, 21.1, 20.8. MS (DART) exact mass: calculated for $(\mathrm{M}+\mathrm{H})^{+}:$195.1128; found: 195.1133 . 


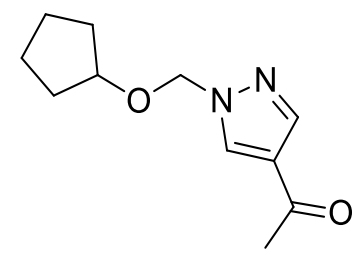

1-(1-((cyclopentyloxy)methyl)-1H-pyrazol-4-yl)ethanone (41): The title compound was prepared from cyclopentyl methyl ether $(2.0 \mathrm{ml})$ and 1-(1H-pyrazol-4-yl)ethanone $(0.4 \mathrm{mmol}, 44.0 \mathrm{mg})$ according to general procedure $\mathrm{C}$ with a reaction time of 36 hours. The crude residue was purified by column chromatography on silica gel with an eluent of hexanes to $50 \%$ EtOAc/hexanes to yield a colorless oil in $55 \%$ yield $(45.8 \mathrm{mg})$.

41: ${ }^{1} \mathrm{H}$ NMR $(500 \mathrm{MHz}$, Chloroform- $d) \delta 8.08(\mathrm{~s}, 1 \mathrm{H}), 7.95(\mathrm{~s}, 1 \mathrm{H}), 5.46(\mathrm{~s}, 2 \mathrm{H}), 4.07(\mathrm{dt}, J=5.6,2.3 \mathrm{~Hz}$, 1H), 2.47 (s, 3H), $1.80-1.65$ (m, 4H), $1.65-1.48(\mathrm{~m}, 4 \mathrm{H}) .{ }^{13} \mathrm{C}$ NMR (126 MHz, Chloroform- $d$ ) $\delta$ 192.1, 140.5, 131.9, 125.2, 80.8, 79.7, 32.2, 28.0, 23.4. MS (DART) exact mass: calculated for $(\mathrm{M}+\mathrm{H})^{+}: 209.1285$; found: 209.1289 .<smiles>Clc1nc(Cl)c2ncn(COC3CCCC3)c2n1</smiles>

2,6-dichloro-9-((cyclopentyloxy)methyl)-9H-purine (42): The title compound was prepared from cyclopentyl methyl ether $(2.0 \mathrm{ml})$ and 2,6-dichloropurine $(0.4 \mathrm{mmol}, 75.6 \mathrm{mg})$ according to general procedure $\mathrm{C}$ with a reaction time of 36 hours. The crude residue was purified by column chromatography on silica gel with an eluent of hexanes to $60 \%$ EtOAc/hexanes to yield a colorless oil in 52\% yield (59.7 $\mathrm{mg})$.

42: ${ }^{1} \mathrm{H}$ NMR (500 MHz, Chloroform- $d$ ) $\delta 8.28(\mathrm{~s}, 1 \mathrm{H}), 5.65(\mathrm{~s}, 2 \mathrm{H}), 4.15-3.91(\mathrm{~m}, 1 \mathrm{H}), 1.77-1.50(\mathrm{~m}$, $8 \mathrm{H}) .{ }^{13} \mathrm{C}$ NMR (126 MHz, Chloroform- $d$ ) $\delta 153.5,153.3,152.0,145.7,130.6,81.5,72.0,32.4,23.4$. MS (DART) exact mass: calculated for $(\mathrm{M}+\mathrm{H})^{+}: 287.0461$; found: 287.0466 .

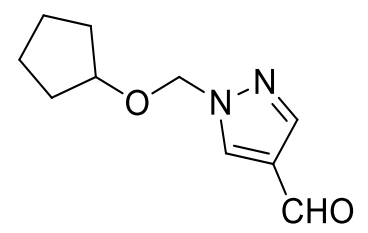

1-((cyclopentyloxy)methyl)-1H-pyrazole-4-carbaldehyde (43): The title compound was prepared from cyclopentyl methyl ether $(2.0 \mathrm{ml})$ and $1 \mathrm{H}$-pyrazole-4-carbaldehyde $(0.4 \mathrm{mmol}, 38.4 \mathrm{mg})$ according to general procedure $\mathrm{C}$ with a reaction time of 36 hours. The crude residue was purified by column chromatography on silica gel with an eluent of hexanes to $50 \%$ EtOAc/hexanes to yield a colorless oil in $49 \%$ yield $(38.1 \mathrm{mg})$. 
43: ${ }^{1} \mathrm{H}$ NMR $(500 \mathrm{MHz}$, Chloroform- $d$ ) $\delta 9.93(\mathrm{~s}, 1 \mathrm{H}), 8.13(\mathrm{~s}, 1 \mathrm{H}), 8.02(\mathrm{~s}, 1 \mathrm{H}), 5.50(\mathrm{~s}, 2 \mathrm{H}), 4.09$ (dt, $J=$ 5.9, $2.5 \mathrm{~Hz}, 1 \mathrm{H}), 1.97-1.36(\mathrm{~m}, 8 \mathrm{H}) .{ }^{13} \mathrm{C} \mathrm{NMR}(126 \mathrm{MHz}$, Chloroform- $d$ ) $\delta 184.1,184.1,140.6,132.9$, 125.3, 81.0, 79.8, 32.2, 23.4. MS (DART) exact mass: calculated for $(\mathrm{M}+\mathrm{H})^{+}:$195.1128; found: 195.1132 .

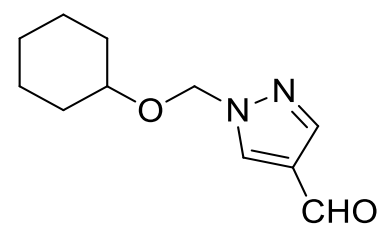

1-((cyclohexyloxy)methyl)-1H-pyrazole-4-carbaldehyde (44): The title compound was prepared from methoxycyclohexane $(2.0 \mathrm{ml})$ and $1 \mathrm{H}$-pyrazole-4-carbaldehyde $(0.4 \mathrm{mmol}, 38.4 \mathrm{mg})$ according to general procedure $\mathrm{C}$ with a reaction time of 36 hours. The crude residue was purified by column chromatography on silica gel with an eluent of hexanes to $50 \%$ EtOAc/hexanes to yield a light yellow oil in $46 \%$ yield ( 38.3 $\mathrm{mg})$.

44: ${ }^{1} \mathrm{H}$ NMR $(500 \mathrm{MHz}$, Chloroform- $d) \delta 9.93(\mathrm{~s}, 1 \mathrm{H}), 8.15(\mathrm{~s}, 1 \mathrm{H}), 8.01(\mathrm{~s}, 1 \mathrm{H}), 5.55(\mathrm{~s}, 2 \mathrm{H}), 3.51(\mathrm{dt}, J=$ 9.1, $5.2 \mathrm{~Hz}, 1 \mathrm{H}), 1.85-1.67(\mathrm{~m}, 5 \mathrm{H}), 1.38-1.17(\mathrm{~m}, 7 \mathrm{H}) .{ }^{13} \mathrm{C}$ NMR $(126 \mathrm{MHz}$, Chloroform- $d$ ) $\delta 184.1$, $184.1,140.5,132.8,125.3,79.0,77.1,32.0,25.4,23.8$. MS (DART) exact mass: calculated for $(\mathrm{M}+\mathrm{H})^{+}$: 209.1285; found: 209.1290 .

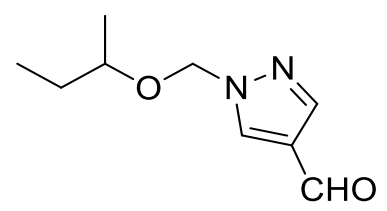

1-(sec-butoxymethyl)-1H-pyrazole-4-carbaldehyde (45): The title compound was prepared from sec-butyl methyl ether $(2.0 \mathrm{ml})$ and $1 \mathrm{H}$-pyrazole-4-carbaldehyde $(0.4 \mathrm{mmol}, 38.4 \mathrm{mg})$ according to general procedure $\mathrm{C}$ with a reaction time of 36 hours. The crude residue was purified by column chromatography on silica gel with an eluent of hexanes to $50 \%$ EtOAc/hexanes to yield a light yellow oil in 51\% yield $(37.2 \mathrm{mg})$.

45: ${ }^{1} \mathrm{H}$ NMR (500 MHz, Chloroform- $d$ ) $\delta 9.93(\mathrm{~s}, 1 \mathrm{H}), 8.14(\mathrm{~s}, 1 \mathrm{H}), 8.01(\mathrm{~s}, 1 \mathrm{H}), 5.53(\mathrm{~s}, 2 \mathrm{H}), 3.60(\mathrm{q}, J=$ $6.1 \mathrm{~Hz}, 1 \mathrm{H}), 1.65-1.37(\mathrm{~m}, 2 \mathrm{H}), 1.13(\mathrm{~d}, J=6.1 \mathrm{~Hz}, 3 \mathrm{H}), 0.83(\mathrm{t}, J=7.4 \mathrm{~Hz}, 3 \mathrm{H}) .{ }^{13} \mathrm{C} \mathrm{NMR}(126 \mathrm{MHz}$, Chloroform- $d$ ) $\delta 184.1,140.5,132.9,125.3,79.4,76.6,29.1,19.2,9.5$. MS (DART) exact mass: calculated for $(\mathrm{M}+\mathrm{H})^{+}$: 183.1128 ; found: 183.1132 .

\section{References}

[1] Huang, H.; Strater, Z. M.; Rauch, M.; Shee, J.; Sisto, T. J.; Nuckolls, C.; Lambert, T. H. Electrophotocatalysis with a trisaminocyclopropenium radical dication. Angew. Chem. Int. Ed. 2019, 58, 13318-13322. Angew. Chem. 2019, 131, 13452-13456 
[2] Huang, H.; Lambert, T. H. Electrophotocatalytic SNAr reactions of unactivated aryl fluorides at ambient temperature and without base. Angew. Chem. Int. Ed. 2019, DOI: 10.1002/anie.201909983

[3] Wu, J.; Zhou, Y.; Zhou, Y.; Chiang, C.-W.; Lei, A. Electrooxidative C(sp3)-H Amination of Azoles via Intermolecular Oxidative $\mathrm{C}(\mathrm{sp} 3)-\mathrm{H} / \mathrm{N}-\mathrm{H}$ Cross-Coupling. ACS Catal. 2017, 7, 8320-8323.

[4] Liu, S.; Liu, A.; Zhang, Y.; Wang, W. Direct C $\alpha$-Heteroarylation of Structurally Diverse Ethers via a Mild N-Hydroxysuccinimide Mediated Cross-Dehydrogenative Coupling Reaction. Chem. Sci. 2017, 8, 4044-4050.

[5] Kamijo, S.; Takao, G.; Kamijo, K.; Tsuno, T.; Ishiguro, K.; Murafuji, T. Alkylation of nonacidic $\mathrm{C}\left(\mathrm{sp}^{3}\right)-\mathrm{H}$ bonds by photoinduced catalytic Michael-type radical addition. Org. Lett. 2016, 18, 4912-4915.

[6] Zhu, S.; Pathigoolla, A.; Lowe, G.; Walsh, D. A.; Cooper, M.; Lewis, W.; Lam, H. W. Sulfonylative and azidosulfonylative cyclizations by visible-light-photosensitization of sulfonyl azides in THF. Chem. Eur. J. 2017, 23, 17598-17604.

[7] Jeffrey, J. L.; Terrett, J. A.; MacMillan, D. W. C. O-H hydrogen bonding promotes H-atom transfer from $\alpha \mathrm{C}-\mathrm{H}$ bonds for Calkylation of alcohols. Science 2015, 349, 1532-1536.

[8] Chen, L.; Yang, J.; Li, L.; Weng, Z.; Kang, Q. Cobalt-catalyzed direct C-C bond formation between tetrahydrofuran and alkynes. Tetrahedron Lett. 2014, 55, 6096 


\section{NMR Spectral Data}

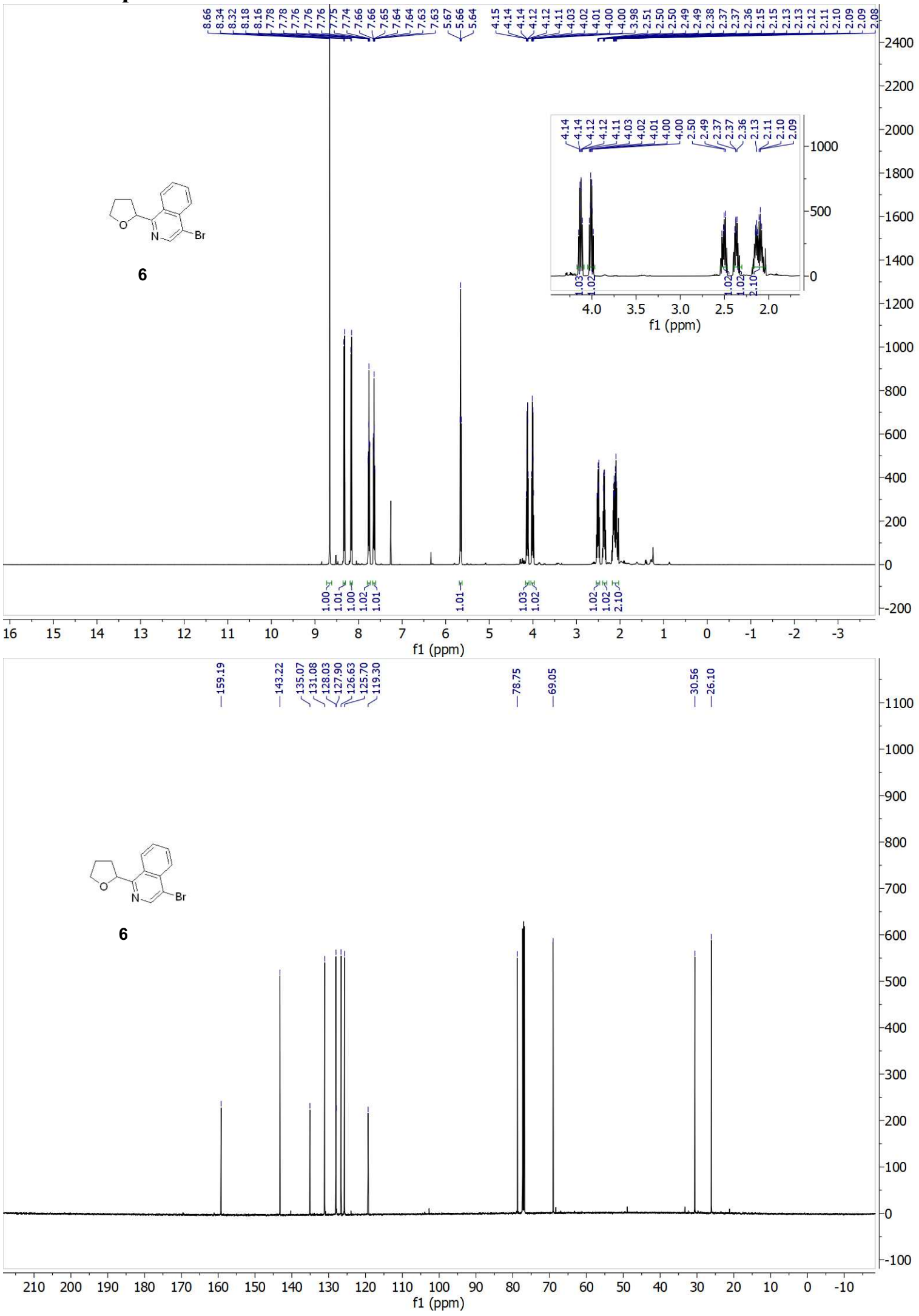




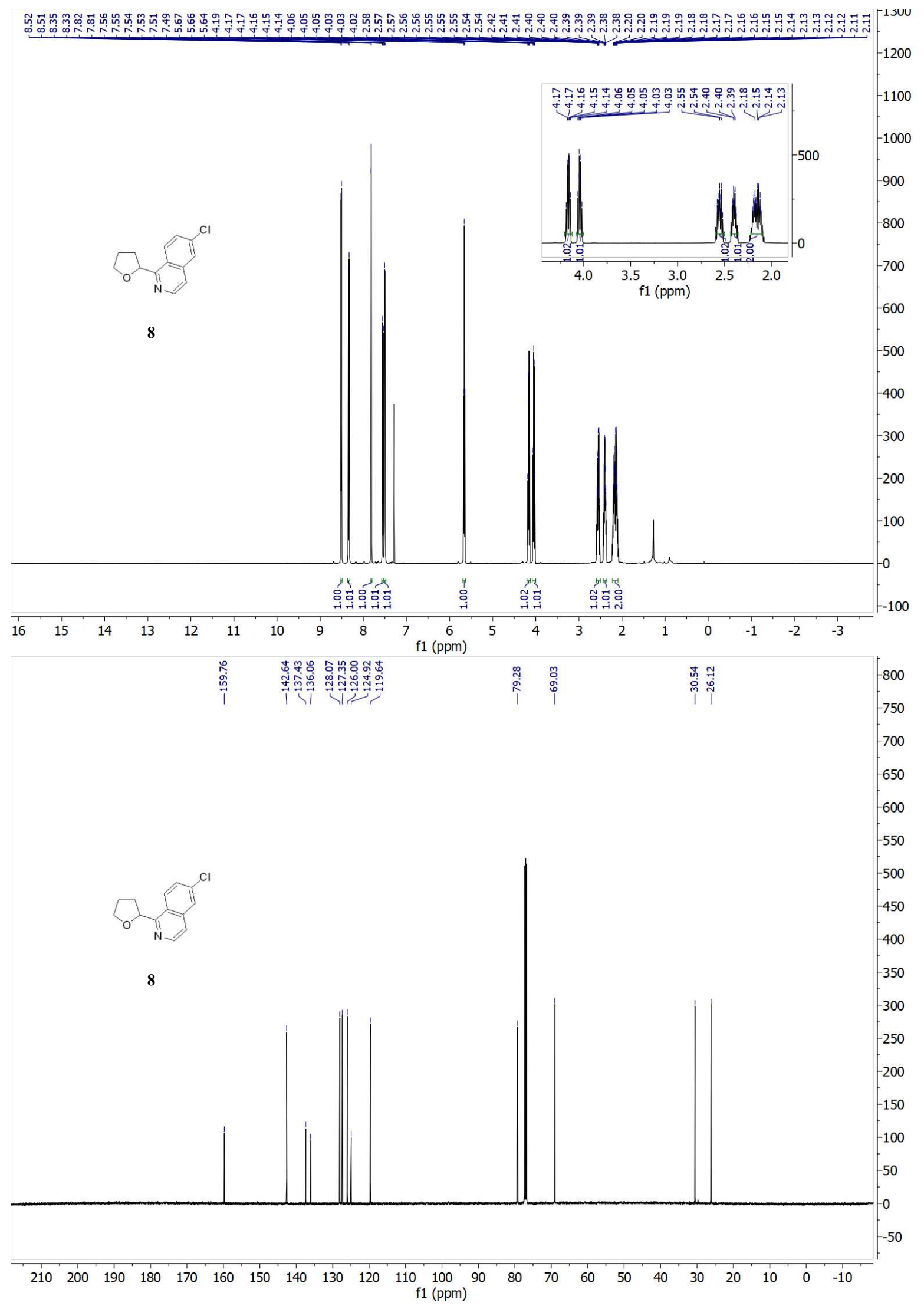




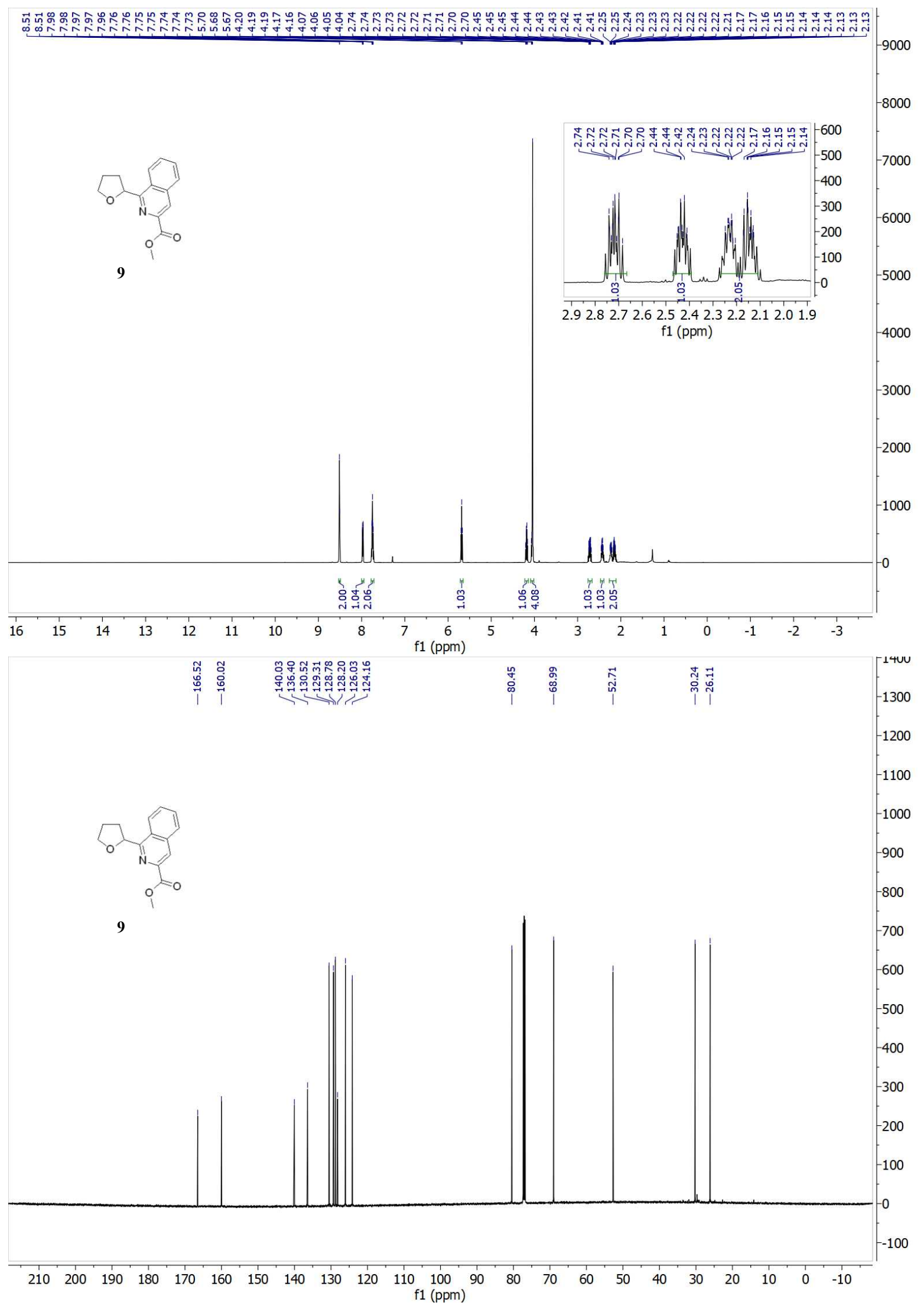




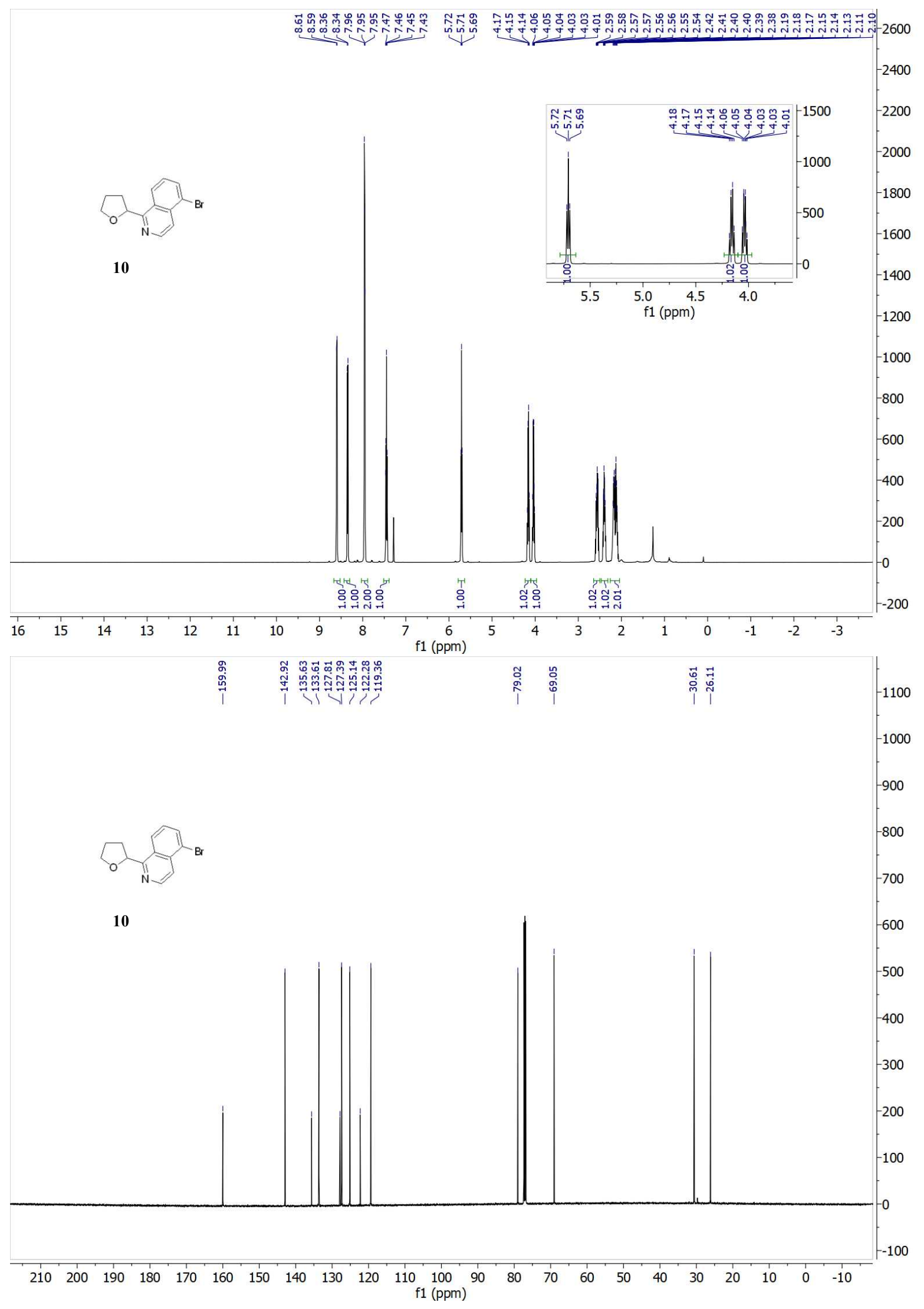




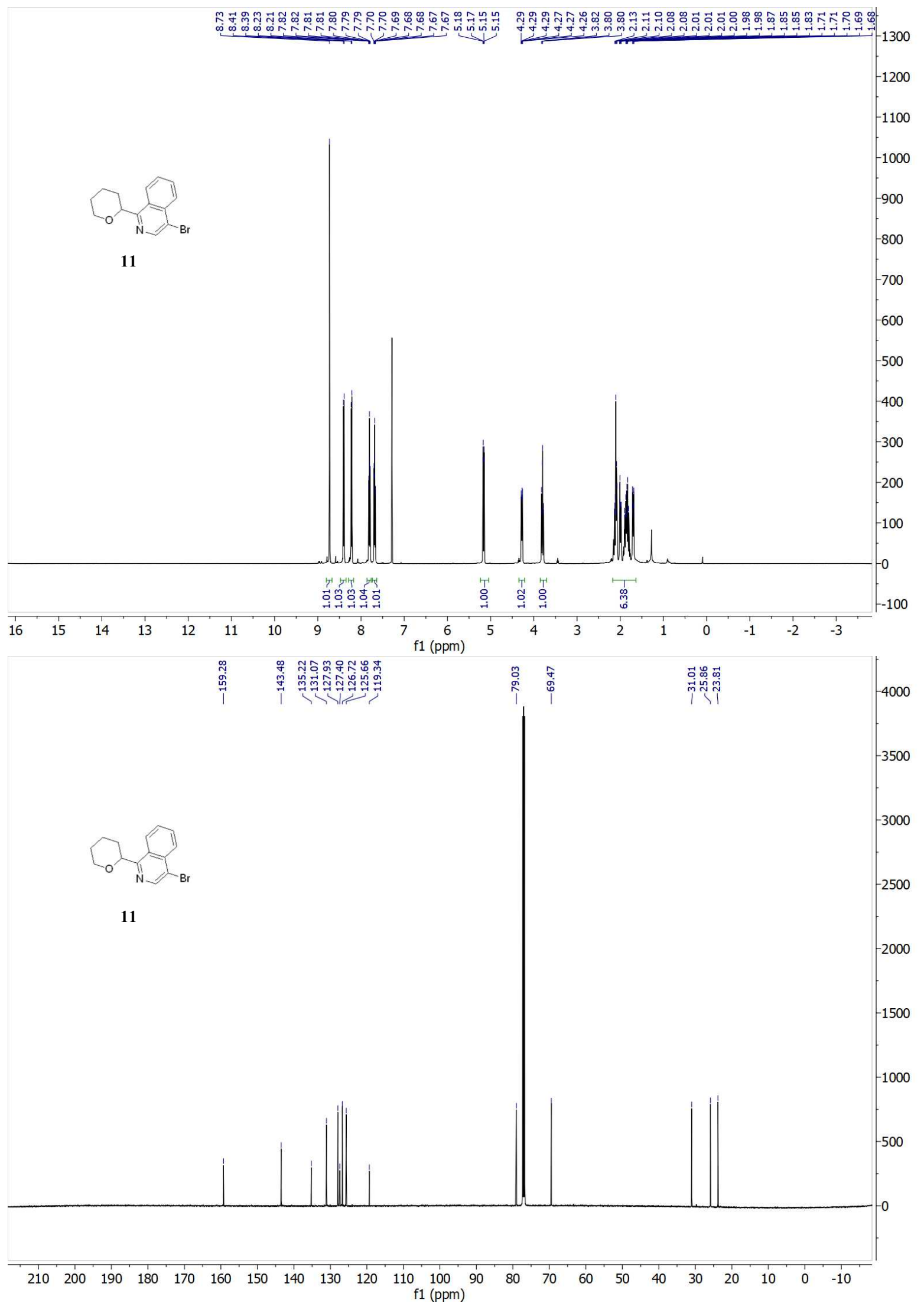




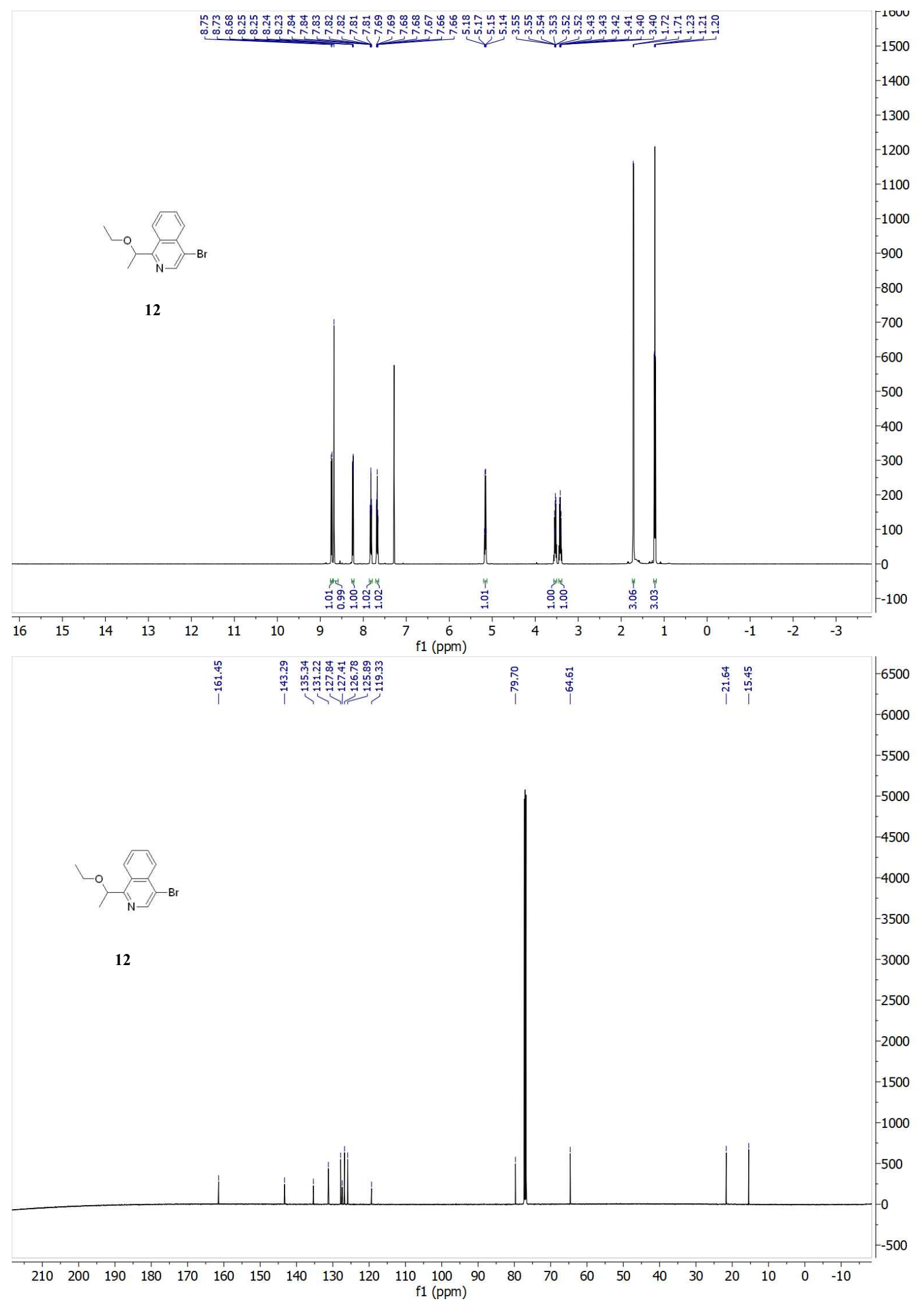




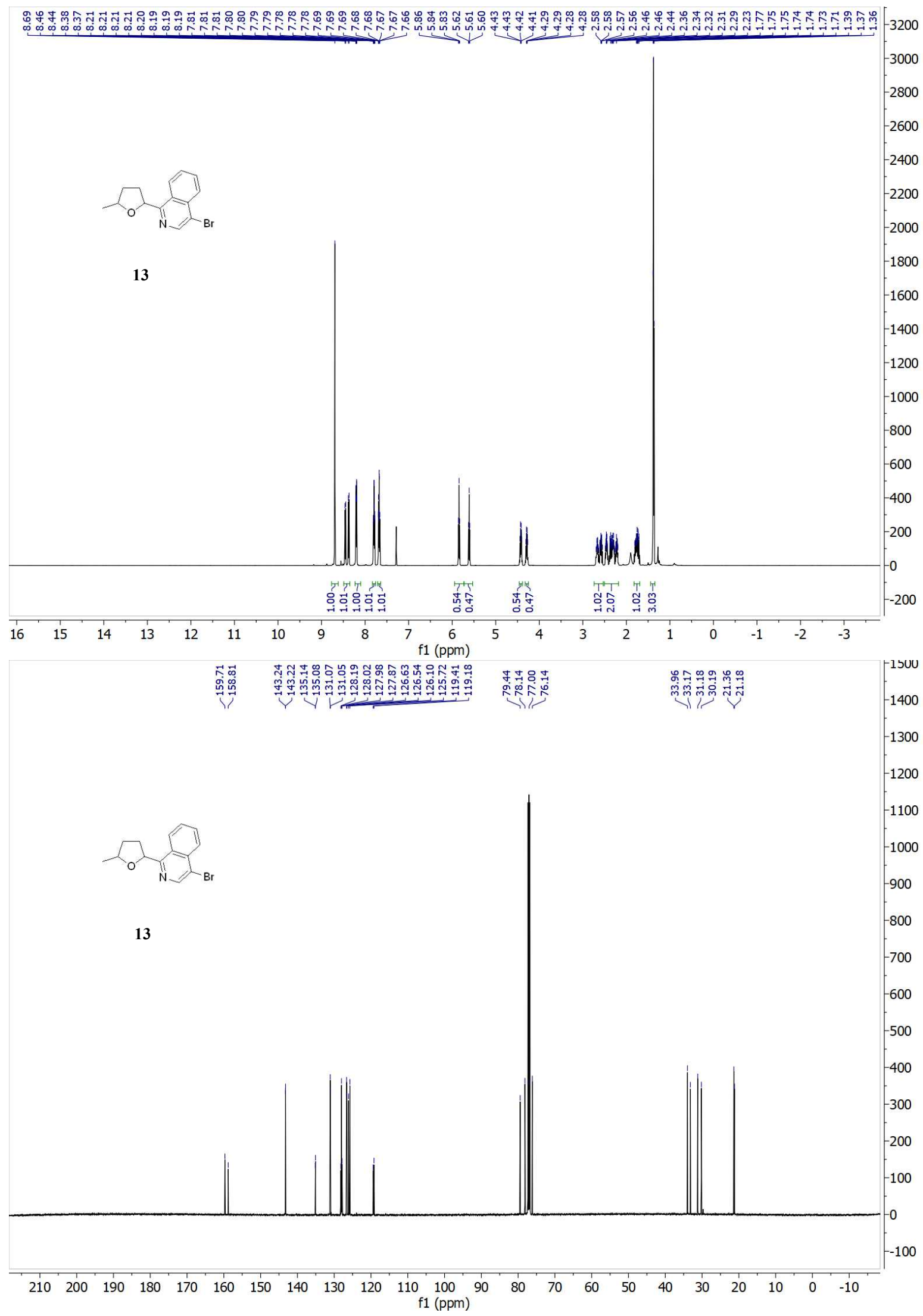




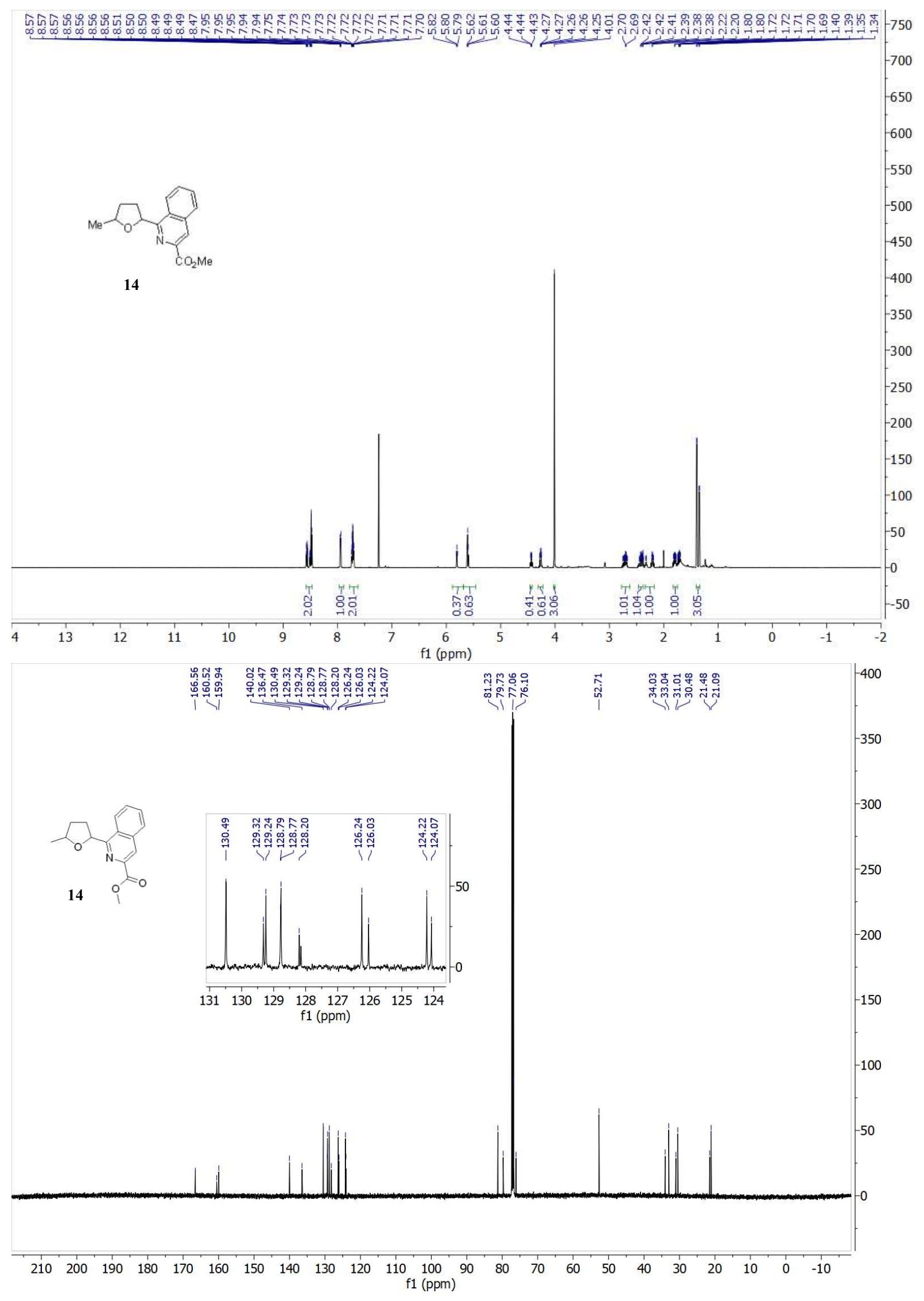




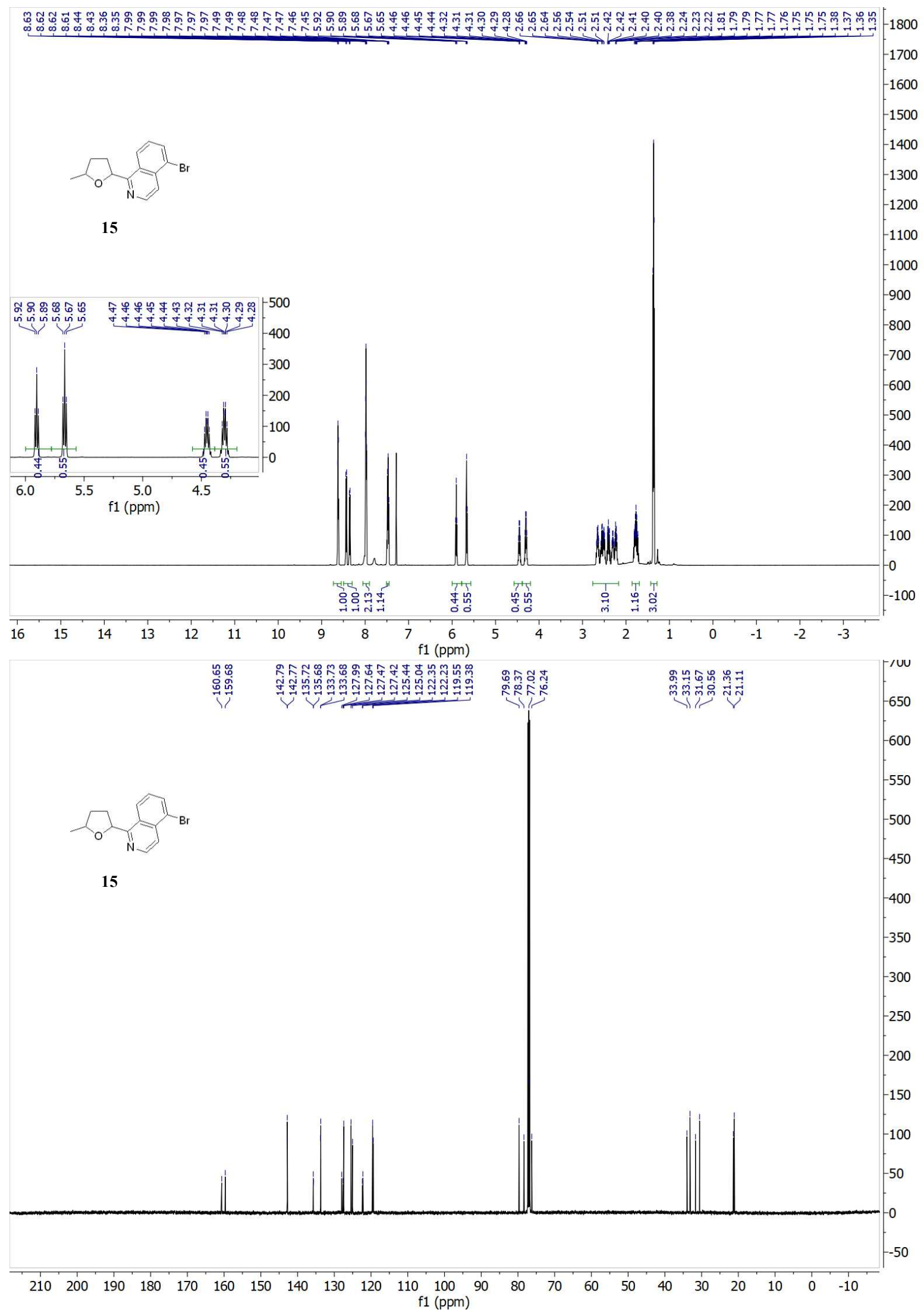




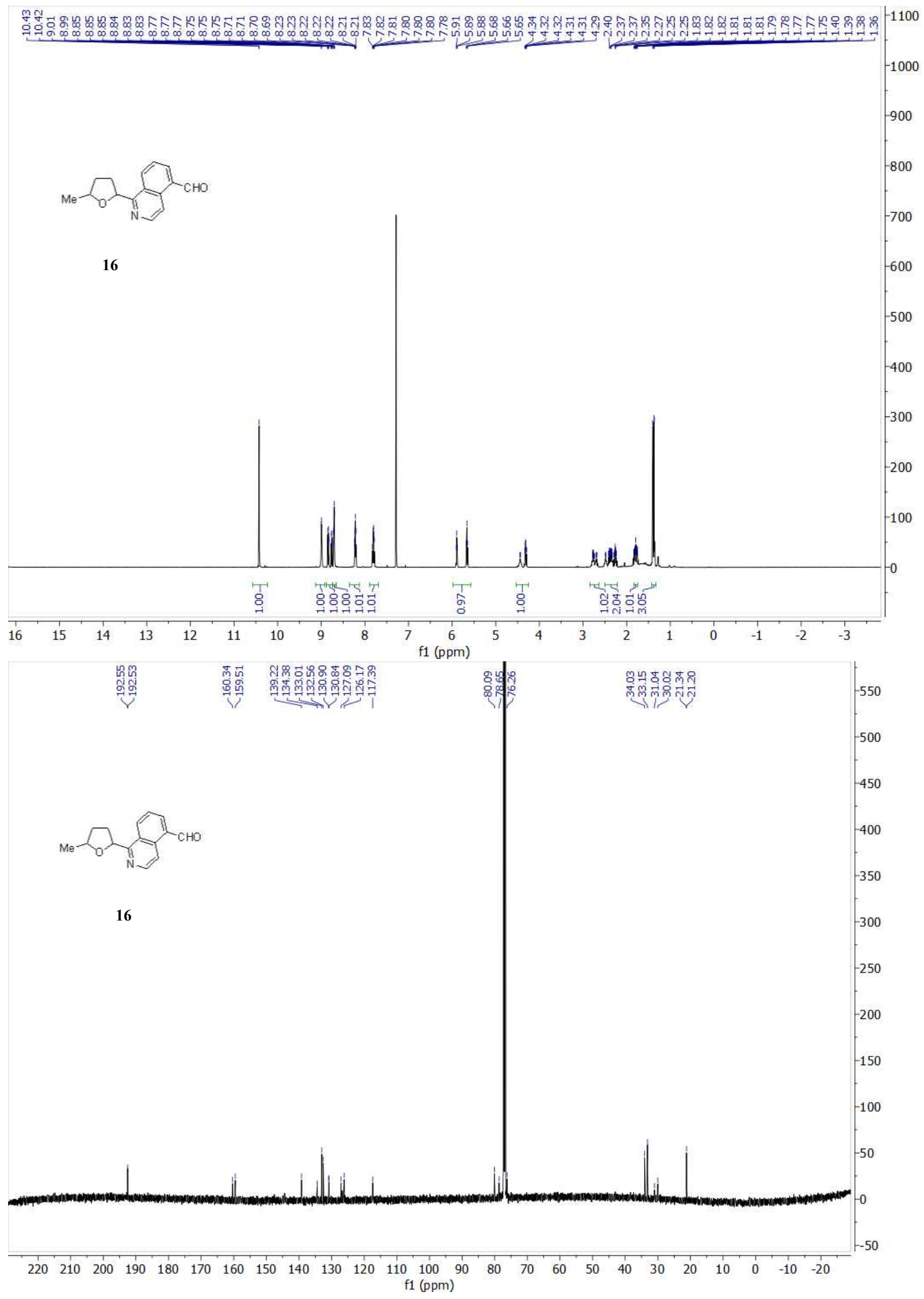




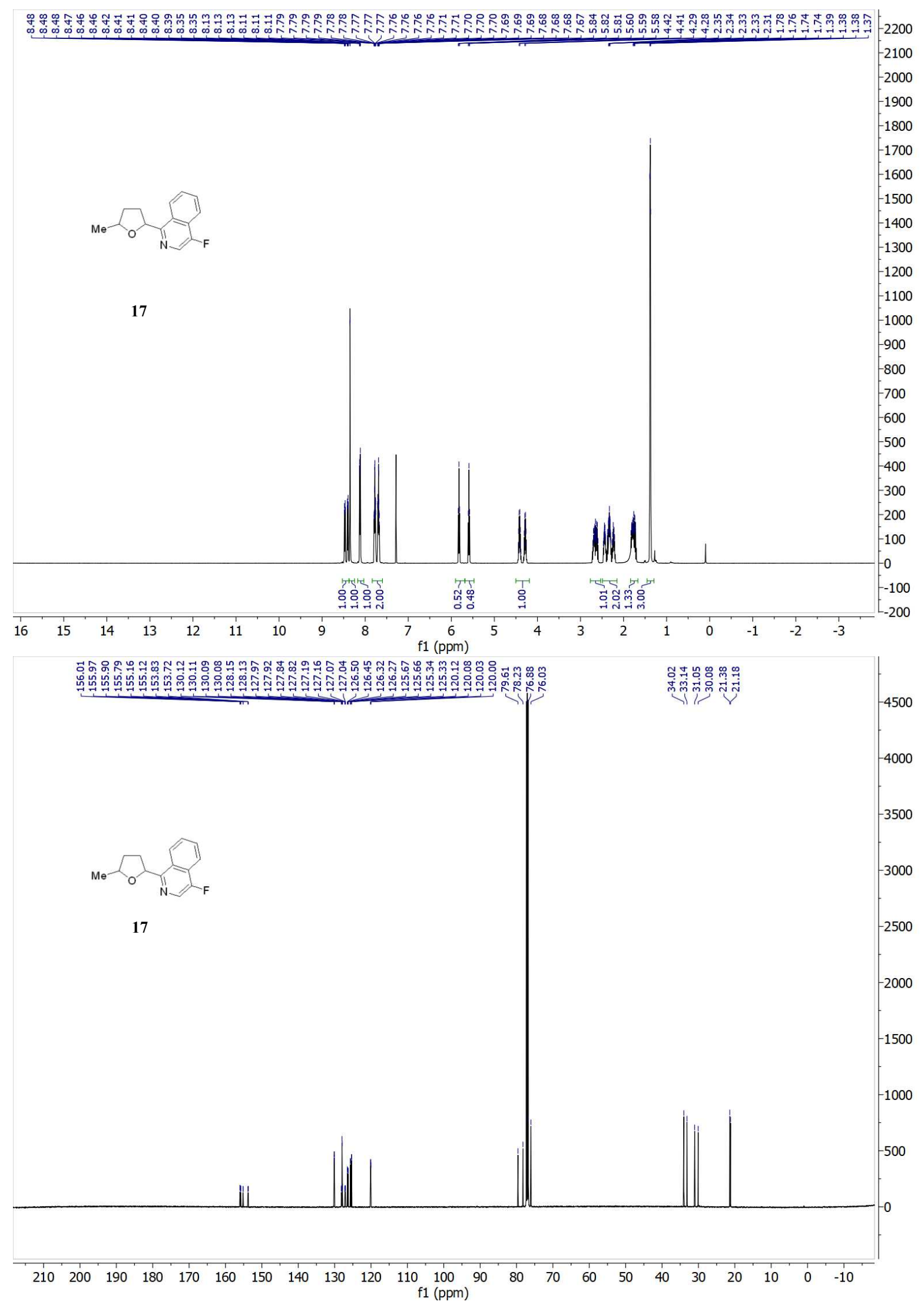




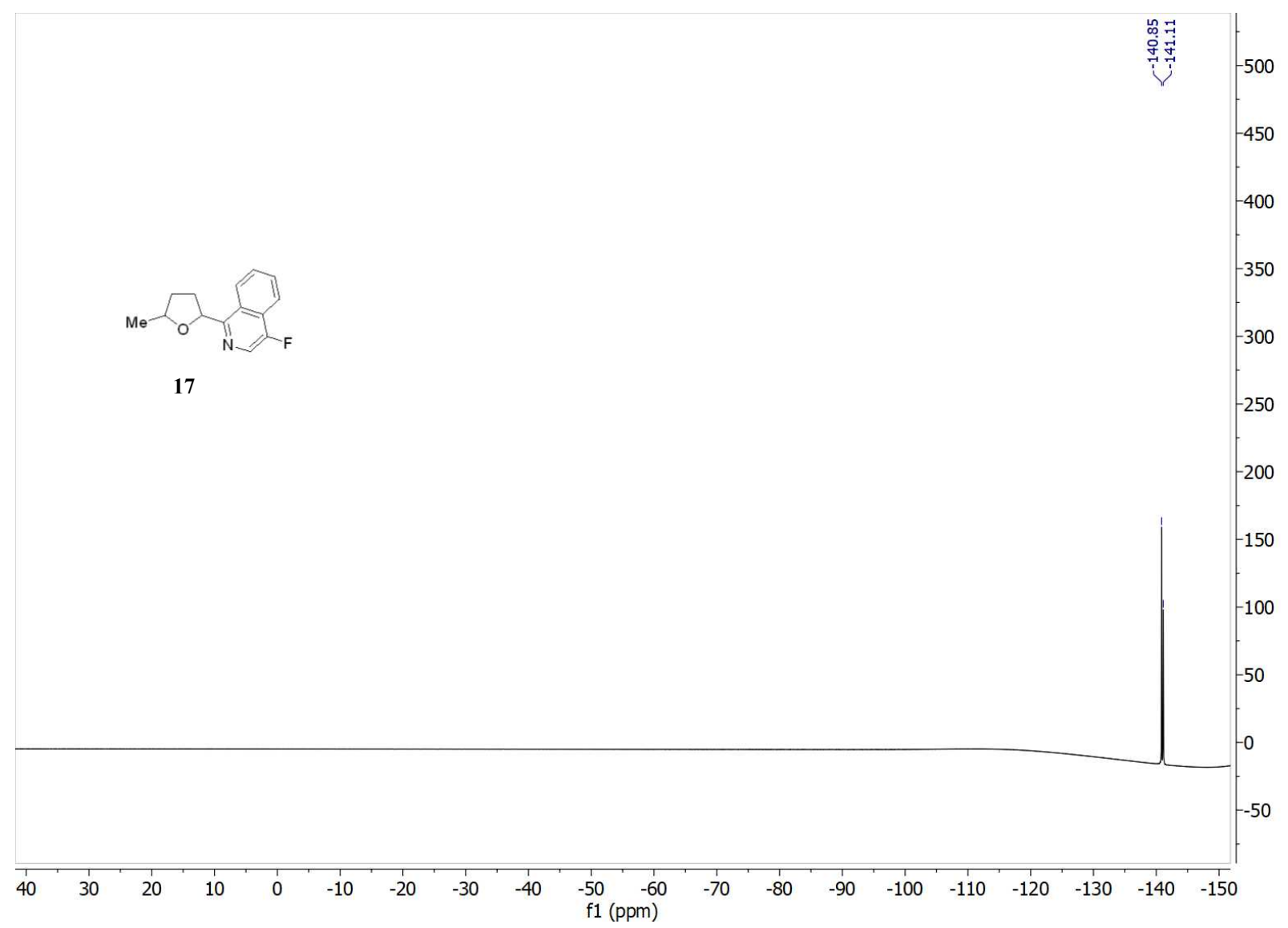




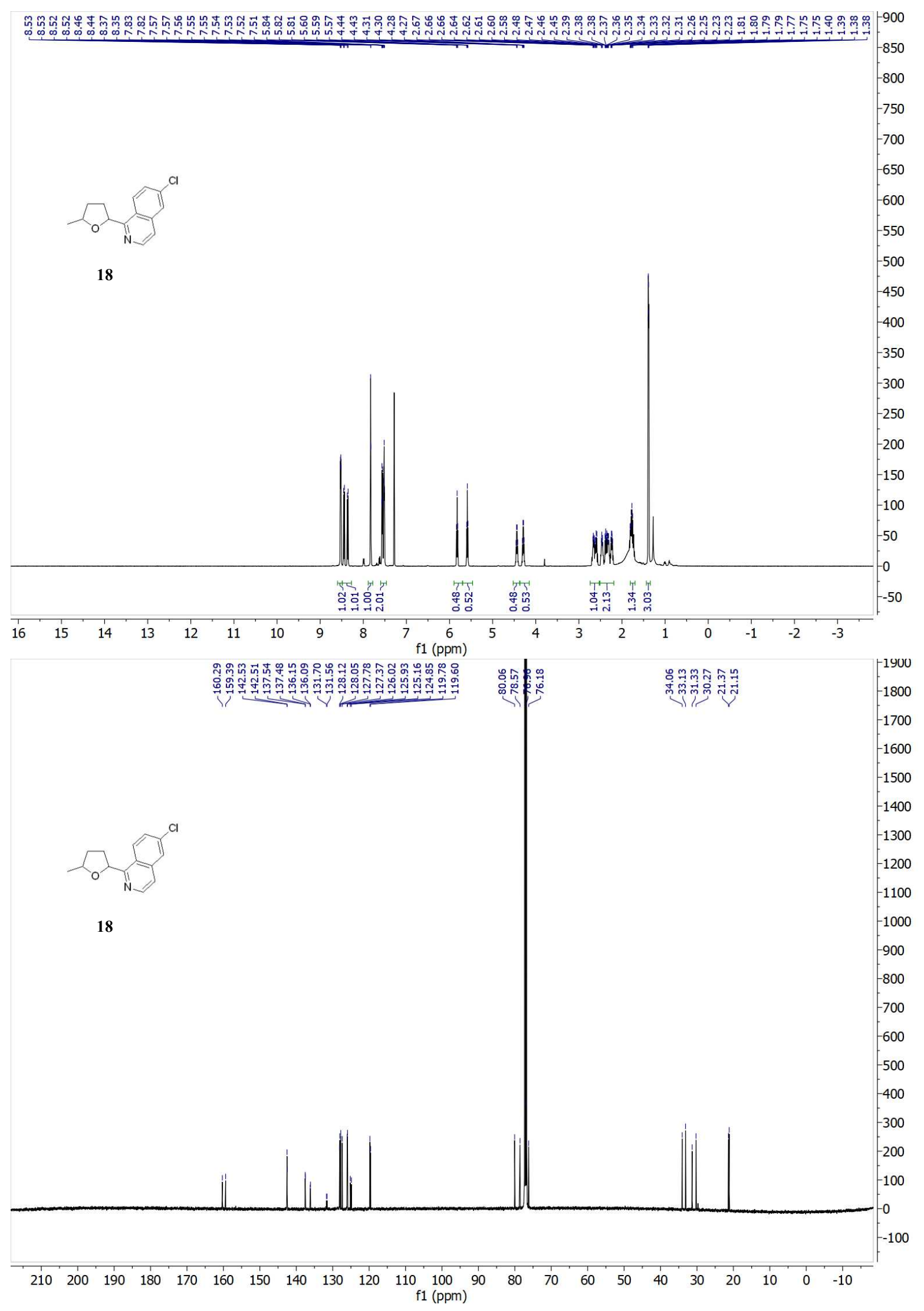




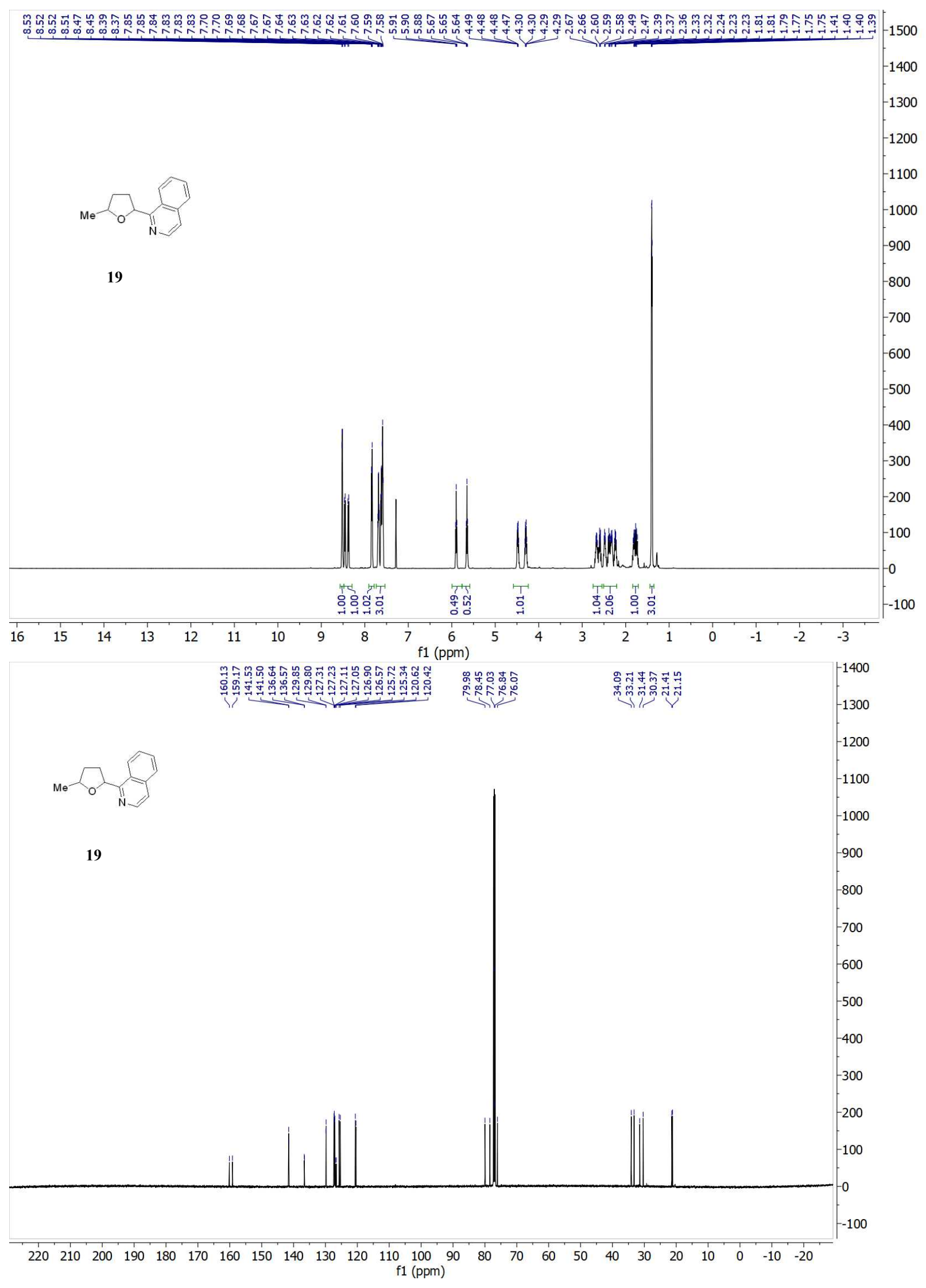




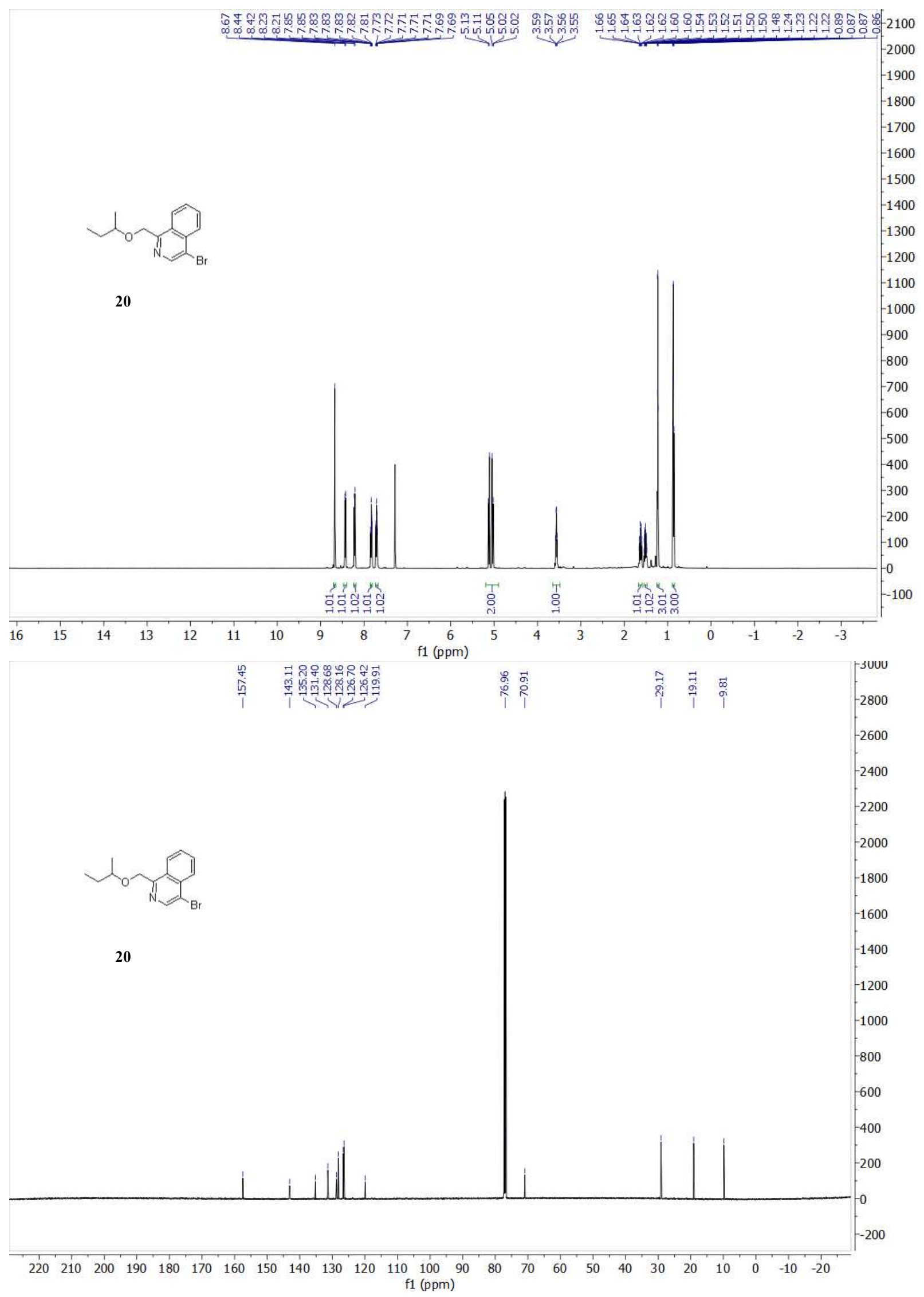




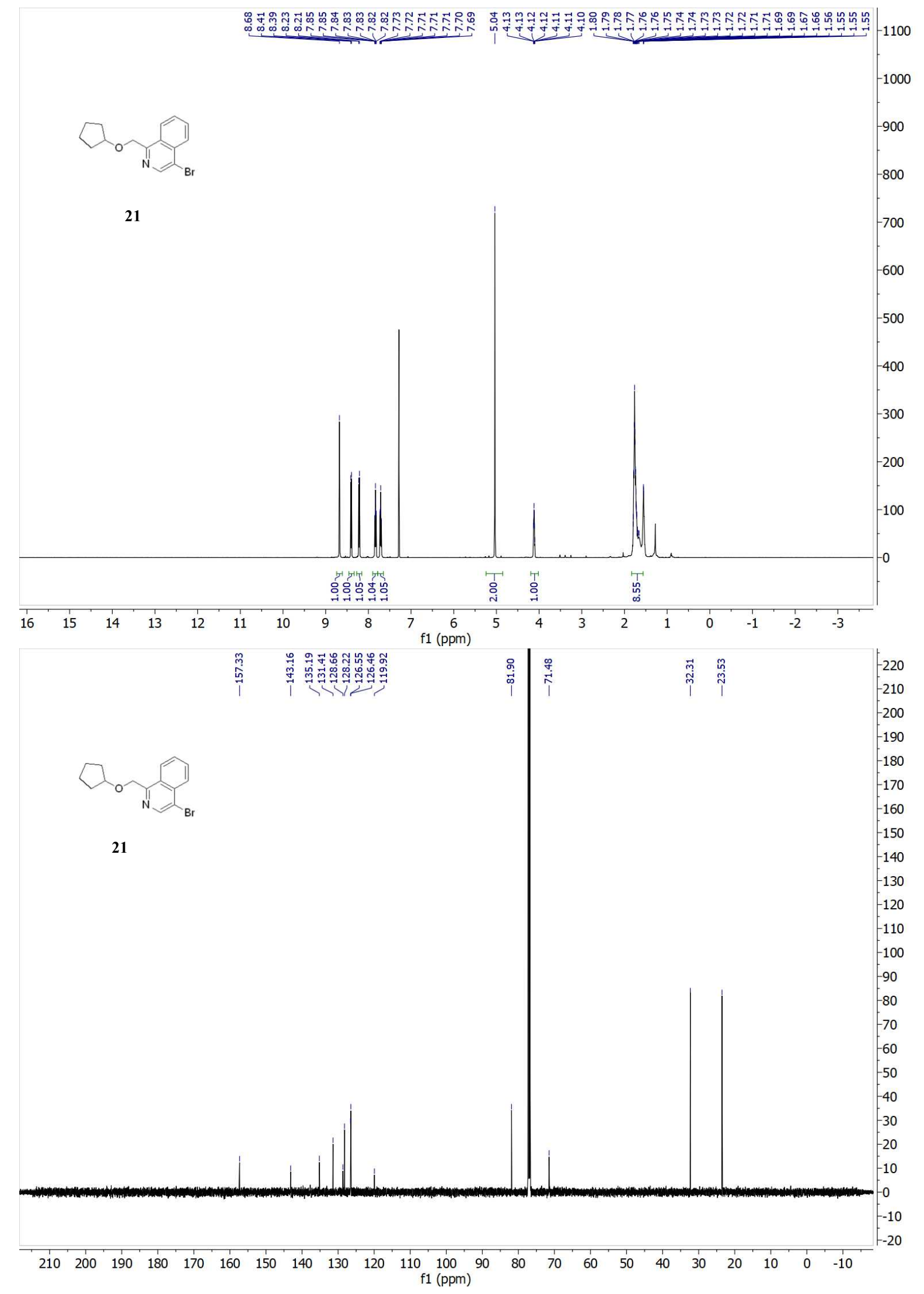




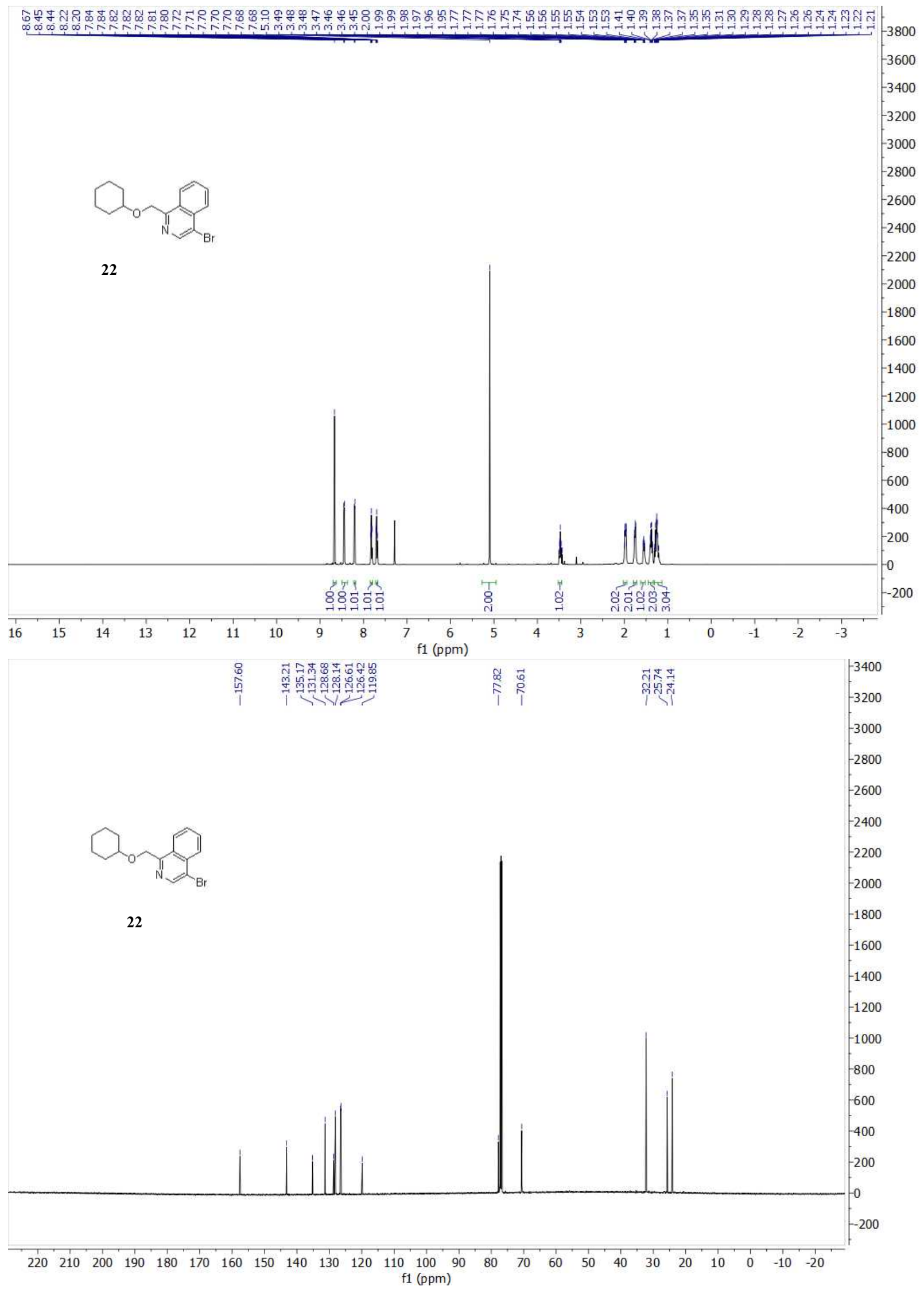




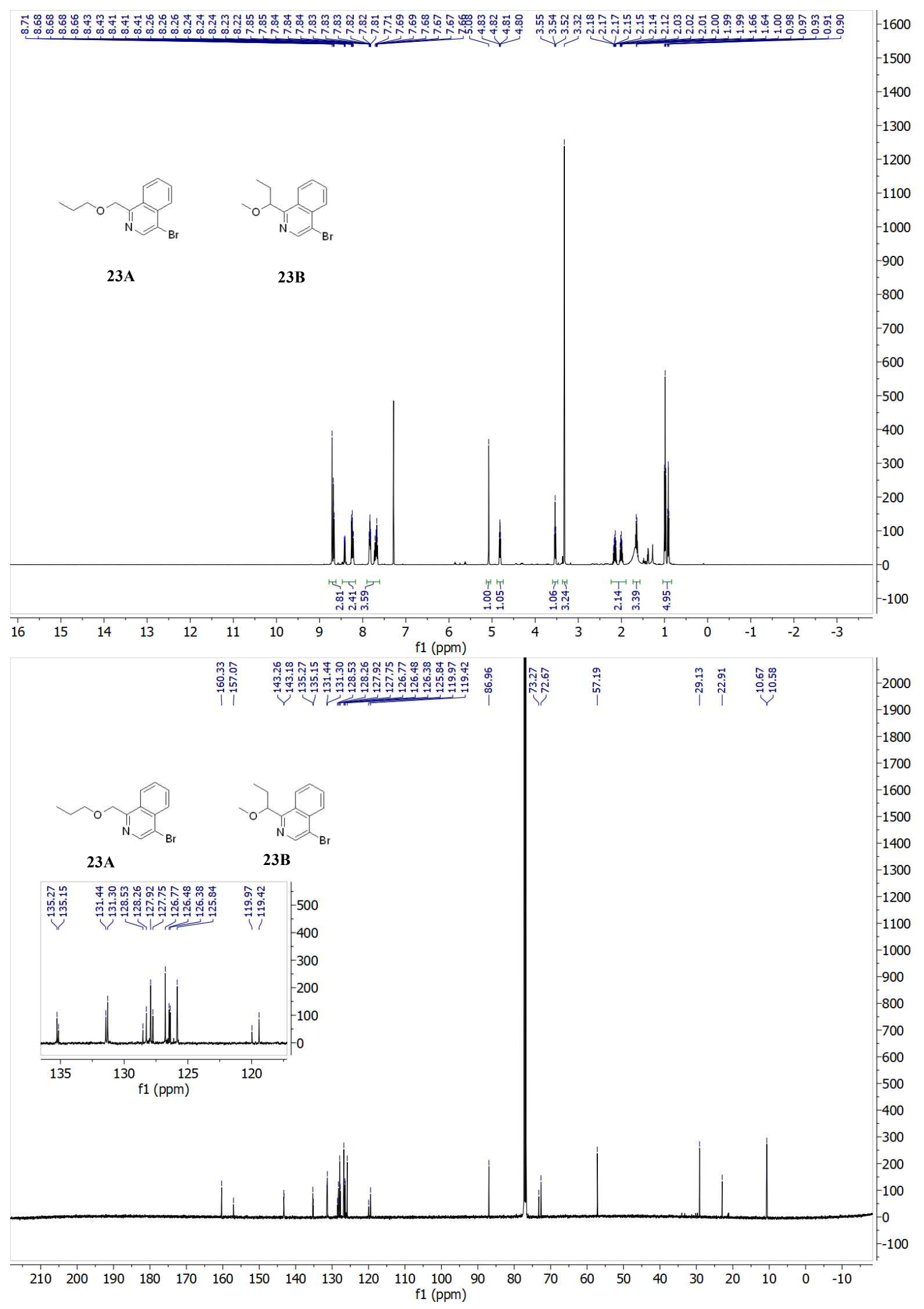




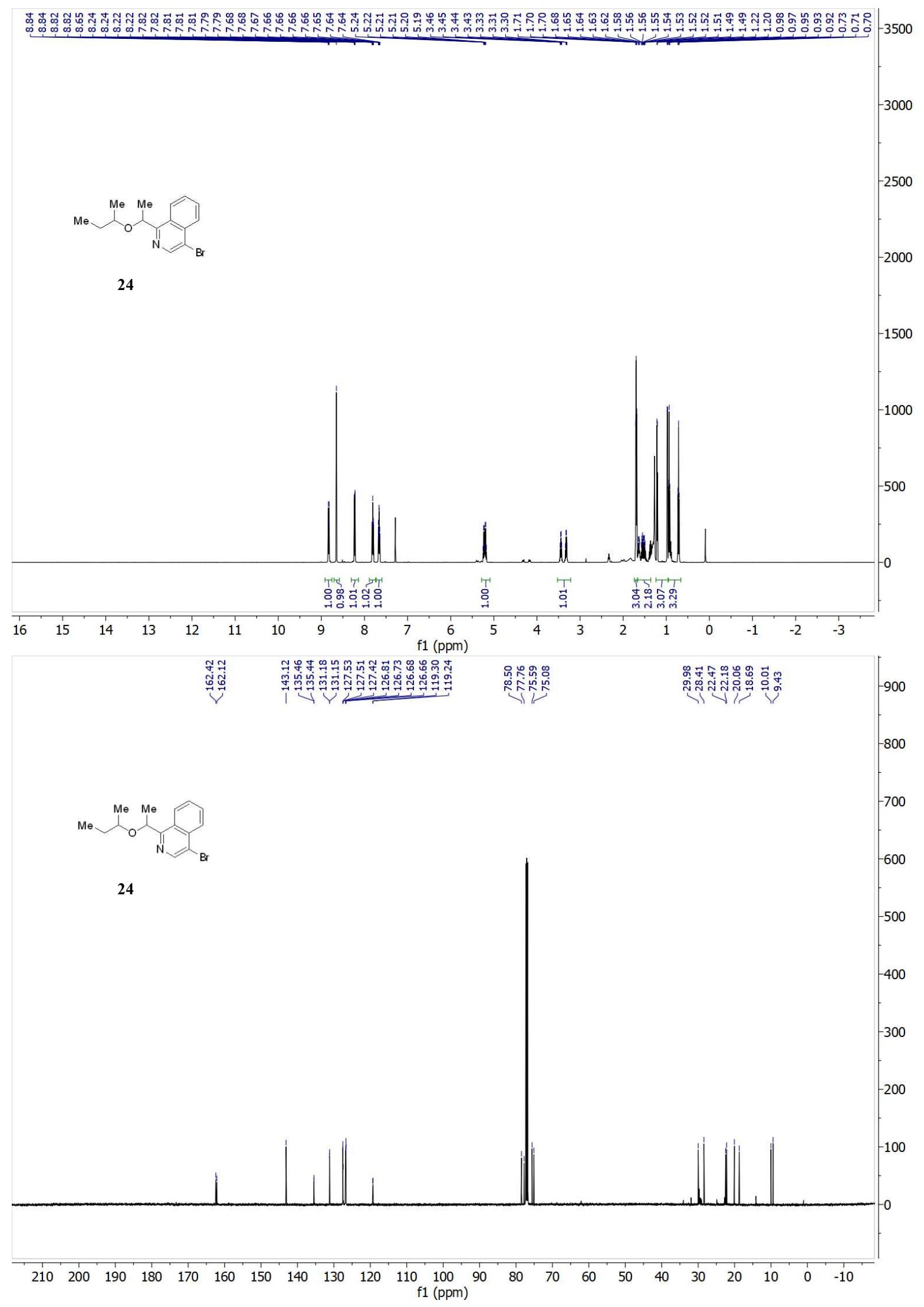




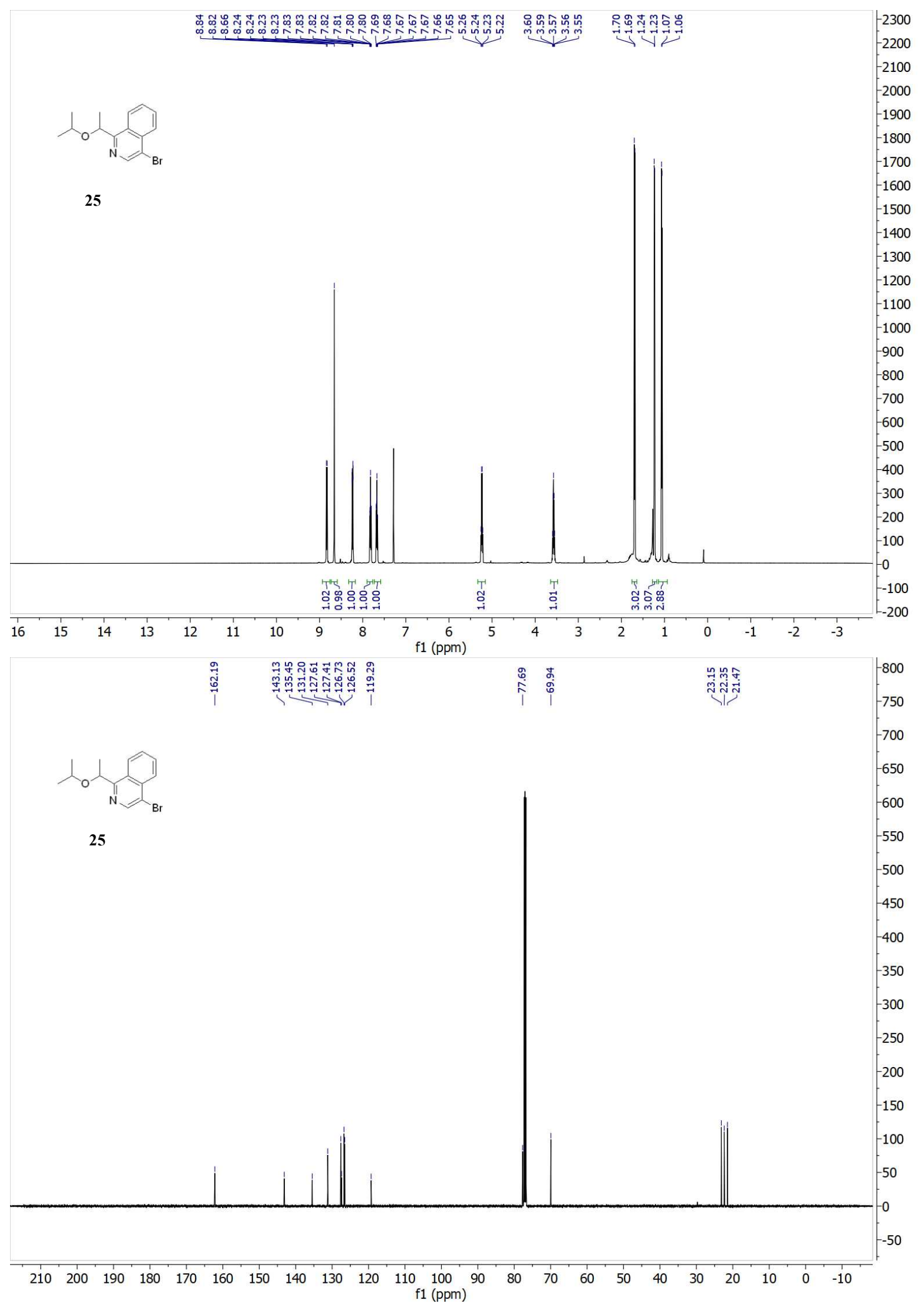




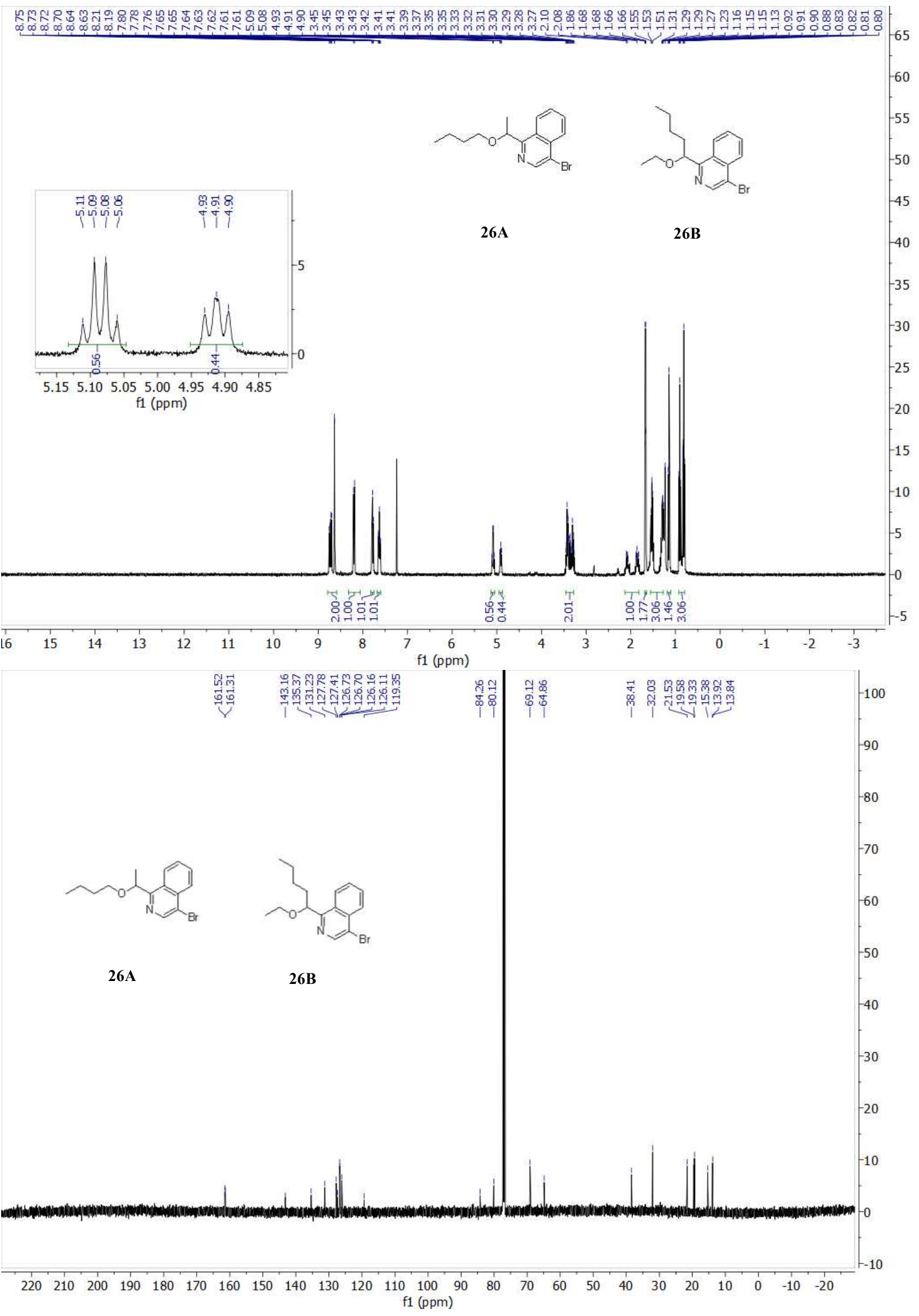




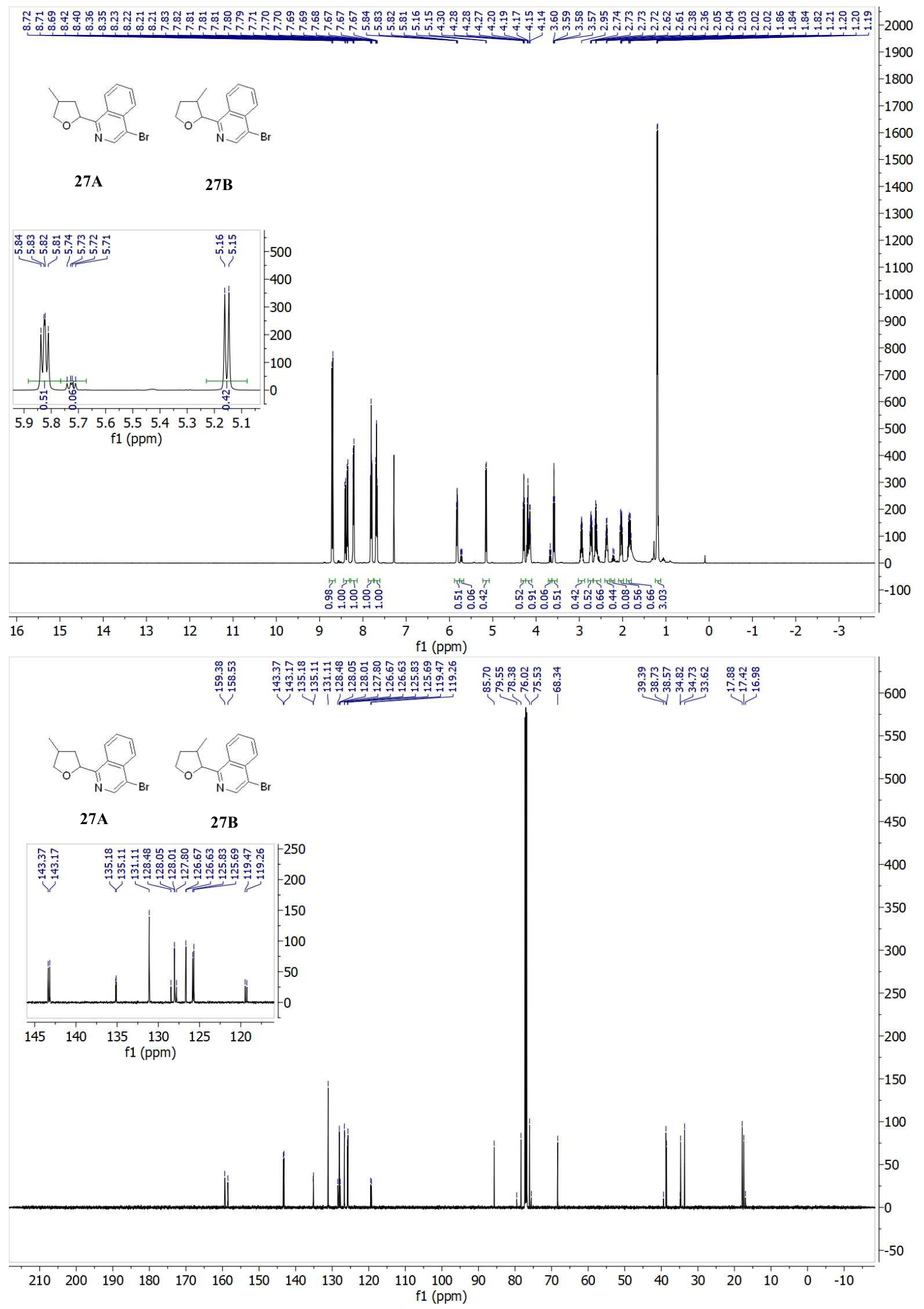




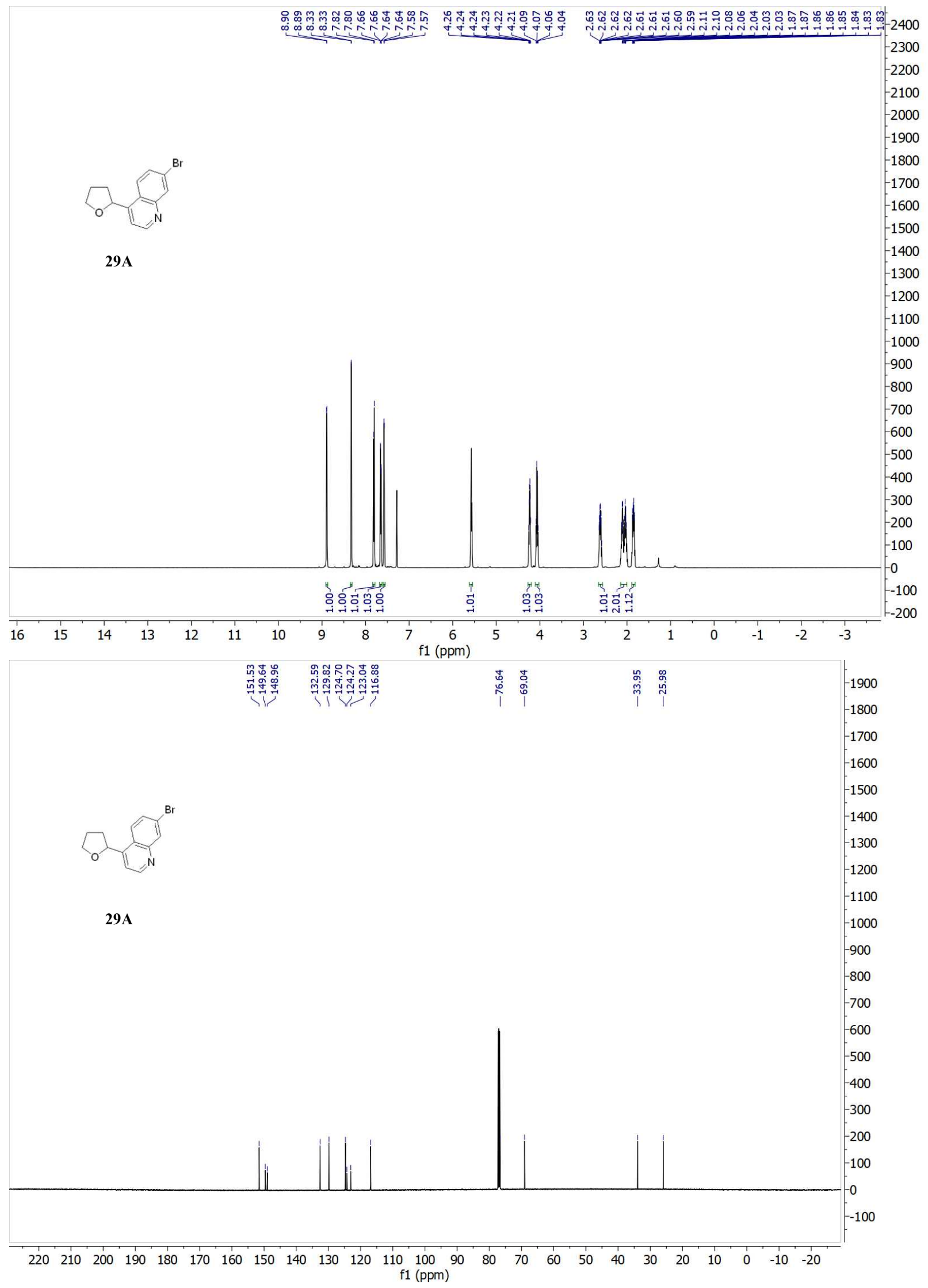




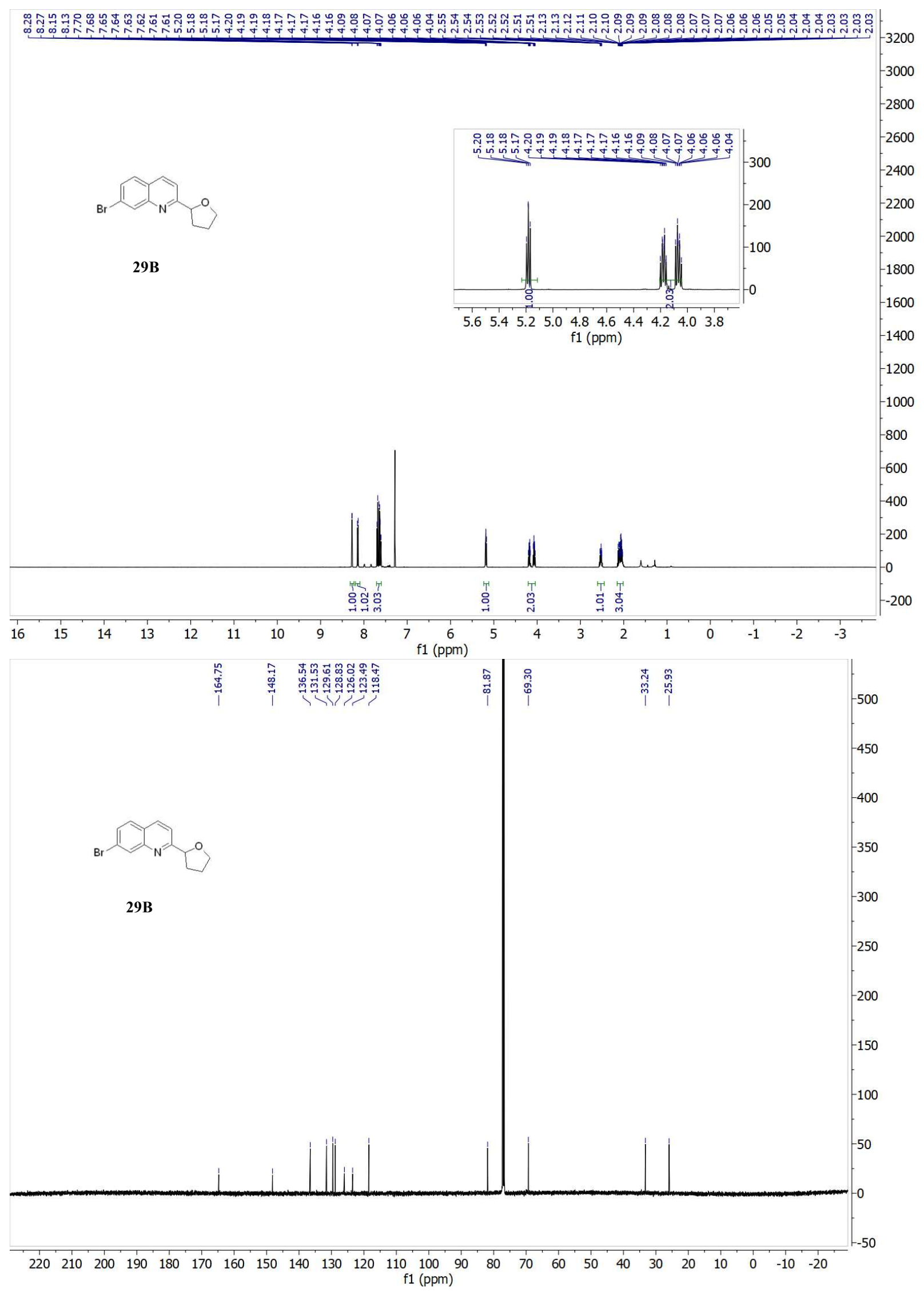




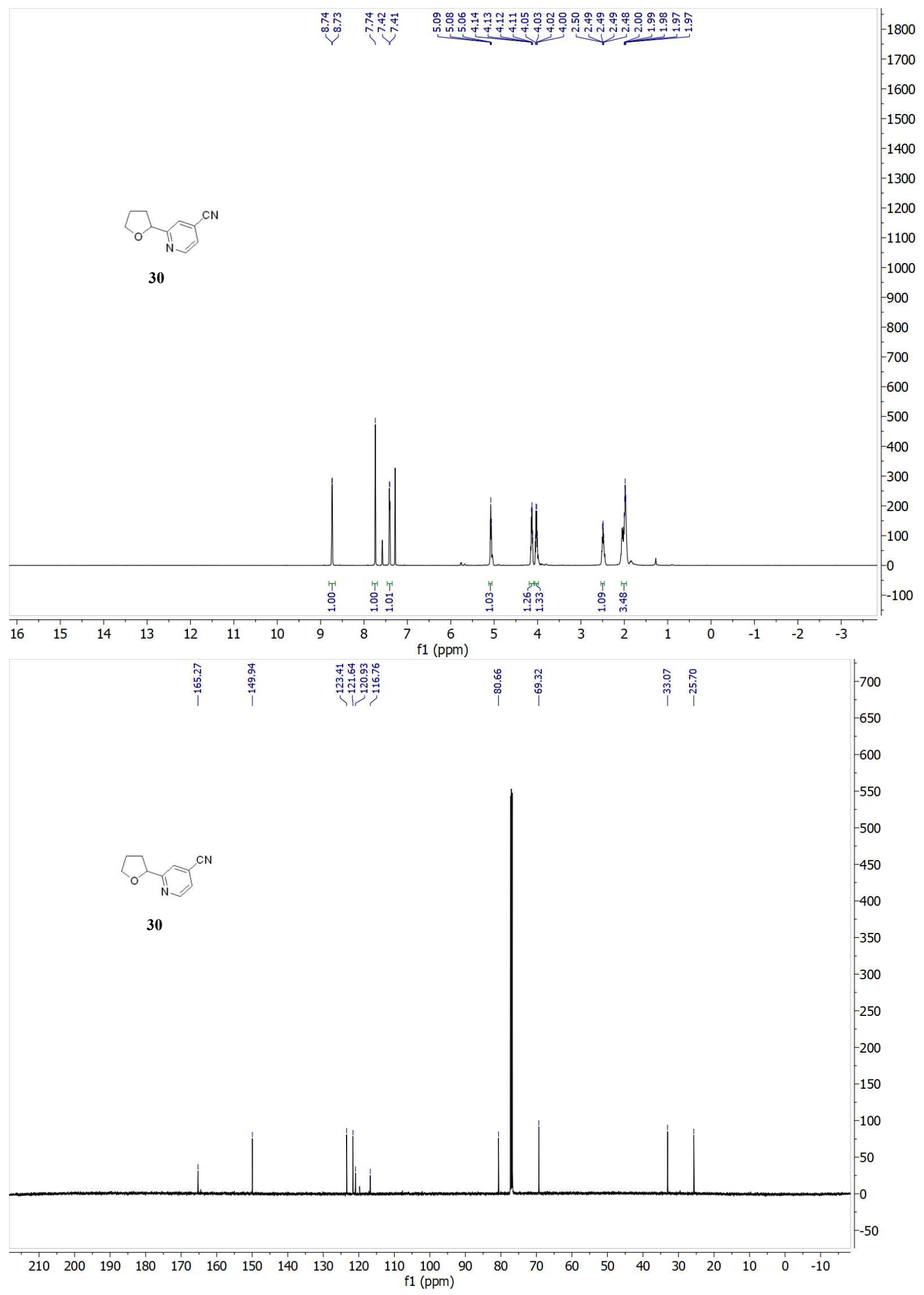




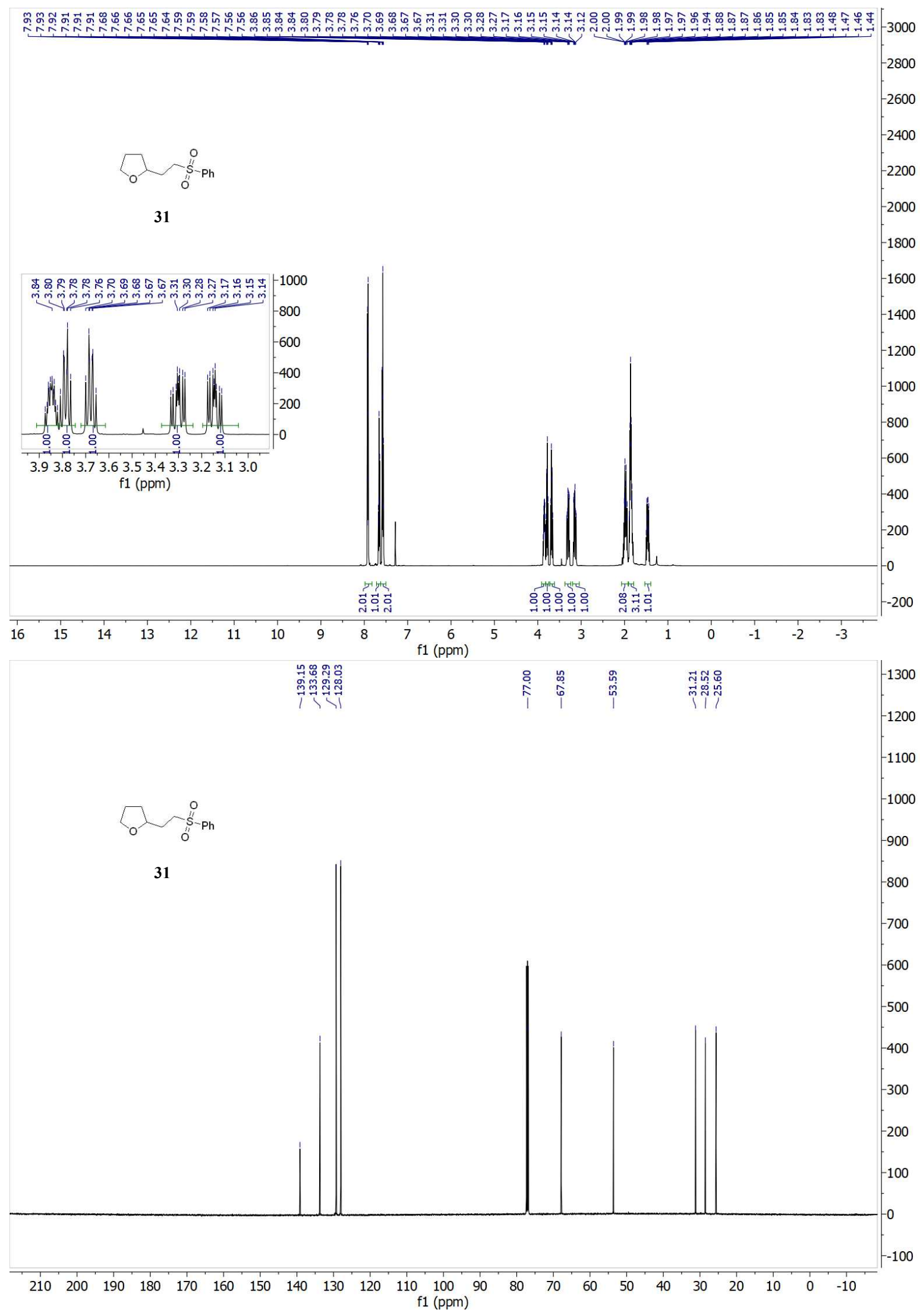




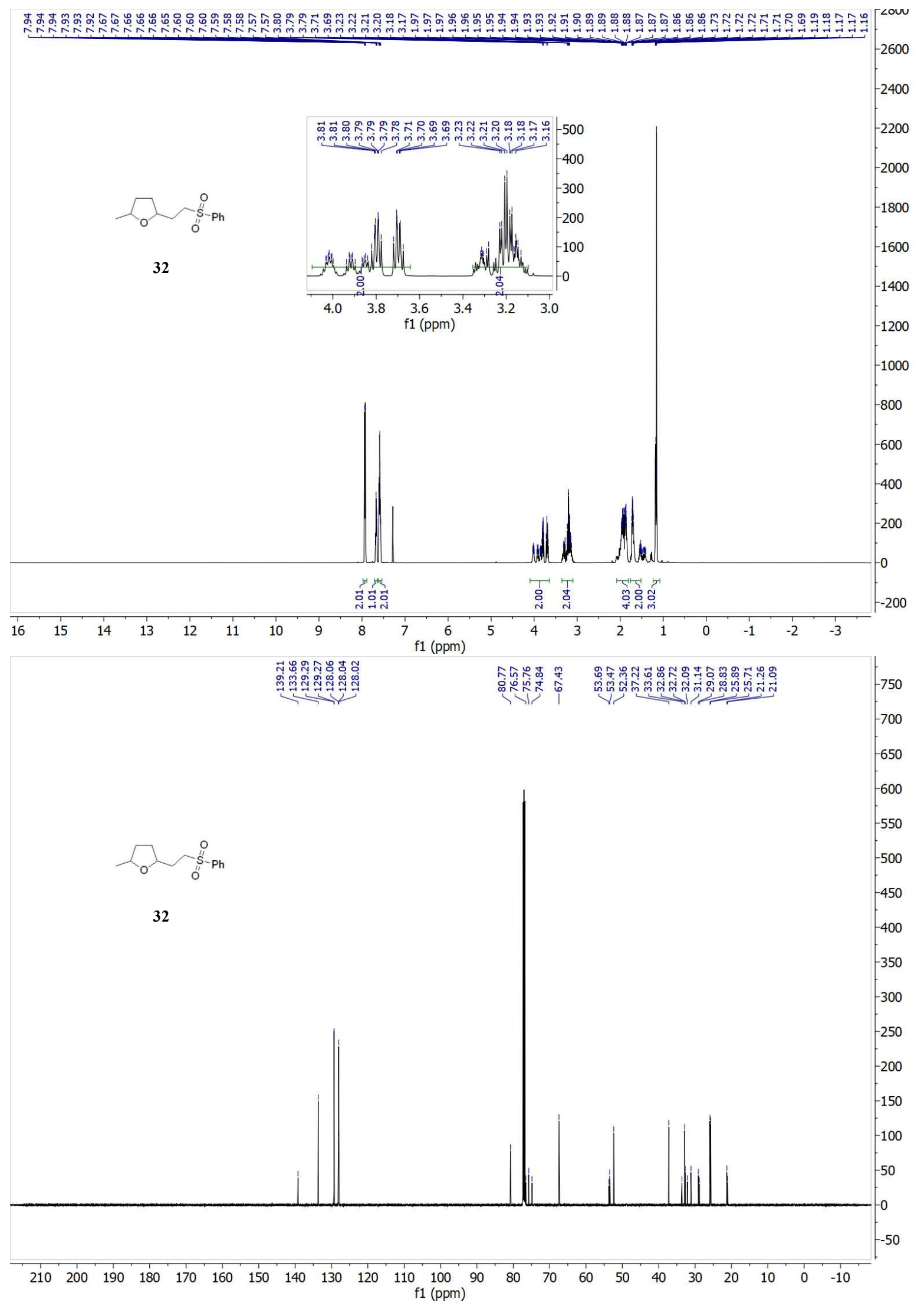




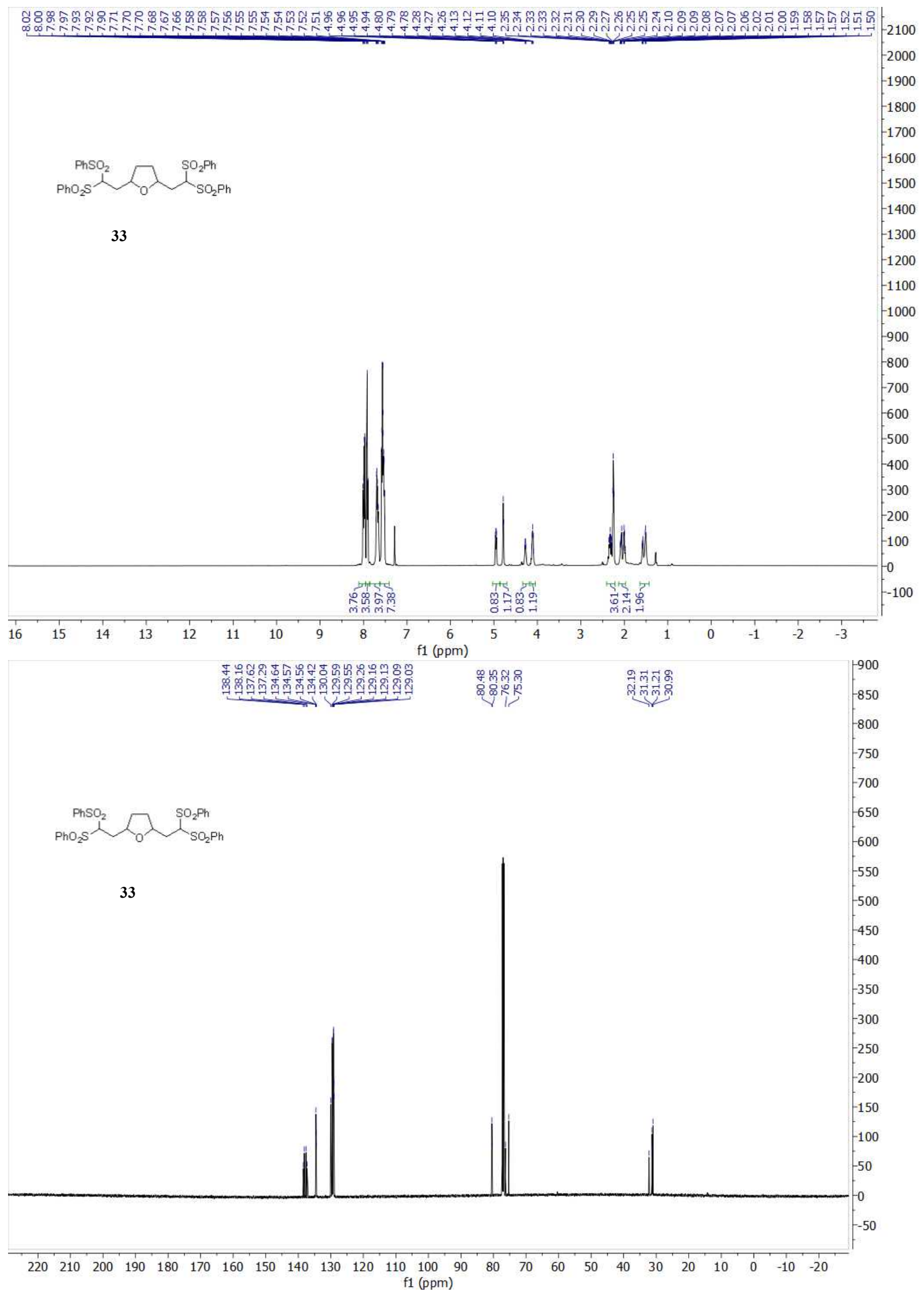




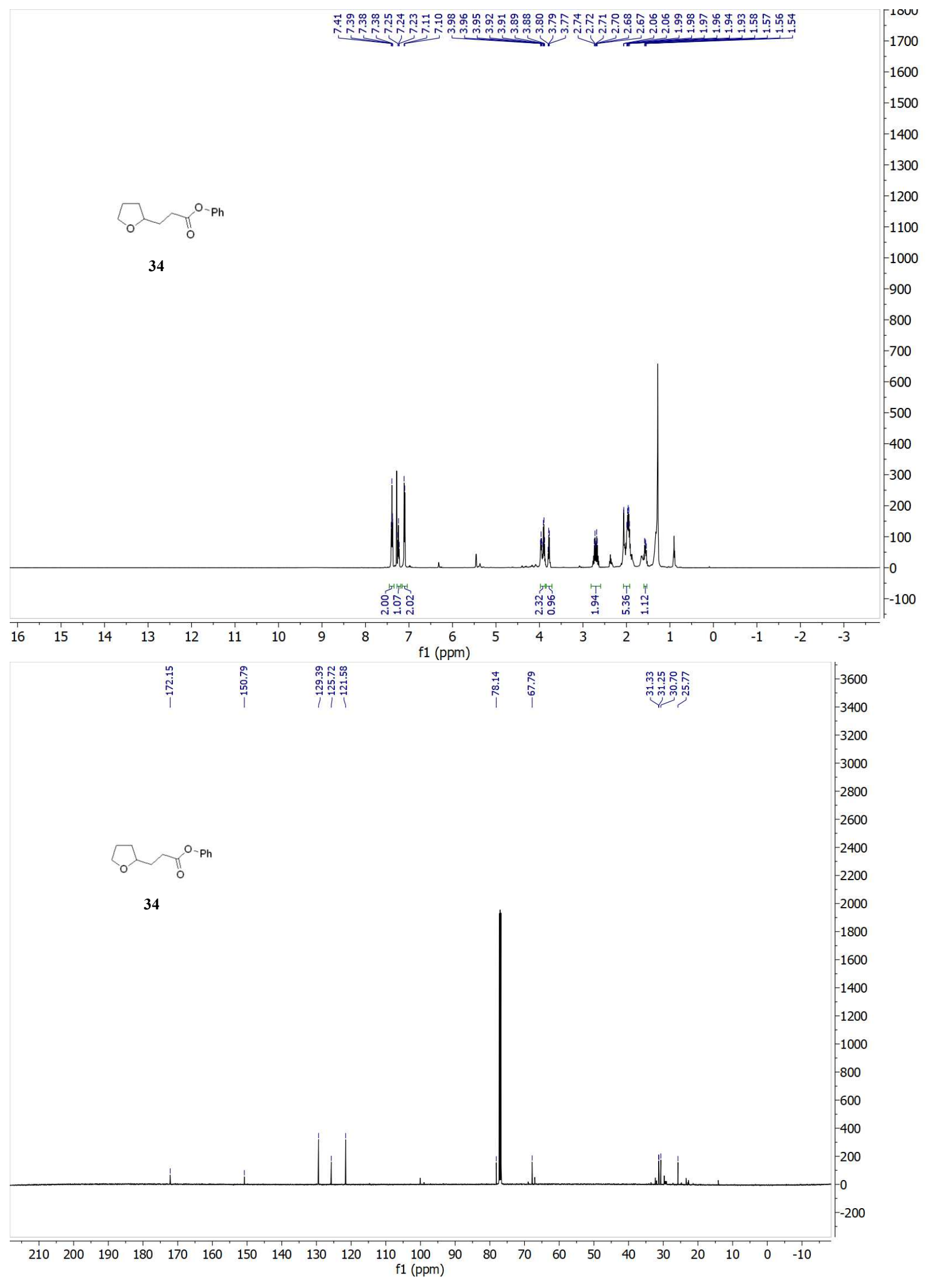




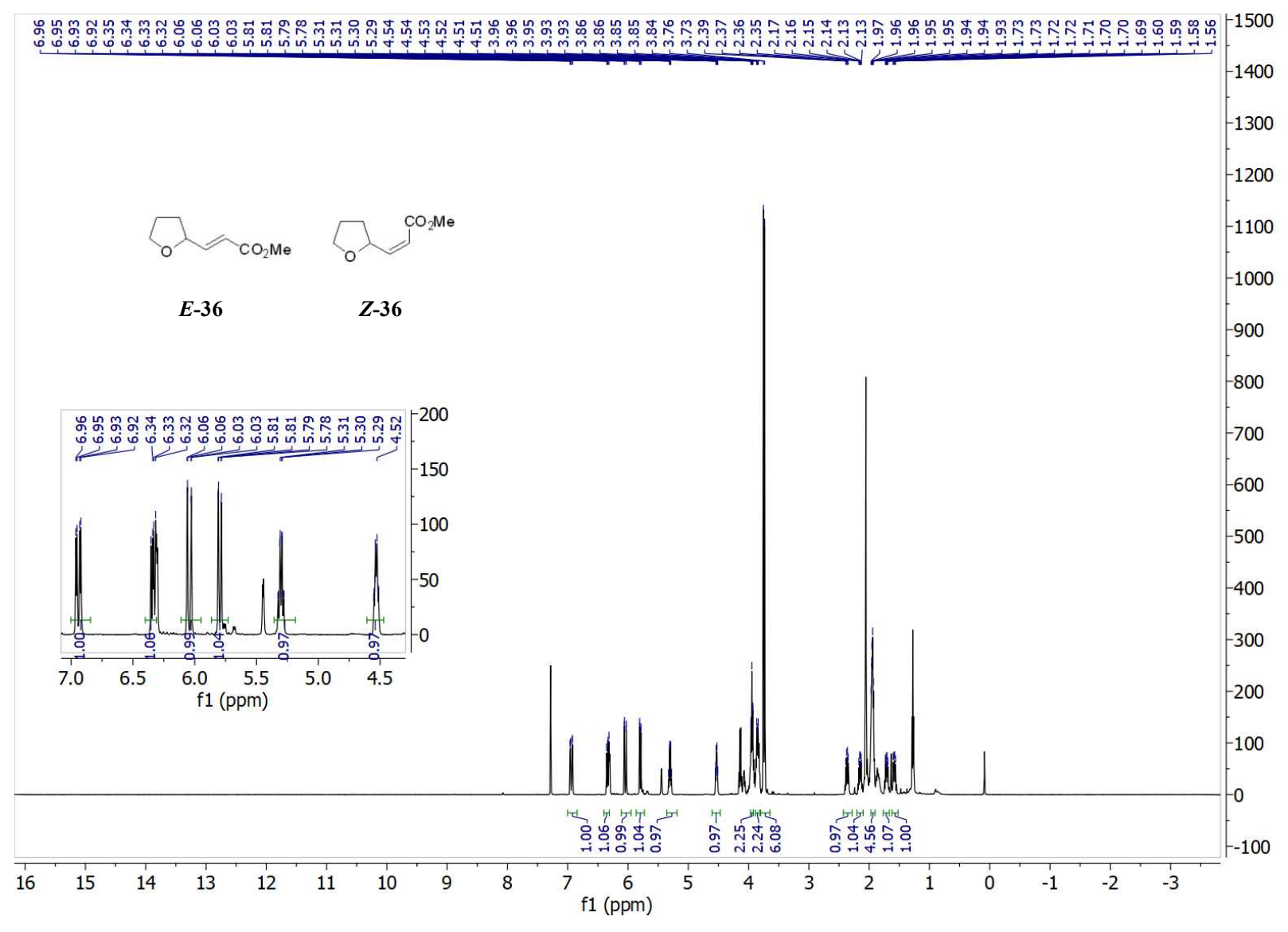




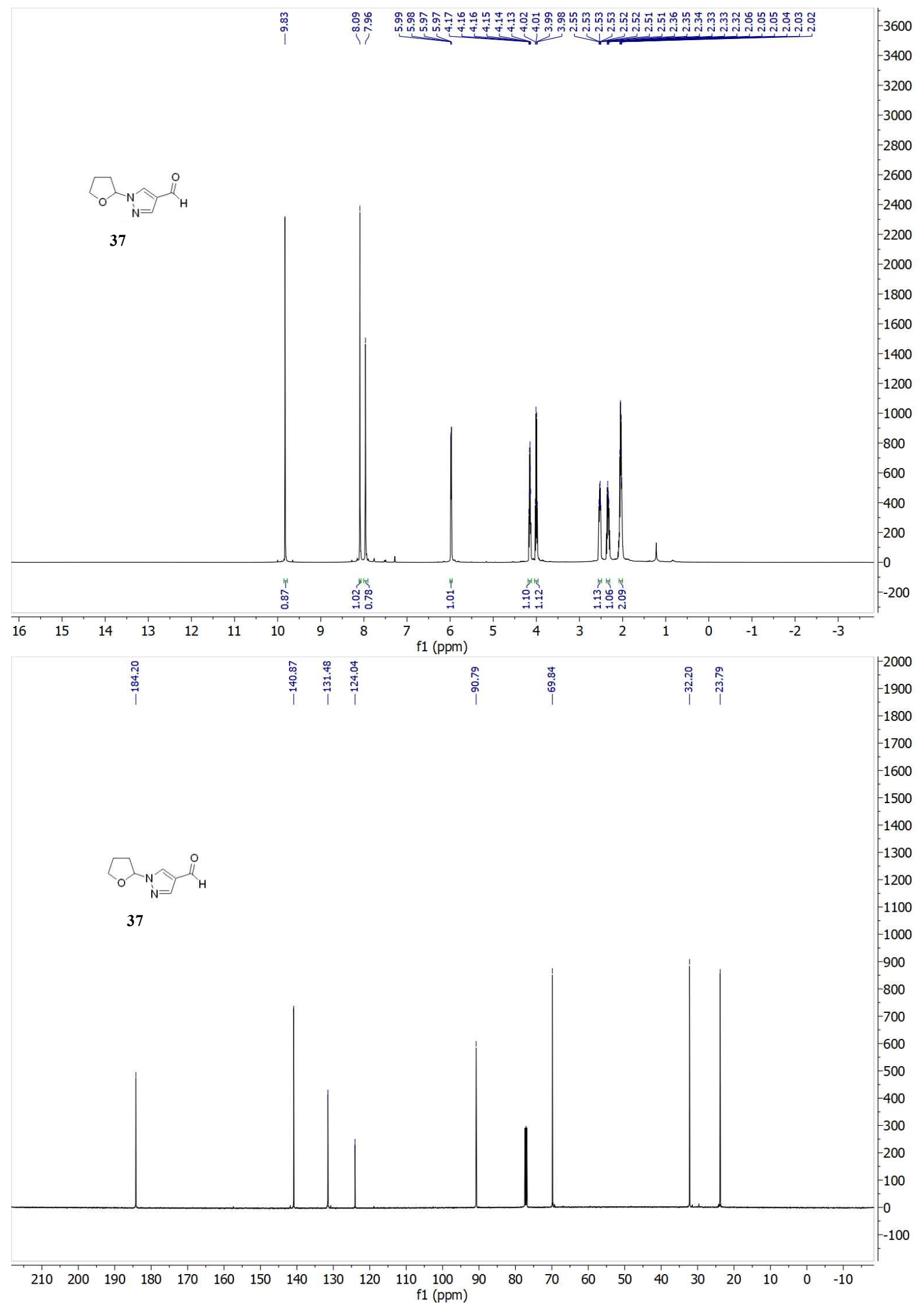




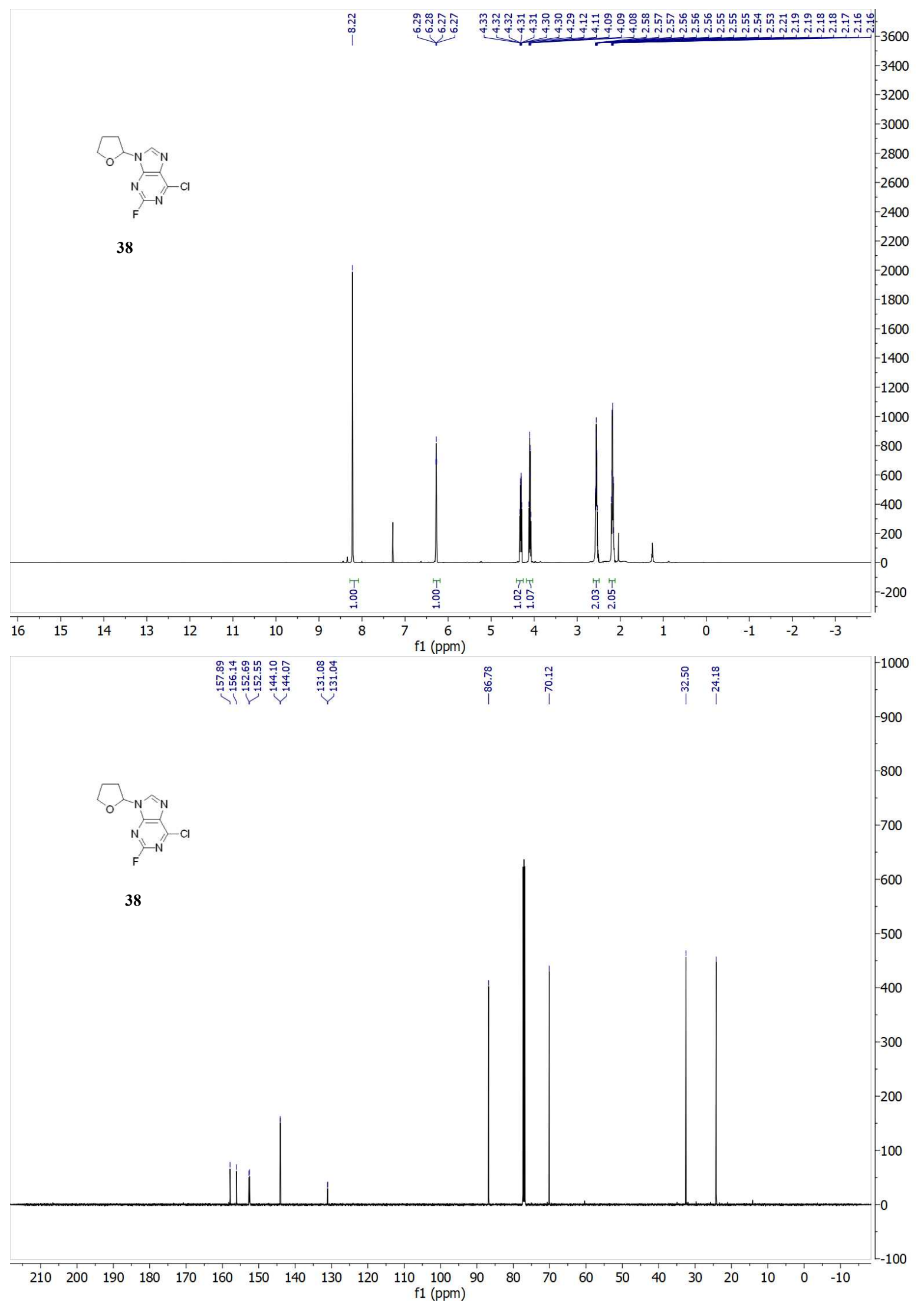




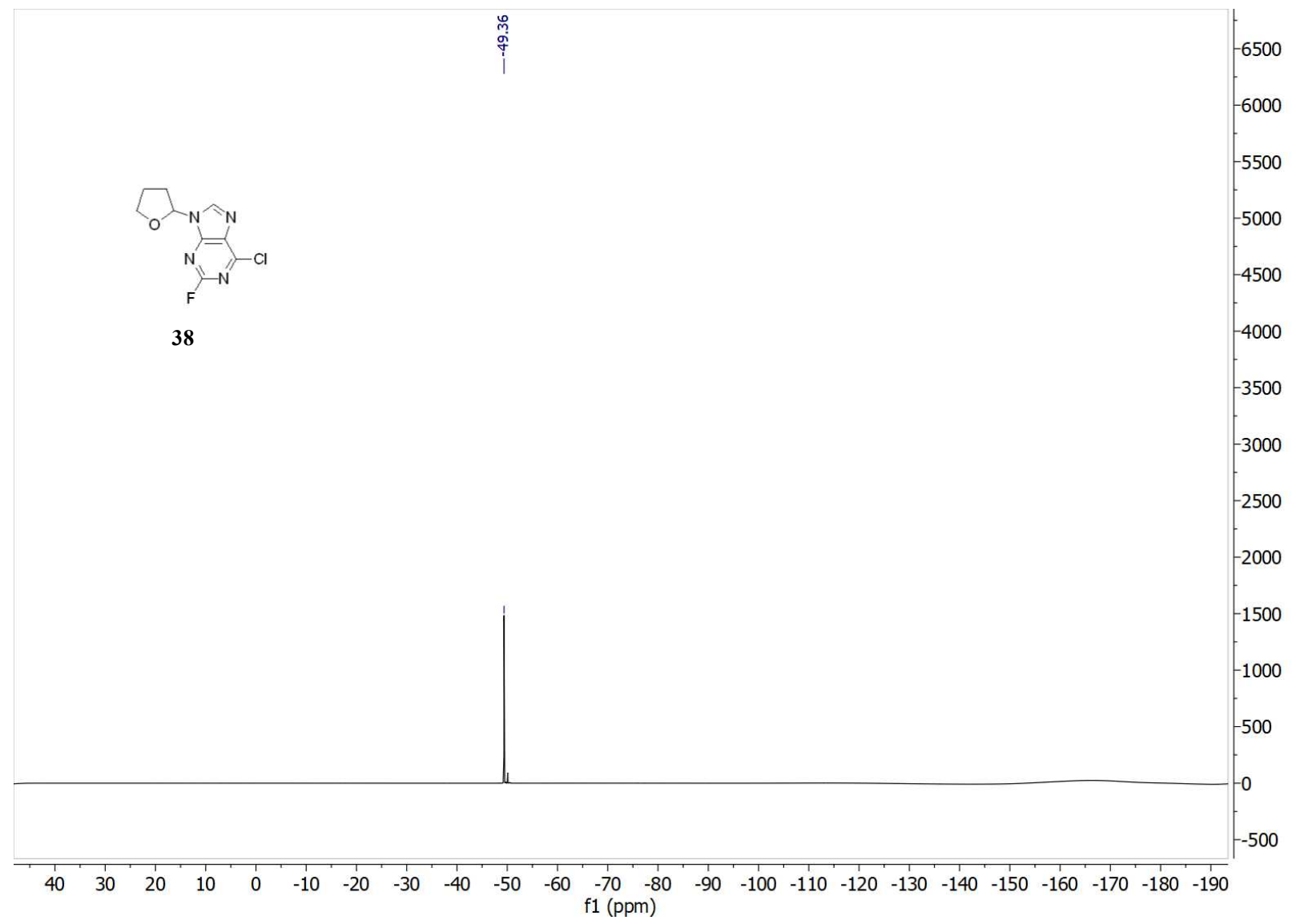




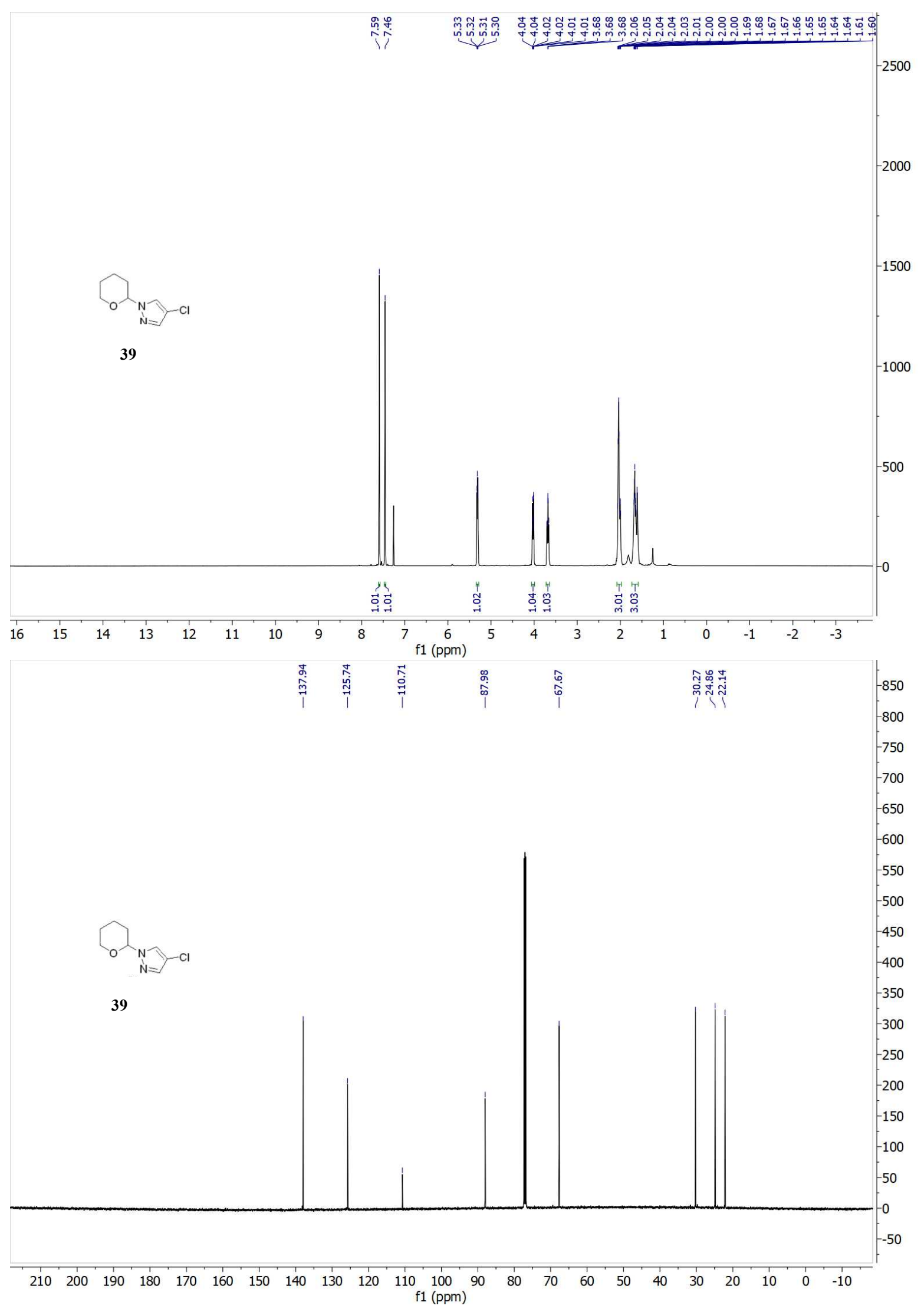




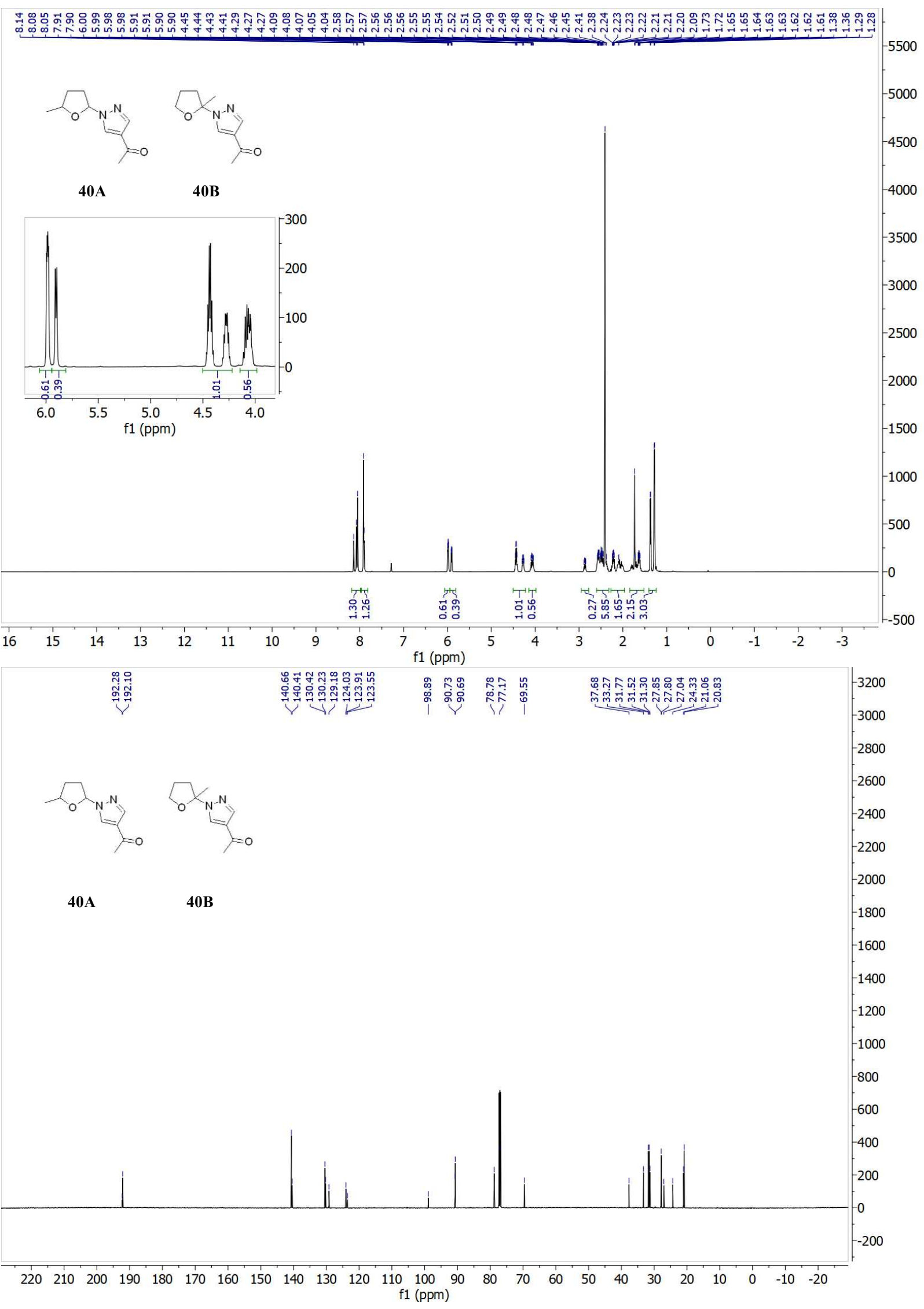




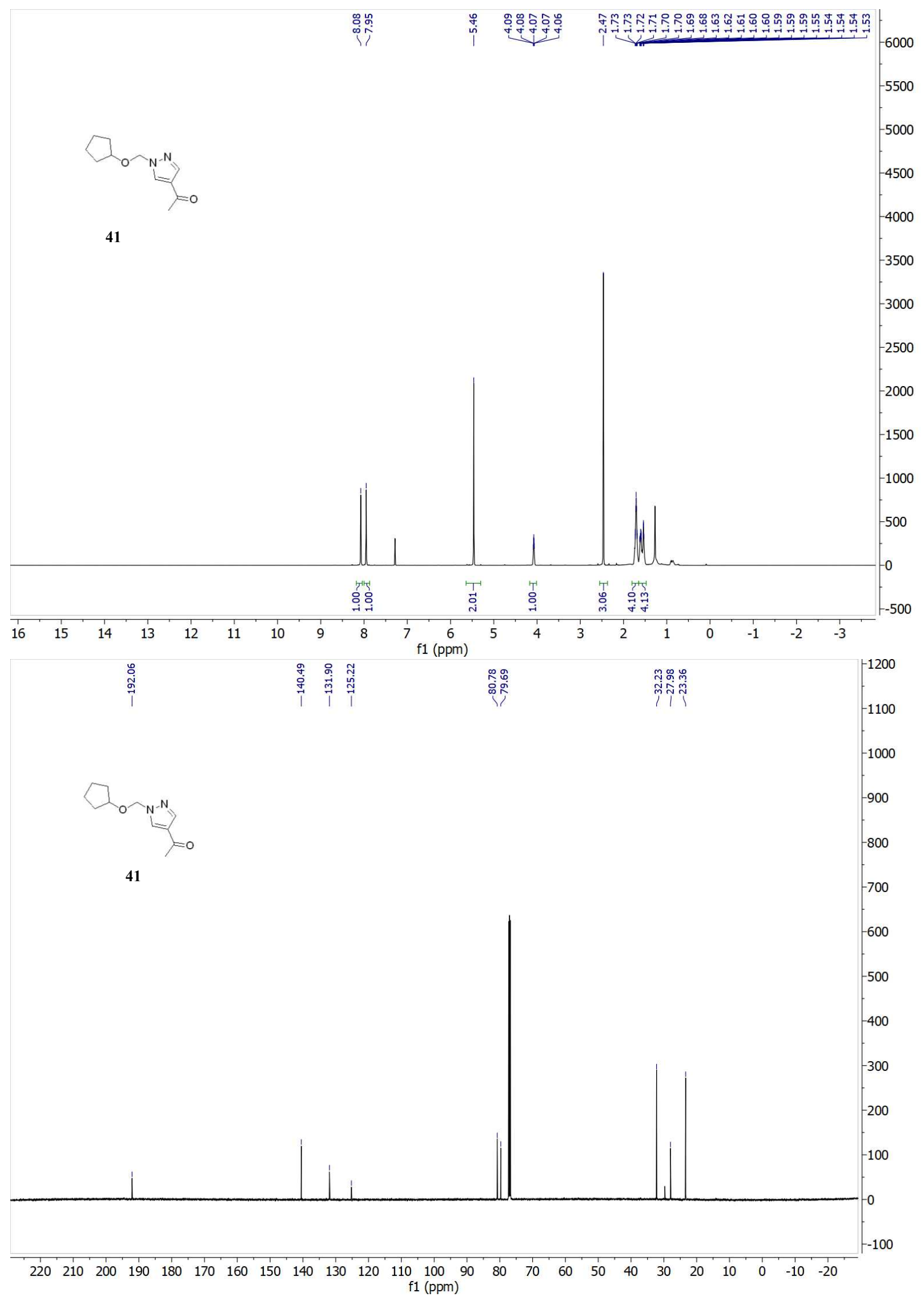




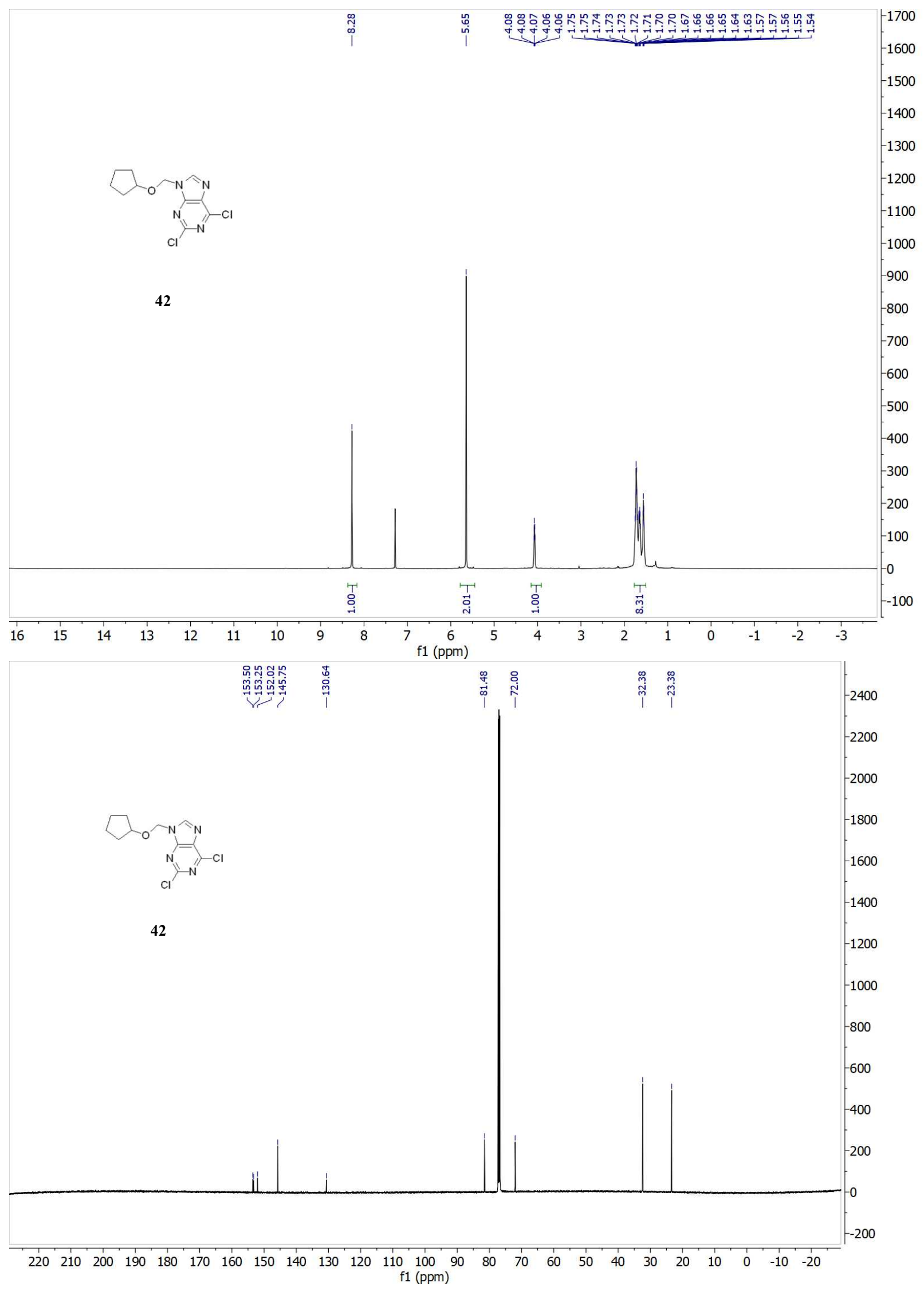




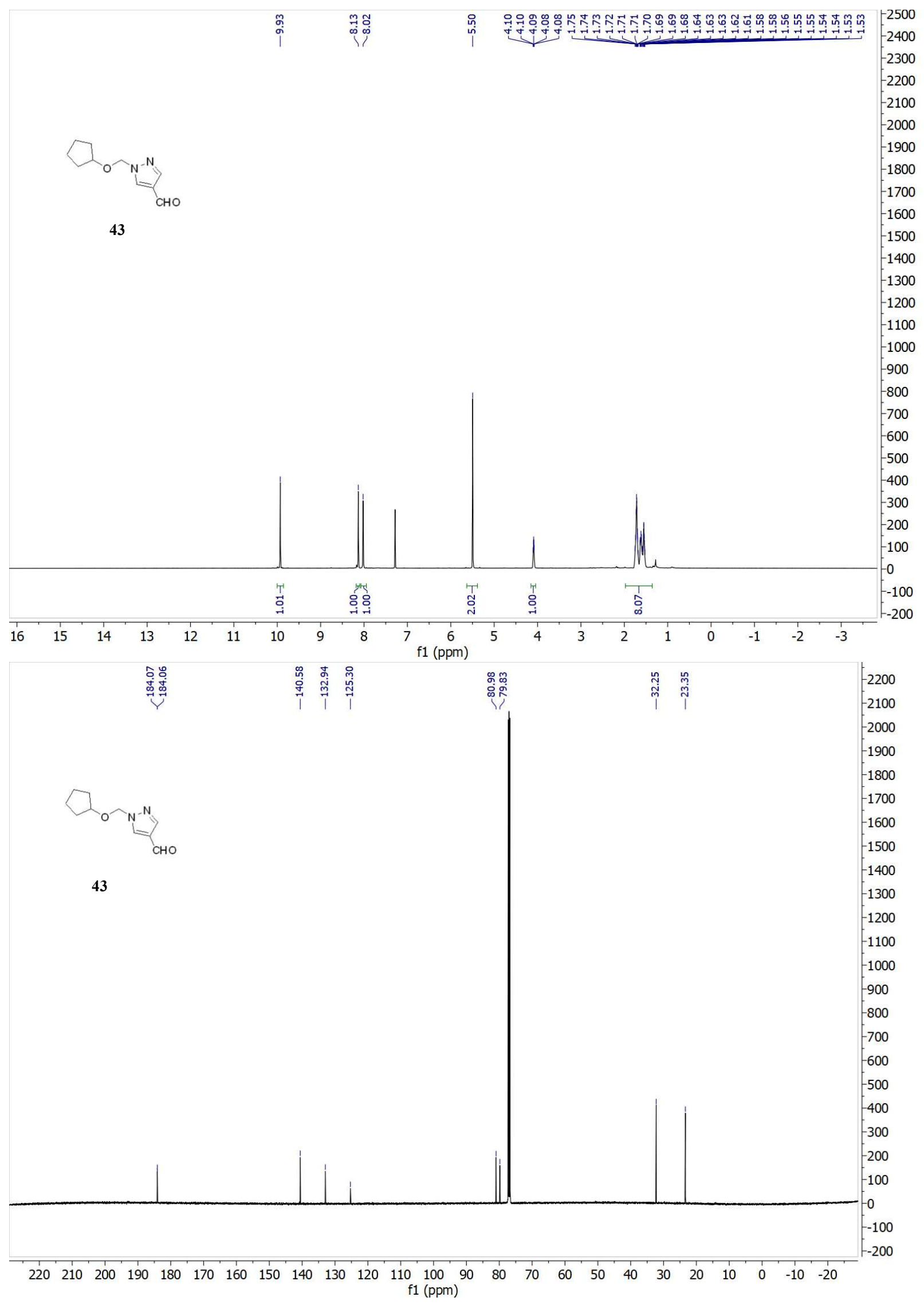




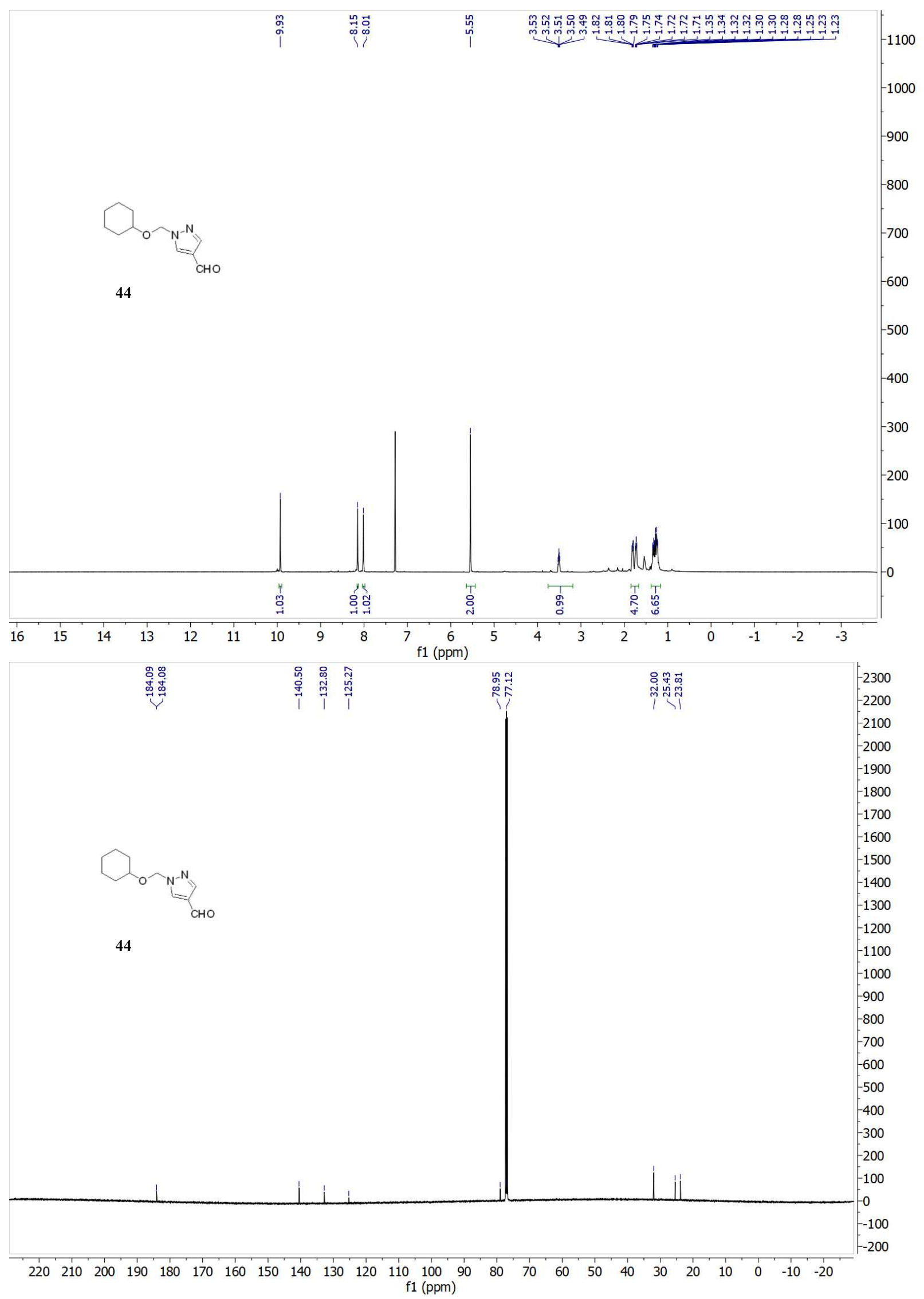




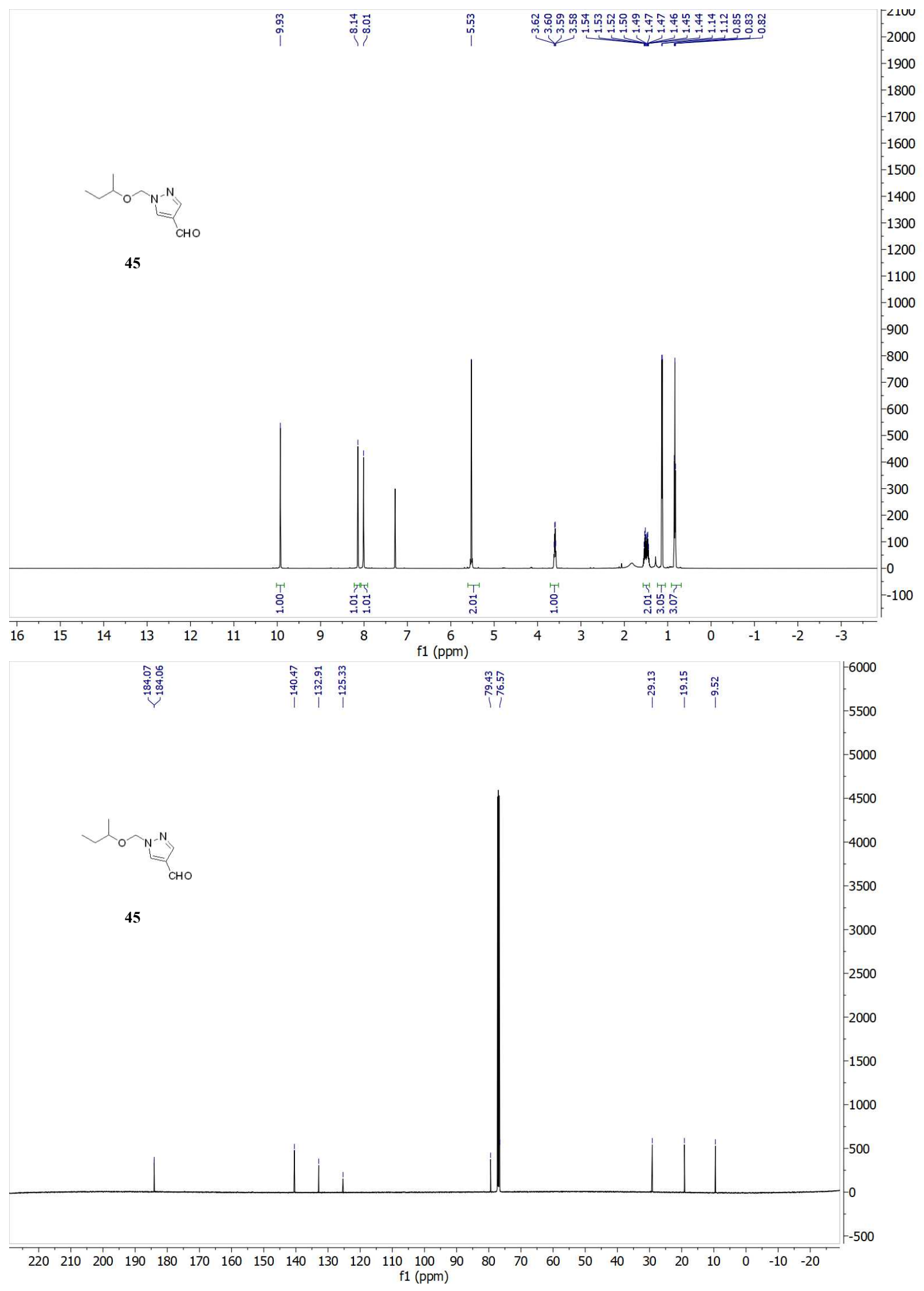

